UNIVERSIDADE DE SÃO PAULO

ESCOLA DE ENFERMAGEM

ANA CLÁUDIA MEDEIROS GALVÃo DE LIMA

ATENDIMENTOS POR CONDIÇÕES SENSÍVEIS À ATENÇÃO PRIMÁRIA À SAÚDE EM UMA UNIDADE DE PRONTO-ATENDIMENTO: PROPOSTA DE COMUNICAÇÃO PARA COORDENAÇÃO DO CUIDADO

SÃO PAULO 


\section{ATENDIMENTOS POR CONDIÇÕES SENSÍVEIS À ATENÇÃO PRIMÁRIA À SAÚDE EM UMA UNIDADE DE PRONTO-ATENDIMENTO: PROPOSTA DE COMUNICAÇÃO PARA COORDENAÇÃO DO CUIDADO}

\section{VERSÃO CORRIGIDA}

\section{VERSÃO ORIGINAL DISPONÍVEL NA EEUSP}

Dissertação de Mestrado apresentada ao Programa de Pós-Graduação - Mestrado Profissional em Enfermagem na Atenção Primária em Saúde no Sistema Único de Saúde da Escola de Enfermagem da Universidade de São Paulo para obtenção do título de Mestre em Ciências.

Área de Concentração: Cuidado em Atenção Primária em Saúde

Orientadora: $\operatorname{Prof}^{\mathrm{a}} \operatorname{Dr}^{\mathrm{a}}$ Lúcia Yasuko Izumi Nichiata Co-orientadora: Dr ${ }^{\mathrm{a}}$ Daiana Bonfim

SÃO PAULO 
AUTORIZO A REPRODUÇÃO E DIVULGAÇÃO TOTAL OU PARCIAL DESTE TRABALHO, POR QUALQUER MEIO CONVENCIONAL OU ELETRÔNICO, PARA FINS DE ESTUDO E PESQUISA, DESDE QUE CITADA A FONTE.

Assinatura:

Data:

Catalogação na Publicação (CIP)

Biblioteca "Wanda de Aguiar Horta"

Escola de Enfermagem da Universidade de São Paulo

Lima, Ana Cláudia Medeiros Galvão de

Atendimentos por condições sensíveis à atenção primária à saúde em uma unidade de pronto-atendimento: proposta de comunicação para coordenação do cuidado / Ana Cláudia Medeiros Galvão de Lima. São Paulo, 2017.

$92 \mathrm{p}$.

Dissertação (Mestrado) - Escola de Enfermagem da Universidade de São Paulo.

Orientadora: Prof. ${ }^{a}$ Dr. ${ }^{a}$ Lúcia Yasuko Izumi Nichiata

Co-orientadora: Dr. ${ }^{a}$ Daiana Bonfim

Área de concentração: Cuidado em Atenção Primária à Saúde

1. Atenção primária à saúde. 2. Hospitalização. 3. Sistema unificado de saúde. 4. Enfermagem. I. Título. 
Nome: Ana Cláudia Medeiros Galvão de Lima

Título: Atendimentos por Condições Sensíveis à Atenção Primária à Saúde em uma Unidade de Pronto-Atendimento: Proposta de comunicação para coordenação do cuidado.

Dissertação de Mestrado apresentada ao Programa de Pós-Graduação - Mestrado Profissional em Enfermagem na Atenção Primária em Saúde no Sistema Único de Saúde da Escola de Enfermagem da Universidade de São Paulo para obtenção do título de Mestre em Ciências.

Aprovado em:

\section{Banca Examinadora}

Orientadora Prof ${ }^{\mathrm{a}}$. Dr ${ }^{\mathrm{a}}$. Lúcia Yasuko Izumi Nichiata

Instituição:

Assinatura:

Co-orientadora Dr. ${ }^{a}$ Daiana Bonfim

Instituição:

Assinatura:

Orientador: Prof. Dr.

Instituição:

Assinatura:

Prof. Dr. Instituição:

Julgamento: Assinatura:

Prof. Dr. Instituição:

Julgamento: Assinatura: 


\section{Dedicatória}

Aos meus pais, grandes incentivadores da minha profissão, os quais dedico todas as minhas conquistas até hoje.

Às minhas irmãs, so6rinhos e cunhados, os quais são minha base em São Paulo.

Às minhas amigas que deixei em Recife, que mesmo longe se fazem presente. 


\section{Agradecimentos}

À minha orientadora, Profa $\mathfrak{D r}^{a}$ Lúcia, por todos os ensinamentos até a conclusão desse processo.

À minha co-orientadora, Profa $\operatorname{Dr}^{a}$ Daiana, pelo imenso apoio e dedicação que me deu.

Aos meus colegas de mestrado, por tudo o que aprendi com vocês no início dessa jornada.

Aos meus companheiros de trabalho e aos meus gestores, por terem contribuído nessa pesquisa. 
LIMA, A. C. M.G. Atendimentos por Condições Sensíveis à Atenção Primária à Saúde em uma Unidade de Pronto-Atendimento: Proposta de comunicação para coordenação do cuidado. [Dissertação]. São Paulo: Escola de Enfermagem, Universidade de São Paulo; 2017.

\section{RESUMO}

Introdução: O estudo da Atenção Primária à Saúde (APS) tem promovido discussões a respeito da organização dos sistemas de saúde e como eles se comunicam, no Brasil e no mundo. A falta de coordenação da atenção à saúde é apontada como um dos principais obstáculos na instituição de melhorias no cuidado aos usuários. Uma vertente de avaliação da APS em diversos países tem utilizado a análise das internações por condições sensíveis à atenção primária (ICSAP), por meio de indicadores de sua efetividade. As taxas de ICSAP podem ser utilizadas como forma de avaliar o acesso, a cobertura, a qualidade e o desempenho da APS e, assim, pensar em melhorias na comunicação entre os serviços de saúde. Objetivos: Propor um fluxo de comunicação entre um serviço de urgência e emergência e a APS em uma região do município de São Paulo; identificar os pontos de fragilidade e potencialidade na comunicação entre os serviços de urgência e emergência e a Atenção Primária à Saúde a partir da análise das condições sensíveis à atenção primária (CSAP). Método: Trata-se de um estudo transversal, descritivo, exploratório e retrospectivo, com abordagem quantitativa, desenvolvido na Unidade de Pronto-Atendimento (UPA 24h) Campo Limpo a partir de dados secundários obtidos de um banco de dados, referente ao período de janeiro de 2015 a dezembro de 2016. As análises foram realizadas com o auxílio do pacote estatístico SPSS. O fluxograma de comunicação foi proposto a partir do sistema informatizado NISI-online. Resultados: O banco de dados foi composto por 434.883 atendimentos, no período de 2 anos, com prevalência de ICSAP de 17,1\%. O sexo feminino foi o mais acometido pelas internações sensíveis e crianças de 1 a 4 anos apresentaram chance aumentada de atendimento por ICSAP. A maioria das ICSAP foi composta por infecções de ouvido, nariz e garganta $(45,4 \%)$. Há evidências de aumento da chance de atendimento por ICSAP em pacientes crônicos $(\mathrm{p}<0,001)$, com possibilidade estimada em torno de quatro vezes a dos pacientes não crônicos. A proposta de fluxograma de comunicação entre UPA e APS se deu a partir de pacientes com doenças crônicas (asma/bronquite, hipertensão arterial sistêmica, diabetes mellitus e transtorno mental) com importância de intervenção junto à APS. Conclusão: A consolidação das Redes de Atenção à Saúde voltada para a coordenação do cuidado, por meio da utilização de abordagens que aproximem os diferentes pontos de atenção à saúde, constitui-se como instrumento importante na continuidade do cuidado aos pacientes crônicos com ICSAP.

Descritores: Atenção Primária à Saúde; Hospitalização; Sistema Único de Saúde; Enfermagem; 
LIMA, A. C. M.G. Ambulatory Care Sensitive Conditions in a emergency department: Communication proposal for care coordination. [thesis]. São Paulo: School of Nursing, University of São Paulo; 2017.

\begin{abstract}
Introduction: The study of Primary Health Care has promoted discussions about the organization of the health systems and how they integrate to each other in Brazil and around the world. The lack of coordination is pointed out as one of the main obstacles to implement improvements in the health care. Some countries are using the numbers of Ambulatory care sensitive conditions (ACSC) as parameter to evaluate the Primary Health Care effectiveness. ACSC indexes can be used to evaluate the coverage, quality, and performance of Primary Health Care, analyzing the potential improvements in communication between the health services. Objectives: Introduce a communication flow between an emergency department and Primary Health Care in determinate region from São Paulo city; Identifying the fragilities and potentialities in the communication between an emergency department and Primary Health Care using the analysis of the ACSC cases. Method: This is a cross-sectional, descriptive, exploratory and retrospective study, with a quantitative approach, developed at the Emergency Department Campo Limpo based on secondary data obtained from a database, from the period of January 2015 to December 2016. The analyzes were executed with the assistance of the statistical package SPSS. The communication flowchart was developed using data from the NISI-online computerized system. Results: The database was composed by 434,883 consultations in a 2-year period, with $17.1 \%$ prevalence of ACSC. The female gender was the most affected by the sensitive hospitalizations and children from 1 to 4 years old presented an increased tendency of ACSC. Most of ACSC were composed by ear, nose and throat infections (45.4\%). There are evidences that increases the chances four times more for ACSC care in chronic patients $(\mathrm{p}<0.001)$, when comparing to non-chronic patients. The proposed communication flow between Emergency department and Primary Health Care was based on patients with chronic diseases (asthma / bronchitis, systemic arterial hypertension, diabetes mellitus and mental disorder) highly recommended to have Primary Health Care intervention. Conclusion: The consolidation of health care networks focused on the coordination of care process using an approach that turn close the different scenarios of health care is important for the continuity of care for chronic patients with ACSC.
\end{abstract}

Descriptors: Primary Health Care; Hospitalization; Unified Health System; Nursing; 


\section{LISTA DE FIGURAS}

Figura 1 - Distribuição dos estabelecimentos municipais de saúde na CRS Sul. São Paulo/SP, 2010. 35

Figura 2 - Proposta de fluxograma de comunicação entre UPA e UBS para coordenação do cuidado dos pacientes com ICSAP. Elaboração própria. São Paulo, SP, 2017

Figura 3 - Tela de entrada do Sistema NISI Einstein utilizado na UPA Campo Limpo. Figura extraída d o Sistema Nisi Einstein

Figura 4 - Tela de cadastro do paciente no Sistema NISI Einstein utilizado na UPA Campo Limpo. Figura extraída do Sistema Nisi Einstein.

Figura 5 - Tela do Histórico de enfermagem Sistema NISI Einstein utilizado na UPA Campo Limpo. Figura extraída do Sistema Nisi Einstein 61 


\section{LISTA DE TABELAS}

Tabela 1 - Características dos pacientes atendidos na UPA Campo Limpo entre 2015 e 2016. São Paulo, SP, 2017.

Tabela 2 - Classificação de risco de Manchester dos atendimentos realizados na UPA Campo Limpo entre 2015 e 2016. São Paulo, SP, 2017.

Tabela 3 - Tipo de finalização dos atendimentos realizados na UPA Campo Limpo entre 2015 e 2016. São Paulo, SP, 2017.

Tabela 4 - Identificação dos grupos de causa nos atendimentos realizados na UPA Campo Limpo entre 2015 e 2016 (n=434.883). São Paulo, SP, 2017.

Tabela 5 - Identificação de ICSAP nos atendimentos realizados na UPA Campo Limpo entre 2015 e 2016. São Paulo, SP, 2017.

Tabela 6 - Número (\%) dos tipos de atendimento por ICSAP por faixa etária dos pacientes $(\mathrm{n}=74.248)$. São Paulo, SP, 2017.

Tabela 7 - Associação entre ICSAP e características dos pacientes (n=323.158). São Paulo, SP, 2017

Tabela 8 - Descrição dos possíveis fatores associados aos desfechos de atendimento na amostra de pacientes com ICSAP atendidos na UPA Campo Limpo entre 2015 e 2016 $(n=74.248)$. São Paulo, SP, 2017.

Tabela 9 - Associação entre desfechos de atendimento e características dos pacientes na amostra de atendimentos com ICSAP na UPA Campo Limpo entre 2015 e 2016 (n=67.662). São Paulo, SP, 2017.

Tabela 10 - Condições associadas nos atendimentos realizados na UPA Campo Limpo com ICSAP entre 2015 e 2016 (n=74.248). São Paulo, SP, 2017. 


\section{SUMÁRIO}

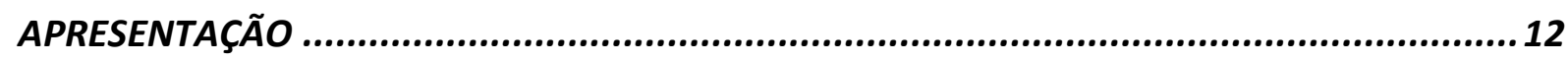

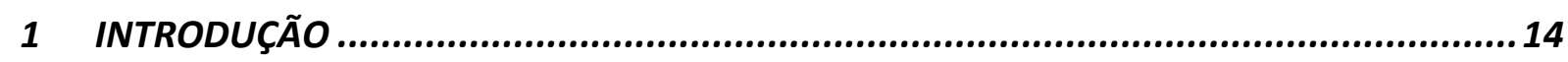

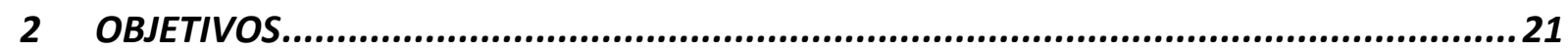

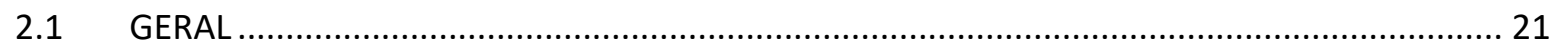

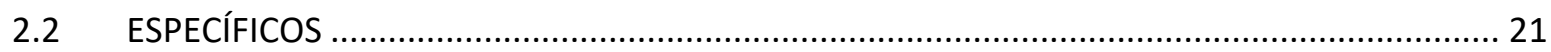

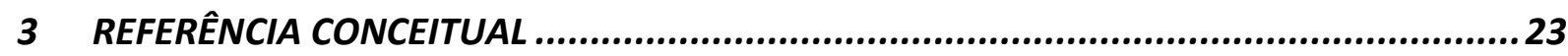

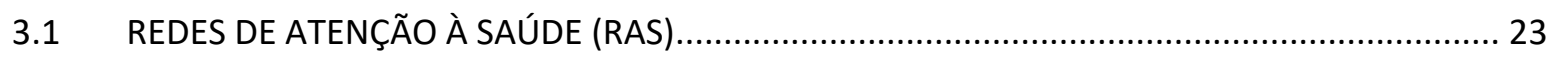

3.2 ATENÇÃO PRIMÁRIA À SAÚDE E COORDENAÇÃO DO CUIDADO …..................................... 26

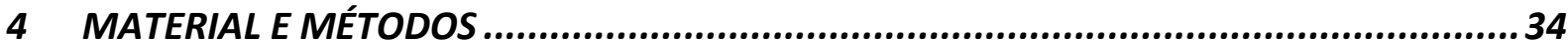

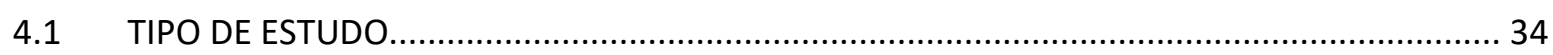

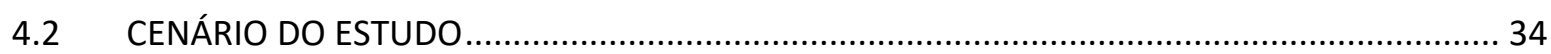

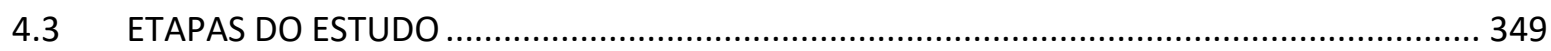

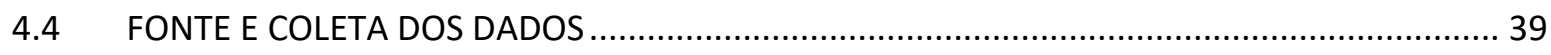

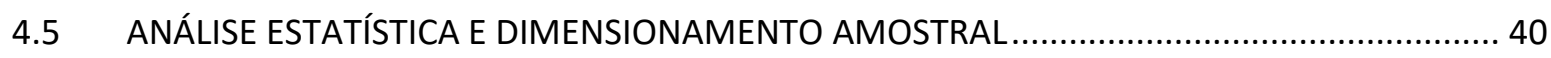

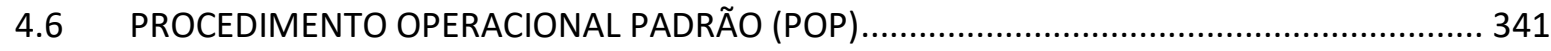

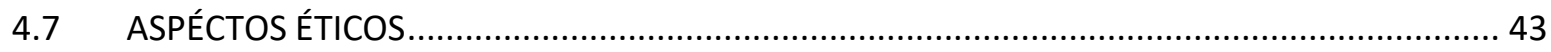

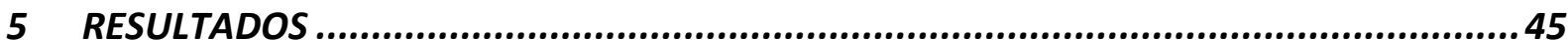

5.1 Proposta de Fluxograma de Comunicação para a Coordenação do Cuidado ........................ 56

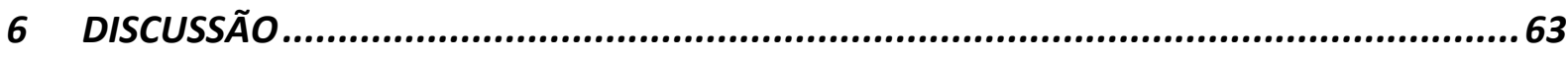

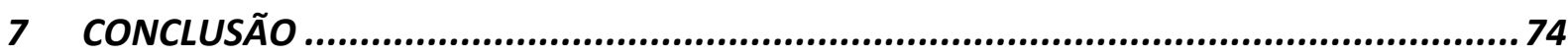

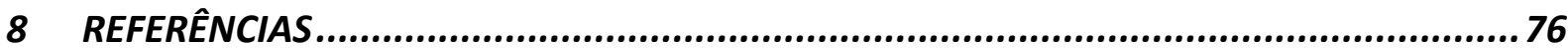

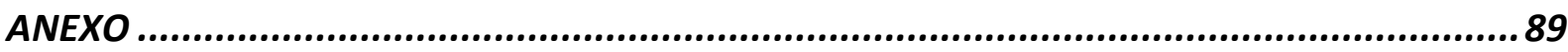


Apresentação 


\section{APRESENTAÇÃO}

Graduada e Licenciada em Enfermagem pela Universidade Federal de Pernambuco (UFPE) em 2012, iniciei minha vida profissional no Hospital da Restauração (HR), em Recife, como Enfermeira no Programa de Residência em Enfermagem em Emergência Geral, onde tive a oportunidade de trabalhar nos mais diversos cenários, intra e extra-hospitalares, sempre relacionados à urgência e emergência.

Após a conclusão da residência, no ano de 2015, e com o apoio da minha família, me mudei para São Paulo com o propósito de buscar novos desafios pessoais e profissionais. Optei por buscar formação no âmbito da Pós-Graduação, em um Programa de Mestrado Profissional, pela especificidade na articulação entre o conhecimento teórico e prático. Simultaneamente à aprovação, fui convidada a trabalhar como Enfermeira em uma Unidade de Pronto-Atendimento na cidade de São Paulo.

O interesse do presente estudo surgiu a partir da minha vivência prática, na qual observei algumas dificuldades de comunicação entre os equipamentos de saúde na rede pública no município de São Paulo, e trata, portanto, da articulação entre os diferentes níveis de atenção à saúde. 
1. Introdução 


\section{INTRODUÇÃO}

Segundo Starfield (2002), “a atenção primária é aquele nível de um sistema de serviço de saúde que oferece a entrada no sistema para todas as novas necessidades $e$ problemas, fornece atenção sobre a pessoa (não direcionada para a enfermidade) no decorrer do tempo, fornece atenção para todas as condições, exceto as muito incomuns ou raras, e coordena ou integra a atenção fornecida em algum outro lugar ou por terceiros".

A APS visa proporcionar uma organização eficiente dos cuidados, cujos objetivos vão desde alcançar os princípios da equidade, universalidade e integralidade, até o acompanhamento dos cuidados continuados, em um movimento de reorganização do modelo assistencial (LEONE et. al., 2014; SHI, 2012).

Contudo, o acompanhamento dos problemas de saúde dos usuários, família e comunidade constitui-se ainda como um desafio à APS, a qual se encontra diante de questões como a falta de investimento financeiro, a elevada taxa de população adscrita, o número insuficiente de equipes de saúde da família e as precárias condições de trabalho e infraestrutura. Tais problemas dificultam a prestação de uma atenção à saúde eficiente e resolutiva, principalmente frente a atual situação epidemiológica brasileira, que traz consigo uma epidemia de doenças crônicas as quais necessitam de acompanhamento contínuo de saúde (LEONE et. al., 2014; SHI, 2012).

Segundo a OMS, em 2003, as condições crônicas foram responsáveis por $60 \%$ de todo o ônus decorrente de doenças no mundo. No ano de 2020, estima-se que serão responsáveis por $80 \%$ da carga de doenças dos países em desenvolvimento e, nesses países, a aderência ao tratamento chega a ser apenas de $20 \%$ (OMS, 2003). A taxa de mortalidade, de acordo com a idade, por doenças crônicas no Brasil, em pessoas de 30 anos ou mais, é de 600 mortes a cada cem mil habitantes, representando o dobro da taxa do Canadá e 1,5 vezes a taxa do Reino Unido (WHO, 2005). Como consequência, estima-se que morram, diariamente, no Brasil, mais de 450 pessoas, somente em decorrência de infartos agudos do miocárdio e acidentes vasculares encefálicos.

Os resultados de um estudo de carga global de doenças, medida por anos de vida perdidos ajustados por incapacidade, apontaram que as doenças crônico-degenerativas respondem por $66,3 \%$ da carga de doenças no Brasil, enquanto as doenças infecciosas 
respondem por $23,5 \%$ e as causas externas por $10,2 \%$, o que caracteriza uma tripla carga de doenças (SCHRAMM et al, 2004).

Assim, uma população em rápido processo de envelhecimento requer um incremento e priorização quanto ao acompanhamento das condições crônicas, já que elas afetam de maneira notadamente superior os segmentos de maior idade. A Pesquisa Nacional por Amostra de Domicílios (PNAD, 2008), demonstrou que à medida que a idade avança, aumentam as doenças crônicas, de modo que $79,1 \%$ dos brasileiros de 65 anos ou mais relatam ser portadores de um grupo de doze doenças crônicas, dentre elas hipertensão arterial sistêmica (HAS) e diabetes mellitus (DM).

Segundo a OMS (2003), os atuais sistemas de saúde foram desenvolvidos para tratar dos problemas agudos e necessidades prementes dos pacientes, desenhados para funcionar em situações de pressão. Dessa forma, um dos problemas centrais da crise dos modelos de atenção à saúde contemporâneos consiste no enfretamento das doenças crônicas com a mesma lógica das agudas, ou seja, por meio de tecnologias destinadas a responder aos momentos agudos dos agravos, através da atenção à demanda espontânea, principalmente, em unidades de pronto-atendimento ou de internações hospitalares de urgência e emergência (SHIMAZAKI, 2009). Nesse sentido, entretanto, os sistemas de saúde predominantes em todo o mundo estão enfrentando dificuldades, pois não estão conseguindo acompanhar a tendência de declínio dos problemas agudos e de ascensão das condições crônicas.

O estudioso Eugênio Vilaça Mendes exemplificou de forma objetiva o problema em questão quando trouxe uma situação ainda comum em nosso meio ao representar a atenção a saúde a um portador de diabetes tipo 2. Segundo o autor,

\begin{abstract}
"Pela lógica da atenção às condições agudas, quando este paciente se sente mal, ou quando agudiza sua doença, ele busca o sistema e é atendido em uma unidade de pronto-atendimento; em um segundo momento, quando este paciente apresenta uma descompensação metabólica, ele é internado em uma unidade hospitalar. Contudo, nos intervalos entre esses momentos de agudização de sua condição crônica não recebe uma atenção contínua, proativa e integral, sob a coordenação da equipe da APS. Esse sistema de atenção à saúde que atende às condições crônicas na lógica da atenção às condições agudas, ao final de um período longo de tempo, determinará resultados sanitários e econômicos desastrosos. A razão disso é que esse sistema só atua sobre as condições de saúde já estabelecidas, em momentos de manifestações clínicas extremistas, percebidas pelos portadores, desconhecendo os determinantes sociais intermediários, os fatores de riscos biopsicológicos ou ligados aos comportamentos e aos estilos de vida e o gerenciamento da condição de saúde estabelecida, com base em uma APS de qualidade" (MENDES, 2012).
\end{abstract}

Apesar dos problemas encontrados na atenção às urgências e emergências, como grandes filas de espera e tratamento de problemas de saúde crônicos de forma equivocada, é inegável que este tipo de atenção à saúde, com caráter qualificado e em tempo oportuno, é de 
grande importância, uma vez que atua frente a problemas emergenciais com risco à vida, evita sequelas e reduz o sofrimento das pessoas no momento em que elas mais necessitam dos serviços de saúde.

Introduzida pelo Ministério da Saúde em 2003 e um dos principais componentes da Política Nacional de Urgência e Emergência, a Unidade de Pronto Atendimento (UPA 24h), constitui um equipamento de saúde de complexidade intermediária, situado entre a Atenção Primária à Saúde (APS) e a rede hospitalar. Funciona de modo ininterrupto, nas vinte e quatro horas do dia, e em todos os dias da semana, incluídos os feriados (CONASS, 2015).

Até o ano de 2015 havia 384 UPAs em funcionamento no País, o que se traduz na realização de 36,9 milhões de consultas de urgência ao ano, 43\% de cobertura da população e mais de 4.488 leitos de observação. O governo federal pretende aumentar a quantidade de UPAs no País e tem como desafios a estruturação pelos gestores estaduais e municipais, o financiamento, a retaguarda de leitos e a organização do processo de trabalho para que a UPA cumpra seu papel assistencial, resguardando o papel dos demais pontos da atenção à saúde, especialmente o da atenção primária (CONASS, 2015).

A partir de experiências nacionais e internacionais, pode-se afirmar que um dos problemas do SUS encontra-se na incoerência entre a condição da saúde brasileira, com tripla carga de doenças, e o sistema de atenção à saúde, fragmentado, episódico, reativo e voltado prioritariamente às condições agudas. $\mathrm{O}$ fracasso das respostas sociais às condições crônicas por um sistema fragmentado é, portanto, universal e deve ser enfrentado por meio de mudanças profundas, como a implantação e o fortalecimento das Redes de Atenção à Saúde (RAS) (BRASIL, 2015).

Os sistemas fragmentados de atenção à saúde, fortemente presentes na nossa sociedade, são aqueles que se organizam através de um conjunto de pontos de atenção à saúde isolados e sem comunicação uns com os outros, e que, por consequência, são incapazes de prestar uma atenção contínua à população. Em geral, não há uma população adscrita de responsabilização, onde a APS não se comunica fluidamente com a atenção secundária à saúde e, esses dois níveis, também não se articulam com a atenção terciária à saúde, nem com os sistemas de apoio ou com os sistemas logísticos (MENDES, 2011).

Pesquisas realizadas em países das Américas, firmadas pela Organização PanAmericana da Saúde (OMS, 2010), demonstram que a credibilidade do sistema fragmentado é baixa entre usuários e gestores. Tais pesquisas comprovaram que apenas 1/5 dos usuários entrevistados, e pouco mais de 1/3 dos gestores e prestadores de serviços, consideram que os 
sistemas de referência e contrarreferência (RCR) da atenção primária para os serviços especializados realmente funcionem. É crença difundida entre tais atores, que cerca da metade das pessoas hospitalizadas poderia ser tratada em ambiente não hospitalar, assim como aponta o fato de que as pessoas são geralmente atendidas de forma descontínua (OPAS, 2011).

$\mathrm{Na}$ Europa, estudiosos da área reconhecem que a gestão da doença crônica (chronic disease management), com acompanhamento contínuo de indivíduos que apresentem alguma doença crônica por anos, ou até décadas, é um dos mais importantes desafios que os sistemas de saúde europeus enfrentam atualmente (SCHELLER-KREINSEN et al, 2009). Para os autores, a falta de coordenação da atenção à saúde no sistema de saúde é apontada como um dos principais obstáculos à melhoria do cuidado de pacientes com doenças crônicas (GIOVANELLA, 2012).

Segundo Starfield (2002), um dos atributos essenciais da APS é a coordenação das diversas ações e serviços indispensáveis para resolver necessidades de saúde que requerem acompanhamento constante, o que garante a continuidade da atenção. A coordenação implica capacidade de garantir a atenção ininterrupta no interior da rede de serviços pela equipe de APS e depende de tecnologias de gestão clínica, mecanismos adequados de comunicação entre profissionais e registro adequado de informações (GIOVANELLA \& MENDONÇA, 2008).

Estudos relataram dificuldades na APS em desenvolver sistemas consistentes para a coordenação do cuidado, incluindo registros integrados de pacientes, sistemas de informação compatíveis, avaliações consistentes e centrais de regulação compartilhadas (POWELL et al, 2008).

O conceito fundamental que preside a relação entre a atenção primária e a atenção secundária é o da coordenação do cuidado, definido como a organização deliberada do cuidado entre dois ou mais participantes envolvidos na atenção às pessoas a fim de facilitar a prestação de serviços de saúde eficientes, efetivos e de qualidade (THE COMMONWEALTH FUND, 2011).

Com o objetivo de melhorar as políticas públicas, a coordenação do cuidado e os planos assistenciais, uma vertente de avaliação da APS em diversos países tem utilizado a análise das internações hospitalares por meio de indicadores de sua efetividade.

No final da década de 1980, teve início nos Estados Unidos (BILLINGS, 1993), o conceito de problemas de saúde sensíveis aos cuidados ambulatoriais, conhecido no Brasil como internações por condições sensíveis à atenção primária (ICSAP) (ALFRADIQUE et al., 
2009; NEDEL, 2010). A partir da segunda metade da década de 90, as ICSAP passaram a ser utilizadas para a análise da qualidade da atenção primária em países que possuem o sistema de saúde focado nos cuidados primários, como a Espanha, a Austrália e o Canadá (CASANOVA, 1995; CAMINAL-HOMAR, 2003; ANSARI, 2003; MENEC, 2006).

Este indicador, que contribui como estratégia no fortalecimento da APS, possui viabilidade para melhorar a coerência e a coordenação da porta de entrada ao sistema especializado, relacionando a acessibilidade aos serviços ambulatoriais e analisando a qualidade da APS (CAMPOS, 2012).

Estudos sobre ICSAP mostraram que os sistemas baseados na APS que asseguraram acesso e primeiro contato melhoraram os resultados sanitários, beneficiaram outros níveis do sistema e permitiram reduzir internações hospitalares, especialmente em anginas, infecções urinárias, doença pulmonar obstrutiva crônica e infecções da garganta, ouvido e nariz. Pessoas que tiveram uma fonte regular de APS durante sua vida ficaram mais satisfeitas com o sistema de atenção à saúde, apresentaram menos hospitalizações e utilizaram menos as unidades de emergência (MENDES, 2012).

As condições sensíveis à atenção primária constituem-se como morbidades que podem ser atendidas oportuna e efetivamente pela atenção primária, sem necessidade de hospitalização. Assim, parte-se do princípio que as ICSAP constituam um evento que pode ser evitado e prevenido, uma vez que as intervenções oportunas no primeiro nível de atenção podem evitar o agravamento clínico do paciente e, por conseguinte, sua hospitalização. Consequentemente, é possível pressupor que as taxas de ICSAP possam ser utilizadas como uma forma de avaliar o acesso, a cobertura, a qualidade e o desempenho da atenção primária (RIZZA, 2007; ELIAS, 2008; NEDEL, 2008).

Em 2008, o Ministério da Saúde publicou a primeira lista brasileira de ICSAP, de acordo com a Portaria $n^{\circ}$. 221 de 17 de abril. A lista, construída por meio de consenso entre pesquisadores e gestores, proporcionou o acesso a um indicador capaz de avaliar e monitorar o sistema de saúde a partir de dados secundários. A padronização da lista brasileira passou a oportunizar a elaboração de estudos que se utilizem de um único instrumento e permitiu, dessa forma, a comparação entre os mesmos (MINISTÉRIO DA SAÚDE, 2008; ALFRADIQUE, 2009). A lista de ICSAP inclui 19 grupos de causas de hospitalização e diagnósticos, de acordo com a décima revisão da Classificação Internacional de Doenças e Causas de Morte (CID-10) (BRASIL, 2008). 
Frente a essa repercussão, inúmeros pesquisadores vêm se dedicando à análise de condições potencialmente evitáveis em diferentes dimensões territoriais, utilizando-as como ferramentas de avaliação da APS, a partir de dados hospitalares (BARDSLEY et al., 2013; BOING et al., 2012; CARDOSO et al., 2013; GIBSON et al., 2013; PAZÓ et al., 2013; REHEM et al., 2013; RODRIGUES-BASTOS et al., 2013; RUBINSTEIN et al., 2014).

Uma revisão sistemática de 18 trabalhos sobre ICSAP evidenciou que a continuidade da atenção se associou a menores taxas nos Estados Unidos e Canadá (NEDEL et.al., 2010). A continuidade da atenção, a equipe multidisciplinar e, em menor destaque, a população adscrita ao médico, mostraram-se associadas, em diferentes estudos, à menor probabilidade de hospitalização por CSAP. A conclusão geral do trabalho foi de que os princípios fundamentais da atenção primária se relacionaram com um menor risco de internar por CSAP (MENDES, 2012).

Nesta perspectiva, o uso criterioso deste indicador pode ajudar a incrementar a capacidade de resolução da APS, ao identificar áreas passíveis de melhorias, evidenciando problemas de saúde que necessitam de melhor seguimento e coordenação entre os níveis assistenciais (GERVAS, 2007; NEDEL et al, 2011).

Inspirado na formulação das ICSAP, o presente estudo tem como foco uma unidade de pronto-atendimento. Entende-se que o estudo das condições sensíveis à atenção primária, embora tenha sido elaborado considerando as hospitalizações que ocorrem no âmbito da atenção terciária, pode também constituir numa ferramenta de avaliação em uma unidade de pronto-atendimento, considerando que este serviço, além de possuir grande fluxo de atendimentos, é ponto da rede de assistência à saúde, o que o torna potente para subsidiar a coordenação do cuidado da APS. 


\section{Objetivos}




\section{OBJETIVOS}

\subsection{GERAL}

Propor um fluxo de comunicação entre um serviço de urgência e emergência e a Atenção Primária à Saúde na região do Campo Limpo, Município de São Paulo.

\subsection{ESPECÍFICOS}

- Determinar a prevalência dos atendimentos por condições sensíveis à APS;

- Identificar e analisar as causas mais frequentes de atendimentos por condições sensíveis à atenção primária (CSAP) em uma Unidade de Pronto Atendimento;

- Descrever as condições sensíveis à APS de acordo com características dos pacientes atendidos no pronto-atendimento, segundo perfil sociodemográfico e de saúde;

- Criar os elementos que compõem um fluxo de comunicação entre UPA e UBS das doenças crônicas mais prevalentes. 
3. Referência Conceitual 


\section{REFERENCIA CONCEITUAL}

\subsection{REDES DE ATENÇÃO À SAÚDE (RAS)}

A incoerência entre a situação de saúde e o sistema de atenção à saúde, praticado hegemonicamente, constitui o problema fundamental do SUS e para ser superado necessita da implantação das Redes de Atenção à Saúde (RAS). Segundo Mendes,

"As Redes de Atenção à Saúde são organizações poliárquicas de conjuntos de
serviços de saúde, vinculados entre si por uma missão única, por objetivos comuns e
por uma ação cooperativa e interdependente, que permitem ofertar uma atenção
contínua e integral a determinada população, coordenada pela APS, de forma
humanizada e segura e com equidade -, com responsabilidades sanitária e
econômica pela população adscrita e gerando valor para essa população"
(MENDES, 2011).

Dessa definição emergem os conteúdos básicos das RAS: apresentam missão e objetivos comuns; operam de forma cooperativa e interdependente; intercambiam constantemente seus recursos; são estabelecidas sem hierarquia entre os pontos de atenção à saúde, organizando-se de forma poliárquica; implicam um contínuo de atenção nos níveis primário, secundário e terciário; convocam uma atenção integral com intervenções promocionais, preventivas, curativas, cuidadoras, reabilitadoras e paliativas; funcionam sob a coordenação da APS; prestam atenção oportuna, em tempos e lugares certos, de forma eficiente e ofertando serviços seguros e efetivos, em consonância com as evidências disponíveis; focam-se no ciclo completo de atenção a uma condição de saúde; têm responsabilidades sanitárias e econômicas inequívocas por sua população; e geram valor para a sua população (MENDES, 2012).

No Brasil, a concepção de RAS vem sendo discutida há algum tempo, mas foi incorporada oficialmente ao SUS por dois instrumentos jurídicos. A Portaria $\mathrm{n}^{\circ} 4.279$, de 30 de dezembro de 2010, que estabelece diretrizes para a organização das redes de atenção à saúde no âmbito do SUS, e o Decreto $n^{\circ} 7.508$, de 28 de junho de 2011, que regulamenta a Lei $\mathrm{n}^{\mathrm{o}}$ 8.080/90. Na Portaria Ministerial, a RAS é definida como "arranjos organizativos de ações e serviços de saúde, de diferentes densidades tecnológicas que, integradas por meio de sistemas de apoio técnico, logístico e de gestão, buscam garantir a integralidade do cuidado". No Decreto Presidencial explicita-se que "a integralidade da assistência à saúde se inicia e se completa na Rede de Atenção à Saúde” (BRASIL, 2011). 
Baseadas nessa Portaria, cinco redes temáticas prioritárias foram pactuadas na Comissão Intergestores Tripartite (CIT), no período de junho de 2011 a fevereiro de 2013: Rede Cegonha, Rede de Urgência e Emergência (RUE), Rede de Atenção Psicossocial para as pessoas com sofrimento ou transtorno mental e com necessidades decorrentes do uso de crack, álcool e outras drogas (Raps), Rede de Cuidados à Pessoa com Deficiências (Viver Sem Limites) e Rede de Atenção à Saúde das Pessoas com Doenças Crônicas, a qual contempla as doenças renocardiovasculares, diabetes, obesidade, doenças respiratórias crônicas e câncer (de mama e colo de útero) (BRASIL, 2013; BRASIL, 2015).

A Rede de Urgência e Emergência (RUE) destaca as doenças cardiovasculares como a principal causa de morte em mulheres e homens no Brasil, com aproximadamente $20 \%$ de todas as mortes em indivíduos acima de 30 anos de idade, ainda que haja a tendência de a mortalidade estar em decréscimo nas últimas décadas (MANSUR e FAVARATO, 2012). O infarto agudo do miocárdio tem relevante impacto em termos de mortalidade e número de hospitalizações (GUIMARÃES et al., 2006). O Acidente Vascular Cerebral (AVC) é uma das maiores causas de morbimortalidade em todo o mundo, e no Brasil, apesar do declínio nas taxas de mortalidade, ainda é a principal causa de morte, sendo que a maioria dos sobreviventes apresenta sequelas, com limitação da atividade física e intelectual e elevado custo social (CALMON et al., 2009).

Em decorrência desse contexto, as prioridades da RUE são as linhas de cuidados cardiovasculares, cerebrovasculares e traumatológicos, e devem ser implementadas gradativamente em todo território nacional, respeitando-se critérios epidemiológicos e a densidade populacional. É indispensável realizar acolhimento com classificação de risco, sendo a qualidade e a resolutividade na atenção a base do processo e dos fluxos assistenciais de toda RUE.

A RUE, também chamada Rede Saúde Toda Hora, tem como diretrizes a ampliação do acesso e o acolhimento aos casos agudos demandados aos serviços de saúde em todos os pontos de atenção, contemplando a classificação de risco e a intervenção adequada e necessária aos diferentes agravos, com garantia da universalidade, equidade e integralidade no atendimento às urgências clínicas, cirúrgicas, gineco-obstétricas, psiquiátricas, pediátricas e relacionadas às causas externas (traumatismos, violências e acidentes). Como toda rede, a atuação é territorial, com definição e organização das regiões de saúde e das redes de atenção a partir das necessidades de saúde das populações, seus riscos e vulnerabilidades específicos (BRASIL, 2015). 
O principal objetivo da RAS é prestar atenção integral, de qualidade e resolutiva, que atenda às reais necessidades da população, tendo em vista a atual situação epidemiológica e demográfica do País, que vem se dando de forma acelerada, com predominância das condições crônicas (BRASIL, 2015).

Importante destacar que nas RAS não há uma hierarquia entre os diferentes pontos de atenção à saúde, a APS e os sistemas de apoio, mas a conformação de uma rede horizontal de pontos de atenção de distintas densidades tecnológicas, a APS e seus sistemas de apoio, sem ordem e sem grau de importância entre eles. Todos os componentes das RAS são igualmente importantes para que se cumpram os objetivos dessas redes; apenas se diferenciam pelas respectivas densidades tecnológicas que os caracterizam (MENDES, 2012).

As RAS apresentam três elementos constitutivos: a população, a estrutura operacional e os modelos de atenção à saúde. O primeiro elemento das RAS, e sua razão de ser, é uma população, colocada sob sua responsabilidade sanitária e econômica. A população de responsabilidade das RAS não é a população dos censos demográficos, mas a cadastrada e vinculada a uma unidade de APS. Ela vive em territórios sanitários singulares, organiza-se socialmente em famílias e é cadastrada e registrada em subpopulações, conforme os riscos sociais e sanitários. O conhecimento profundo da população usuária de um sistema de atenção à saúde é o elemento básico que torna possível romper com a gestão baseada na oferta característica dos sistemas fragmentados - e instituir a gestão com base nas necessidades de saúde da população, elemento essencial das RAS (BRASIL, 2015).

A estrutura operacional das RAS é composta por cinco componentes: o centro de comunicação, a APS; os pontos de atenção à saúde secundários e terciários; os sistemas de apoio (sistemas de apoio diagnóstico e terapêutico, sistemas de assistência farmacêutica, sistemas de teleassistência e sistemas de informação em saúde); os sistemas logísticos (registro eletrônico em saúde, sistemas de acesso regulado à atenção e sistemas de transporte em saúde); e o sistema de governança das RAS (BRASIL, 2015).

O terceiro elemento constitutivo das RAS são os modelos de atenção à saúde, os quais são sistemas lógicos que organizam o funcionamento das RAS, articulando, de forma singular, as relações entre os componentes da rede e as intervenções sanitárias, e são definidos em função da visão prevalecente da saúde, das situações demográficas e epidemiológicas e dos determinantes sociais da saúde, vigentes em determinado tempo e em determinada sociedade. Os modelos de atenção à saúde são diferenciados por modelos de atenção às condições agudas e às condições crônicas (MENDES, 2011). 


\subsection{ATENÇÃO PRIMÁRIA À SAÚDE E COORDENAÇÃO DO CUIDADO}

A moderna concepção de APS surgiu no Reino Unido, em 1920, no Relatório Dawson que preconizou a organização do sistema de atenção à saúde em diversos níveis: os serviços domiciliares, os centros de saúde primários, os centros de saúde secundários, os serviços suplementares e os hospitais de ensino (PENN et. al., 1920). Esse clássico documento descreveu as funções de cada nível de atenção e as relações que devem existir entre eles, impondo-se como texto fundante da regionalização dos sistemas de atenção à saúde organizados em bases populacionais e tendo influenciado a organização desses sistemas em vários países do mundo (MENDES, 2012).

A institucionalização da APS ocorreu na Conferência Internacional sobre Cuidados Primários de Saúde, realizada em Alma-Ata (1978), que definiu a APS como "cuidados essenciais baseados em métodos de trabalho e tecnologias de natureza prática, cientificamente críveis e socialmente aceitáveis, universalmente acessíveis na comunidade aos indivíduos e às famílias, com a sua total participação e a um custo suportável para as comunidades e para os países, à medida que se desenvolvem num espírito de autonomia e autodeterminação" (OMS, 1979).

Em 1979, a Assembleia Mundial da Saúde convidou todos os países-membros a definir e pôr em prática estratégias nacionais, regionais e globais, tendentes a alcançar a meta de "Saúde para Todos no ano 2000". Porém, quando a OMS propôs sua agenda para operacionalização das metas acordadas em Alma-Ata, os países desenvolvidos já as haviam alcançado em grande parte, enquanto a maioria dos países em desenvolvimento ainda estavam longe de atingi-las, o que gerou problemas de conceituação e implementação (VUORI, 1984), que se propagam até os dias de hoje.

As variações na interpretação da APS se explicam pela mesma história de como se gestou e evoluiu esse conceito e pela ambiguidade de algumas de suas definições formais estabelecidas nos foros internacionais, bem como pelo uso diferenciado que algumas escolas do pensamento sanitário fazem do termo e pela tentativa de se instituir uma concepção positiva do processo saúde/doença em momento de nítida hegemonia de uma concepção negativa da saúde (MENDES, 2002). Por isso, há três interpretações principais da APS: a APS como atenção primária seletiva, a APS como o nível primário do sistema de atenção à saúde e a APS como estratégia de organização do sistema de atenção à saúde. Essas três 
decodificações dos cuidados primários são encontradas em vários países e, até mesmo, convivem dentro de um mesmo país ao mesmo tempo (MENDES, 2002).

A interpretação da APS como estratégia de organização do sistema de atenção à saúde compreende-a como uma forma singular de apropriar, recombinar e reordenar todos os recursos do sistema para satisfazer as necessidades, demandas e representações da população, o que implica a articulação da APS como parte e coordenadora de uma RAS. Por esse motivo, há quem sugira que a APS deve ocupar o "banco do motorista" (SALTMAN, 2006) para dirigir o sistema de atenção à saúde, e há quem proponha RAS baseadas na APS (OPAS, 2010).

A decodificação da APS como estratégia de organização do sistema de atenção à saúde é a mais compatível com a proposta das RAS por ter a interpretação mais correta, do ponto de vista técnico, ser abrangente, factível e viável no estágio de desenvolvimento do Brasil e com o volume de gasto público que o SUS apresenta, além de tornar possível o exercício das funções da APS como coordenadora das RAS (MENDES, 2012).

Segundo Mendes (2002), uma APS como estratégia só existirá se ela cumprir seus três papéis essenciais: a resolutividade, a coordenação e a responsabilização. $O$ papel da resolutividade, relativa ao nível de cuidados primários, significa que eles devem ser resolutivos - capacitados cognitiva e tecnologicamente para atender a $90 \%$ da demanda da APS. O papel de coordenação expressa o exercício, pela APS, de centro de comunicação das RAS, o que significa ter condições de ordenar os fluxos e os contrafluxos das pessoas, dos produtos e das informações entre os diferentes componentes das redes. A função de responsabilização, por fim, implica o conhecimento e o relacionamento íntimo - nos microterritórios sanitários - com a população adscrita, o exercício da gestão de base populacional e a responsabilização econômica e sanitária em relação a essa população adscrita.

Mesmo diante das robustas evidências sobre as vantagens de sistemas de atenção à saúde baseados numa APS forte, sua valorização política, econômica e social é baixa, em todo o mundo. Nos países desenvolvidos, com tradição em cuidados primários, há quem fale na crise da APS (MOORE, 2004). Na Europa levanta-se a questão da credibilidade, relativa à habilidade da APS em obter ou manter o respeito necessário e ao status para suportar o seu desenvolvimento nos sistemas de saúde (SALTMAN, 2006). Nos países em desenvolvimento, em que, em geral, a APS ainda não se institucionalizou, os problemas decorrem, principalmente, das fragilidades da concepção da atenção primária seletiva. 
No Brasil, o discurso oficial da APS como estratégia de organização do SUS, vige diferentes modelos de estruturação. A Estratégia de Saúde da Família (ESF) convive com variados modelos de cuidados primários, especialmente quando se considera o trabalho médico (MENDES, 2012). Ainda que não se possa, rigorosamente, comparar a ESF com os modelos tradicionais de APS, porque são opções de políticas de cuidados primários totalmente distintas, ao contrário do que algumas vezes se anuncia, trabalhos revisados demonstraram a superioridade da ESF em relação aos modelos tradicionais, especialmente no cumprimento dos atributos da APS (MENDES, 2012).

O conceito fundamental que preside a relação entre a ESF e a atenção especializada é o da coordenação do cuidado que, segundo Mendes (2012), na perspectiva das pessoas usuárias e de suas famílias, constitui-se como qualquer atividade que auxilie a assegurar as necessidades e as preferências dessas pessoas por serviços de saúde e o compartilhamento de informações entre profissionais, pessoas e locais de atendimento, para que assim sejam realizados de forma oportuna.

Segundo Cecílio (2011), o cuidado é definido como "provimento e disponibilização de tecnologias de saúde de acordo com as necessidades singulares de cada pessoa, em diferentes momentos de sua vida, visando o ser bem-estar, segurança e autonomia, para seguir com uma vida produtiva e feliz". O conceito de cuidado na área da saúde pode mostrar ou abrir caminhos para novas respostas, a partir do momento que os profissionais e os serviços de saúde se comprometem com a ação necessária para superar a atual fragmentação da atenção ao indivíduo (GARIGLIO, 2012).

Em sua análise para avaliar a atenção primária à saúde, Starfield (2002), destaca a coordenação como um dos atributos essenciais. A pergunta síntese do conceito de coordenação, pela perspectiva do usuário, para esta autora, resultou na seguinte expressão: "se vários profissionais estão envolvidos no meu tratamento, meu médico de atenção primária organiza-o". A essência da coordenação para a autora é a disponibilidade de informações a respeito de problemas e serviços anteriores e o reconhecimento daquela informação, na medida em que está relacionada às necessidades para o presente atendimento (STARFIELD, 2002: 49).

Mendes (2010), então, identificou alguns desafios a serem enfrentados no nosso País em relação à coordenação entre a APS e outros níveis assistenciais, quais sejam: dificuldades em realizar referência e contrarreferência de pacientes, inexistência de sistemas logísticos que resultam em falta de mecanismos de regulação, como marcação de consultas e exames, e 
pouca comunicação entre os profissionais de saúde de níveis assistenciais distintos, no que diz respeito à conduta e aos registros clínicos dos pacientes. Todos esses problemas resultam em descontinuidade do cuidado à saúde dos usuários do SUS (HARTZ \& CONTANDRIOPOULOS, 2004).

Na perspectiva dos profissionais de saúde, há que se considerar que a coordenação do cuidado é uma atividade centrada nas pessoas e nas famílias, destinada a atender às necessidades dessas pessoas, apoiando-as a se moverem, de modo eficiente e efetivo, através do sistema de atenção à saúde, o que implica que a coordenação clínica determine a quem e para onde os usuários devem se referir, quais informações são necessárias transferir na referência e na contrarreferência e que responsabilidades são imputadas aos diversos membros das equipes de saúde. Além disso, há uma coordenação logística que envolve sistemas de apoio e de informação, de transportes e, até mesmo, sistemas financeiros (ANTONELLI, 2009). As falhas na coordenação do cuidado, na perspectiva dos profissionais, surgem quando a pessoas são referidas a um profissional não adequado ou a uma unidade de saúde errada, ou ainda quando se atingem resultados ruins em função de um mau manejo clínico, ou de fluxos de informações inadequados (MENDES, 2012).

Na perspectiva do sistema de atenção à saúde, a coordenação do cuidado tem como objetivo integrar recursos humanos, materiais e informações necessárias para dar suporte às atividades dentro e dentre os diferentes pontos de atenção à saúde, sistemas de apoio e sistemas logísticos. As falhas na coordenação do cuidado, na perspectiva do sistema de atenção à saúde, manifestam-se em serviços inefetivos e ineficientes, que resultam de problemas clínicos resultantes da fragmentação da atenção à saúde (MCDONALD, 2007).

De acordo com Mendes (2012), as relações descoordenadas, ou com baixo grau de coordenação, entre a ESF e a atenção especializada trazem muita insatisfação às pessoas usuárias, às suas famílias e aos profissionais de saúde. Estudos realizados (CUMMINS, 1980; GANDHI, 2000) mostraram que $47 \%$ das pessoas entrevistadas reportaram estarem insatisfeitas com a atenção especializada recebida; $63 \%$ dos médicos generalistas e $35 \%$ dos médicos especialistas estavam muito insatisfeitos com a atenção prestada; e $68 \%$ dos médicos especialistas relataram não receberem as informações adequadas ou receberem referências inadequadas de parte dos generalistas. De sua parte, os generalistas referiram que não recebiam as informações dos especialistas e que não eram notificados quando as pessoas sob sua responsabilidade eram atendidas nas unidades de urgência ou de especialidades, ou eram internadas em hospitais. Uma pesquisa nos Estados Unidos entrevistou 4.720 médicos 
generalistas e especialistas e verificou que $69,3 \%$ dos médicos generalistas relataram encaminhar as pessoas usuárias "sempre" ou "na maior parte das vezes" com a história clínica e a razão da referência, mas somente $34,8 \%$ dos especialistas disseram que "sempre" ou "na maior parte das vezes" receberam esses relatórios (MCDONALD, 2010).

Mendes (2012) destaca as diferentes relações entre a ESF e a atenção especializada que acontecem no SUS como: o generalista não conhece o especialista a quem refere a pessoa usuária e vice-versa, quando o faz; o generalista e o especialista nunca partilharam atividades clínicas ou educacionais; o especialista não tem as informações adequadas do generalista ao receber a pessoa encaminhada; o generalista não recebe as orientações do especialista ao ter de volta a pessoa; a pessoa se queixa de que o especialista parecia não saber por que ela estava ali com ele; o especialista não resolve o problema para o qual o generalista encaminhou; o especialista se apossa definitivamente da pessoa na atenção especializada; o especialista repete exames que já haviam sido feitos na ESF; uma mesma pessoa adscrita a uma equipe da ESF é encaminhada, por uma central de regulação, a diferentes especialistas de uma mesma especialidade, em tempos diferentes, com o critério de onde tem vaga; o especialista recebe pessoas que não deveriam ser referidas a ele; o especialista se queixa de que o médico de família encaminha errado porque tem pouco conhecimento; as relações entre os generalistas e os especialistas são impessoais e de desconfiança mútua; a consulta com especialista demora muito tempo para ser realizada, sendo uma fonte de insatisfação da população; as pessoas se sentem abandonadas quando chegam à unidade de atenção especializada por falta de apoio na transição; e a atenção especializada é concentrada no médico, sem participação protagônica de outros profissionais de uma equipe multiprofissional. Todos estes fatores, contribuem para que haja pouca agregação de valor para as pessoas que necessitam de cuidados especializados ambulatoriais, mesmo quando os recebem.

A relação entre a ESF e a atenção especializada tem como elementos centrais o fluxo dos usuários entre os equipamentos de saúde e o apoio que deve ser dado nos momentos de transição. As transições ocorrem quando as informações ou as responsabilidades sobre as pessoas usuárias são transferidas entre duas ou mais unidades de saúde e são áreas críticas para a segurança da atenção à saúde. Um bom sistema de apoio à transição baseia-se na transferência conjunta de informações e responsabilidades e, por isso, há dois tipos de transição: a transição entre unidades de saúde, que pode ser realizada entre diferentes profissionais de uma equipe dentro da mesma unidade, ou ainda, entre diferentes 
equipamentos de saúde, e a transição temporal, quando se transfere informações e responsabilidades entre episódios de cuidados (MCDONALD, 2010).

O modelo da coordenação do cuidado é proposto na perspectiva da APS, que considera os pontos de atenção especializada, bem como suas relações com a ESF, e sumariza os elementos que contribuem para o alcance de fluxos de referência e transição de alta qualidade. São quatro os elementos do modelo: assegurar a responsabilização (accountability); prover apoio à pessoa usuária; desenvolver relações e acordos entre a ESF e a atenção especializada; e desenvolver conectividade pela via de sistemas de informação clínica, preferencialmente eletrônicos, que propiciem informações oportunas e efetivas entre a ESF e a atenção especializada. Esses elementos, quando aplicados, permitem que os prestadores recebam as informações de que necessitam em tempo oportuno, que os profissionais saibam a situação de referência e transição das pessoas sob sua responsabilidade e que as pessoas usuárias sintam que recebem uma atenção coordenada (MENDES, 2012).

A responsabilização pela coordenação do cuidado, nesse modelo e na perspectiva das RAS, é uma função da ESF. É a equipe da ESF que deve, a partir das orientações contidas nas diretrizes clínicas, e considerando a estratificação de riscos das condições crônicas, definir quais pessoas se beneficiarão da atenção especializada e referi-las. Para tal, é necessário que a ESF desenvolva infraestrutura, relações e processos que tornem possíveis referências e transições de qualidade. Isso implica que os profissionais de saúde envolvidos no processo se conheçam e conheçam as expectativas de cada qual, assim como que a unidade da ESF tenha pessoal preparado e infraestrutura de informação adequada (MENDES, 2012).

A existência de prontuários clínicos, preferivelmente eletrônicos, que interliguem os equipamentos de saúde é fundamental. A existência de um instrumento de referência padronizado, com dados da pessoa e de sua história clínica é imprescindível. A responsabilização pela transição é da unidade de atenção especializada, que deve apoiar as pessoas enquanto são atendidas e tem de se comunicar com a ESF sobre o que está sendo feito. Um relatório padronizado de contrarreferência é importante para garantir a boa comunicação. As equipes da ESF e a da atenção especializada devem passar por processos de educação permanentes e contínuos, para que assim possam desenvolver os mecanismos essenciais do processo de coordenação do cuidado (MENDES, 2012).

Ao longo do tempo, conforme os cuidados vão se coordenando, as relações entre os generalistas e os especialistas devem deixar de ser de desconfiança e de distância para transformarem-se em parcerias próximas (PHAM, 2009), pressupondo que as referências e as 
Ana Cláudia Medeiros Galvão de Lima

contrarreferências não sejam burocráticas e impessoais, mas que sejam feitas entre pessoas que se conhecem e trabalham em conjunto. A conectividade é um preditor crítico de sucesso da coordenação do cuidado entre os equipamentos de saúde e significa que os profissionais de saúde envolvidos dispõem da informação de que necessitam e de um sistema de comunicação fluido para prestarem os cuidados adequados (MENDES, 2012). 
4. Material e Métodos 


\section{MATERIAL E MÉTODOS}

\subsection{TIPO DE ESTUDO}

Trata-se de um estudo transversal, descritivo, exploratório e retrospectivo com abordagem quantitativa. Este tipo de abordagem visa descrever os fatos e fenômenos de determinada realidade, permitindo ao investigador aumentar a sua experiência, aprofundar seu estudo e adquirir maior conhecimento a respeito de um problema (TRIVIÑOS, 1987).

O estudo no Mestrado Profissional em Enfermagem na Atenção Primária busca contribuir com a transformação das práticas em saúde. Pode ainda servir para levantar possíveis problemas de pesquisa e, com isso, sugerir possíveis soluções.

\subsection{CENÁRIO DO ESTUDO}

O estudo toma como cenário uma região do Município de São Paulo (MSP). É o maior município do estado, com uma população estimada em 11.253.503 habitantes, segundo dados do IBGE (IBGE, 2011). Está organizado em 31 subprefeituras e 96 distritos administrativos. As subprefeituras são órgãos da administração direta com limites territoriais estabelecidos em função de parâmetros e indicadores socioeconômicos (SÃO PAULO, 2002). Divido em seis coordenadorias regionais de saúde (Centro, Oeste, Leste, Norte, Sudeste e Sul), a Coordenadoria Regional de Saúde (CRS) Sul, região onde se encontra o equipamento de saúde alvo do estudo, é composta pelas subprefeituras do Campo Limpo, Capela do Socorro, Cidade Ademar, M’Boi Mirim, Parelheiros e Santo Amaro (Figura 1) (SÃO PAULO, SP, 2015). 
Figura 1 - Distribuição dos estabelecimentos municipais de saúde na CRS Sul. São Paulo/SP, 2010.

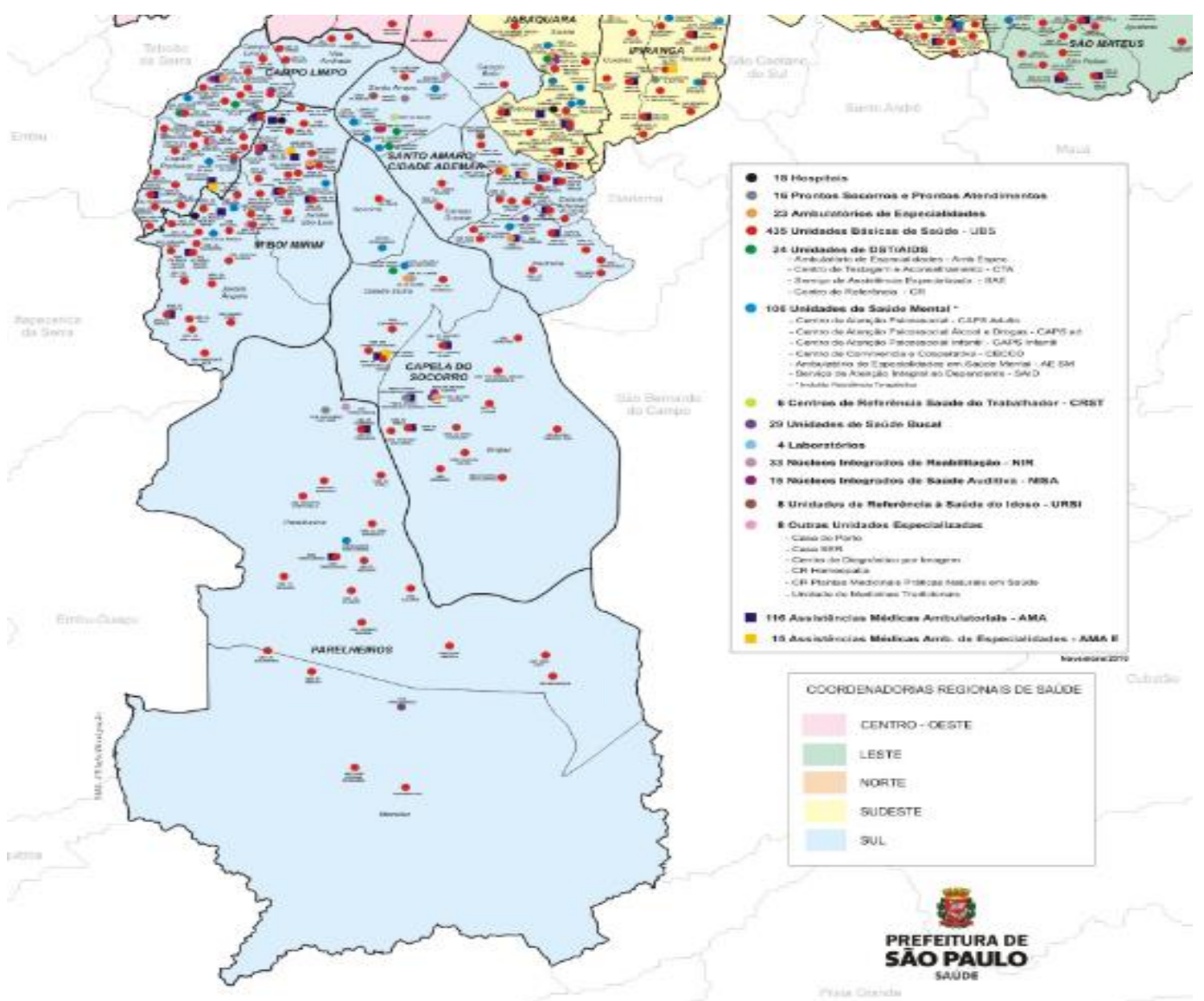

A Prefeitura Regional do Campo Limpo, locus do estudo, ocupa uma área de $36,7 \mathrm{~km}^{2}$ e está situada entre as Subprefeituras de Butantã, ao norte, Santo Amaro, a leste, e M'Boi Mirim, ao sul, e em fronteira com os municípios de Taboão da Serra, a oeste e de Itapecerica, a sudoeste. É formada pelos distritos de Campo Limpo, Capão Redondo e Vila Andrade. Possui uma população aproximada de 650.000 habitantes e uma taxa de urbanização de $100 \%$ e densidade demográfica média de 17.486,65 hab. $/ \mathrm{km}^{2}$, com uma rede de saúde composta por aproximadamente 25 equipamentos de saúde (SÃO PAULO, 2009).

O MSP se caracteriza por uma redução da taxa de natalidade com discreto aumento na taxa de mortalidade, o que conduz a cidade a um envelhecimento populacional, com aumento de adultos e idosos e redução na proporção de crianças e adolescentes (IBGE, 2010). Observou-se que a faixa etária prevalente, entre as mulheres, foi de 25 a 29 anos, sendo também destaque entre os homens (SÃO PAULO, 2012). 
Segundo boletim publicado pela Coordenação de Epidemiologia e Informação (CEINFO, 2010), todas as CRS do MSP obtiveram crescimento positivo entre os anos de 2000 a 2010, embora em diferentes ritmos. Cresceram acima da média do município a CRS Centro-Oeste e Sul, sendo que a maior taxa de crescimento da década foi verificada na CRS Sul com $1,25 \%$ de taxa média geométrica de crescimento anual, quando a média do MSP foi de $0,76 \%$.

A CRS Sul apresentou a maior taxa de crescimento no MSP em 10 anos (2000 a 2010). Só quatro de seus quinze distritos cresceram abaixo da taxa municipal, sendo que desses, três perderam população. No outro extremo, o do crescimento positivo, Vila Andrade foi o distrito que mais cresceu em São Paulo na década e à taxa muito alta $(5,60 \%)$, praticamente semelhante a taxa que o MSP vivenciou na década de 1950/60 (5,50\%). A região apresentou o menor contingente de idosos, mas muito próximo ao da região Leste. Apresentou ainda o maior percentual de pardos, o segundo maior percentual de pessoas ganhando até dois salários mínimos e pouco menos de um quarto da população vive em aglomerados subnormais (CEINFO, 2010).

No que diz respeito à população, segundo distribuição de renda no MSP, dados relativos a rendimentos, divulgados até março de 2012 pelo IBGE e que dizem respeito ao número de pessoas de 10 anos ou mais de idade com renda mensal, apontou que a condição mais equilibrada está na CRS centro-oeste e a pior distribuição está na CRS Sul, a qual também possui a maior proporção de pessoas vivendo em aglomerados com $23,5 \%$, quando a média do MSP foi de 13,2\% (CEINFO, 2010).

Quanto aos indicadores socioeconômicos, os problemas mais urgentes de saneamento básico estão localizados na CRS Sul (coleta de esgoto), onde predominam também proporções maiores de baixa escolaridade e renda da população, juntamente com a CRS Leste. As moradias tipo favelas abrigam 14\% dos moradores da cidade (SÃO PAULO, 2012).

Do ponto de vista epidemiológico observou-se um incremento das doenças crônicas não transmissíveis na capital, com redução da incidência das doenças infecciosas, acompanhada do aumento de morte por causas externas decorrentes da urbanização desenfreada na cidade (SÃO PAULO, 2012).

A APS no município de São Paulo começou a ser implantada em 1996, através de uma ação conjunta entre o Ministério da Saúde, a Secretaria de Estado da Saúde e duas organizações sociais sem fins lucrativos com a denominação de Qualidade Integral em Saúde (Projeto QUALIS). Este fato se deu em virtude dos serviços de saúde do município de São 
Paulo terem sido transformados em cooperativas de saúde, operados pelo setor privado, através do Plano de Assistência à Saúde (PAS) por questões políticas. No início de 2001, após a inativação do PAS, iniciou-se a transição em direção ao SUS com a municipalização das unidades estaduais de saúde, além de eleger a UBS como componente estruturante da APS do sistema municipal de saúde (GUERRA, 2006). Na sua implementação foram realizadas as parcerias de cogestão dos serviços de saúde.

A rede de atenção básica do MSP passa por um processo de reestruturação articulada às RAS na perspectiva da atenção integral. Está constituída por 450 Unidades Básicas de Saúde (UBS) e 117 unidades de Assistência Médica Ambulatorial (AMA), sendo 87 delas integradas à UBS. Esta rede de atenção conta com mais de 1300 equipes de Estratégia Saúde da Família (ESF), apoiadas pelos Núcleos de Apoio à Saúde da Família - NASF, além de arranjos assistenciais inovadores como os consultórios na rua, equipes do melhor em casa articuladas com a comunidade e com os demais serviços do território, como as unidades de pronto-atendimento (UPAs) (SÃO PAULO, 2016).

As UPAs foram criadas para atuar como porta de entrada aos serviços de urgência e emergência, onde, dependendo do caso atendido, eles podem ser solucionados no local, estabilizados e/ou encaminhados para os hospitais ou redirecionados às UBS. De acordo com as suas atribuições, as UPAs devem funcionar 24 horas por dia, realizar a classificação de risco dos pacientes, resolver os casos de baixa e média complexidade, estabilizar os casos de pacientes graves e possuir estrutura física, recursos humanos e tecnológicos suficientes para o atendimento da população de sua área de abrangência (SILVA et.al, 2012).

Segundo o CONASS (2015), a implantação das UPAs deve atender às orientações gerais, diretrizes e parâmetros estabelecidos na Portaria GM/MS n. 2.648, de 7 de novembro de 2011, que estabelece como competência delas: (i) atendimento à urgência e emergência traumáticas e não traumáticas; (ii) realização de exames laboratoriais, eletrocardiográficos e radiológicos para diagnosticar situações de urgência e emergência; (iii) distribuição de medicamentos para que o paciente realize o tratamento domiciliar em situações de urgência; (iv) realização do transporte de enfermos que lá tenham recebido seu primeiro atendimento; entre outras.

Conforme o CONASS (2015), em 2012 foi disponibilizado pelo Ministério da Saúde uma planilha com informações relativas às UPAs em funcionamento em todo o território nacional, onde São Paulo contava com 36 UPAs, sendo 10 de porte I, 18 de porte II e 8 de porte III, localizadas em 17 municípios diferentes. Do total, 11 UPAs encontravam-se na 
grande São Paulo, estando as demais distribuídas por seis regiões do interior do estado. O município de São Paulo optou por um modelo de unidades de atendimento às urgências, as AMAs, diferente da proposta do Ministério da Saúde.

A SBIBAE, parceira na gestão das UBS das áreas de Vila Andrade e Campo Limpo, com atuação na Estratégia de Saúde da Família desde 2001, opera especificamente na região da Supervisão Técnica de Saúde do Campo Limpo, na zona Sul de São Paulo, e faz o gerenciamento 1 UPA, 3 AMAS, 3 CAPS e 13 Unidades Básicas de Saúde (UBS), com 82 equipes de saúde da família (eSF), 25 equipes de saúde bucal (eSB) e com os Núcleos de Apoio à Saúde da Família (NASF's), representando pouco mais de mil profissionais das áreas assistencial, administrativa e de apoio que prestam assistência a uma população de 368.133 habitantes. Os seis NASF dão apoio às 82 eSF e 25 eSB distribuídas nas 13 UBS's (SBIBAE, 2016).

As Unidades Básicas de Saúde onde as equipes estão alocadas são: UBS Alto do Umuarama - 5 eSF, 2 eSB, UBS Arrastão (Francisco Scalamandré Sobrinho) - 5 eSF, 1 eSB, UBS Campo Limpo - 8 eSF, 3 eSB, UBS Jardim das Palmas - 5 eSF, 3 eSB, UBS Jardim Helga - 4 eSF, UBS Jardim Mistutani - 9 eSF, UBS Jardim Olinda - 7 eSF, 3 eSB, UBS Paraisópolis 1 - 6 eSF, 3 eSB, UBS Paraisópolis 2 - 6 eSF, 2 eSB, UBS Paraisópolis 3 - 5 eSF, 3 eSB, UBS Parque Arariba - 10 eSF, UBS Parque Regina - 7 eSF, 2 eSB, UBS Vila Prel - 5 eSF, 3 Esb (SBIBAE, 2016).

O estudo foi desenvolvido na Unidade de Pronto-Atendimento (UPA 24h) Campo Limpo onde, previamente, funcionava um ambulatório de Assistência Médica Ambulatorial (AMA). Segundo a Secretaria Municipal de Saúde de São Paulo (2015), a UPA, inaugurada em abril de 2014 e primeira do MSP, tem a capacidade de atender até 900 pacientes por dia, que dão entrada na unidade por meios próprios ou encaminhados de outra unidade de saúde, beneficiando cerca de 1,1 milhão de pessoas do M'boi Mirim e do Campo Limpo. A UPA Campo Limpo possui gestão compartilhada com Sociedade Beneficente Israelita Brasileira Albert Einstein (SBIBAE) e realiza, em média, 18.000 atendimentos por mês.

Constituída como o maior nível de organização, porte III, a unidade conta com 41 leitos de observação, isolamento e pediatria, aproximadamente 425 profissionais, dentre os quais enfermeiros, técnicos de enfermagem, médicos (emergencistas, clínicos gerais, pediatras, ortopedistas e cirurgião geral), assistente social e quadro administrativo. Conta com sala de radiografia, exames laboratoriais, eletrocardiograma e sala de esterilização própria (BRASIL, 2014). 
Ana Cláudia Medeiros Galvão de Lima

As UPAs 24h estão inseridas na rede Saúde Toda Hora, que está reorganizando a atenção às urgências e emergências no SUS. Na unidade, os pacientes são avaliados de acordo com a classificação de risco de Manchester, podendo ser liberados, permanecer em observação por até 24 horas ou, se necessário, serem removidos para um hospital de referência, no caso da UPA Campo Limpo, Hospital Municipal do Campo Limpo (BRASIL, 2014).

\subsection{ETAPAS DO ESTUDO}

1) Acesso ao banco de dados da SBIBAE, o qual é atualizado com as informações dos atendimentos realizados na UPA Campo Limpo periodicamente.

2) Após a análise destas informações, e com o auxílio de um profissional estatístico fornecido pela SBIBAE, foram identificadas as principais condições crônicas com importância de intervenção junto à APS.

3) Criação de um procedimento operacional padrão (POP) para sistematização de um fluxograma de comunicação.

4) Construção do fluxograma de comunicação entre UPA e UBS para coordenação do cuidado.

\subsection{FONTE E COLETA DOS DADOS}

A pesquisa foi desenvolvida a partir de dados secundários obtidos por meio de um banco de dados da SBIBAE, o qual é atualizado periodicamente com informações dos pacientes e de seus atendimentos realizados na UPA. Foram coletadas as informações contidas no banco de dados relativas ao período de dois anos (janeiro de 2015 a dezembro de 2016). A população do estudo foi composta por pacientes que realizaram atendimento na UPA Campo Limpo e que apresentaram Internação por Condição Sensível à Atenção Primária (ICSAP).

As seguintes variáveis compõem o banco de dados: data de nascimento, número do Cadastro Nacional de Saúde (CNS), data e horário do atendimento, data e horário da finalização do atendimento, tipo de finalização do atendimento (alta, liberação, evasão, óbito 
ou transferência hospitalar), classificação de Manchester atribuída na Classificação de Risco (branco, azul, verde, amarelo, laranja ou vermelho) e identificação da ICSAP por meio do CID-10.

O Protocolo de Manchester permite a identificação da prioridade clínica e a definição do tempo alvo recomendado até a avaliação médica caso a caso, quer em situações de funcionamento normal do serviço de urgência, ou em situações de catástrofe e múltiplas vítimas. Foi criado para permitir ao profissional médico e ao enfermeiro, habilidade para atribuir rapidamente uma prioridade clínica ao paciente em situação aguda, baseado em categorias de sinais e sintomas, composto por 52 fluxogramas. O método não objetiva estabelecer diagnóstico médico e por si só não garante o bom funcionamento do serviço de urgência. O Sistema Manchester pretende, na verdade, assegurar que a atenção médica ocorra de acordo com o tempo resposta determinado pela gravidade clínica do paciente, além de ser ferramenta importante para o manejo seguro dos fluxos dos pacientes quando a demanda excede a capacidade de resposta. O paciente é classificado em uma das cinco prioridades emergente (vermelha), muito urgente (laranja), urgente (amarelo), pouco urgente (verde) e não urgente (azul) - identificadas por número, nome, cor e tempo alvo para a observação médica inicial (GBCR, 2015). No fluxo interno da UPA Campo Limpo ainda existe a classificação de risco de cor branca, atribuída a pacientes não urgentes, que não apresentam queixas e que procuraram a unidade para realização de procedimentos ambulatoriais, como realização de curativos e passagem de sondas.

A lista de internações por condições sensíveis à atenção primária (Anexo A) utilizada é a publicada pelo Ministério da Saúde, na portaria No 221, em 17 de abril de 2008, composta por 19 grupos de doenças: Doenças preveníveis por imunização e condições sensíveis, gastroenterites infecciosas e complicações, anemia, deficiências nutricionais, infecções de ouvido, nariz e garganta, pneumonias bacterianas, asma, doenças pulmonares, hipertensão, angina, insuficiência cardíaca, doenças cerebrovasculares, diabetes mellitus, epilepsias, infecção do rim e trato urinário, infecção da pele e tecido subcutâneo, doença inflamatória de órgão pélvico feminino, úlcera gastrointestinal e doenças relacionadas ao pré-natal e parto.

\subsection{ANÁLISE ESTATÍSTICA E DIMENSIONAMENTO AMOSTRAL}

Foram utilizados dados referentes a dois anos de atendimentos na UPA Campo Limpo, a qual realiza em torno de 13.000 atendimentos por mês com incidência de ICSAP por volta 
Ana Cláudia Medeiros Galvão de Lima

de $25 \%$. Dessa forma, o total de atendimentos deveria ser em torno de 300.000. Com esse tamanho de amostra foi possível construir um intervalo de confiança de $99 \%$ para a incidência de atendimentos devido a ICSAP com margem de erro de 0,4\% (PASS 14, 2015; FLEISS \& COLS., 2003; NEWCOMBE, 1998).

As análises foram realizadas com o auxílio do pacote estatístico SPSS (IBM CORP, 2016). Os dados foram descritos por meio de frequências absolutas e relativas para as variáveis categóricas e por médias, desvio padrão (DP), mediana e quantis, valores mínimos e máximos para as variáveis quantitativas (ALTMAN, 1991). Foram ajustados modelos de regressão logística multinomial em abordagem simples para avaliar possíveis fatores associados aos desfechos de atendimento: transferência hospitalar e evasão.

\subsection{PROCEDIMENTO OPERACIONAL PADRÃO (POP)}

Optou-se pela realização de um procedimento operacional padrão (POP) para sistematizar o fluxograma de comunicação entre UPA e UBS para coordenação do cuidado.

\subsubsection{Definição}

A coordenação do cuidado constitui-se como um desafio para os profissionais e serviços de saúde pois, na maioria das vezes, a equipes de saúde não tem informações sobre os atendimentos prestados ao paciente nos demais pontos da rede, o que dificulta a continuidade do cuidado (SHIMAZAKI, 2009). O fluxograma de comunicação para coordenação do cuidado proposto neste estudo caracteriza-se pela sua inovação no serviço, a fim de integrar atenção primária e secundária para alcançar melhores resultados no cuidado em saúde dos usuários. 


\subsubsection{Objetivo}

Disponibilizar informações a respeito dos atendimentos por ICSAP realizados na UPA e assim fortalecer o trabalho em rede, tomando a comunicação como eixo para coordenação do cuidado na APS.

\subsubsection{Indicação}

Pacientes que apresentarem as seguintes condições crônicas: asma, diabetes mellitus, hipertensão arterial sistêmica e/ou transtorno mental.

\subsubsection{Local}

Pacientes admitidos na observação infantil (OI), observação adulto (OA) ou sala de choque (SC).

\subsubsection{Responsável}

Enfermeiro.

\subsubsection{Descrição do Procedimento}

1) Enfermeiro deverá realizar a admissão do paciente na Observação Infantil, Observação Adulto ou Sala de Choque.

2) Identificar os pacientes que apresentam as seguintes comorbidades: asma, hipertensão arterial sistêmica, diabetes mellitus e/ou transtorno mental.

3) Acessar o sistema NISI-Einstein online em posse de seu login e senha pessoal para realização da Sistematização da Assistência de Enfermagem (SAE). 
4) Preencher o sistema com as informações básicas do paciente como nome completo, data de nascimento, idade, cadastro nacional de saúde (CNS), gênero, estabelecimento de vínculo (UBS de origem), médico e enfermeiro da UBS responsáveis pelo usuário e informações adicionais, como e-mail da UBS, CPF e RG do usuário, telefone para contato, entre outros.

5) Realizar o resumo de admissão do paciente, informando a queixa principal, motivo da necessidade de observação clínica na unidade e o CID-10.

6) Após finalizar a realização da SAE, as informações deverão ser enviadas diretamente para a UBS do paciente informada no início.

\subsubsection{Riscos/Pontos Críticos}

Falta de adesão do profissional de saúde;

O fluxograma tem como limitação para sua realização a necessidade de funcionamento do sistema online;

\subsubsection{Periodicidade de Treinamento}

Admissional, treinamento mediante necessidade ou solicitação da unidade.

\subsection{ASPÉCTOS ÉTICOS}

Esta pesquisa foi realizada seguindo as normatizações contidas na Resolução n ${ }^{\circ} 510$ de abril de 2016, do Conselho Nacional de Saúde (CNS), referente aos aspectos éticos recomendados quando da realização de pesquisas envolvendo seres humanos. O projeto foi aprovado na Plataforma Brasil após avaliação do Comitê de Ética em Pesquisa da Escola de Enfermagem da USP, Secretaria Municipal da Saúde de São Paulo e Hospital Israelita Albert Einstein com CAAE: 63883617.9.0000.5392. 


\section{Resultados}




\section{RESULTADOS}

O banco de dados, no período de 01 de janeiro de 2015 a 31 de dezembro de 2016, continha registros de 434.883 atendimentos de pacientes na UPA Campo Limpo. Destes, $219.214(50,4 \%)$ foram realizados no primeiro ano e $215.669(49,6 \%)$ no segundo. No total foram atendidos 236.801 pacientes, que tiveram entre 1 e 165 atendimentos na unidade no período estudado.

A idade dos pacientes variou entre zero e 114,6 anos, com média de 29,7 anos (DP=21,6 anos), mediana de 26,9 anos (Q1=11,7 anos; Q3=44,1 anos). Do total de 434.883 atendimentos, a maior parte foi de clínica médica $(72,7 \%)$, seguida de pediatria $(27,1 \%)$. Quanto à procedência, 79,1\% dos pacientes eram provenientes de suas residências, seguidos dos que chegaram por meio de ambulância (10,6\%). Apenas 2,1\% dos pacientes foram encaminhados de UBS.

Do total de 434.883 atendimentos, 74.248 (17,1\%), foram classificados como ICSAP, o que representa 54.268 pacientes que foram atendidos entre 1 e 47 vezes na UPA.

A tabela 1 compara as características dos pacientes atendidos na UPA em sua totalidade com os que foram classificados como ICSAP. Observou-se maioria do sexo feminino (UPA 54\%; ICSAP 52,2\%) e prevalência de faixa etária de 20 a 39 anos (34\%) na UPA e de 1 a 4 anos $(23,3 \%)$ nos pacientes com ICSAP.

Tabela 1 - Características dos pacientes atendidos na UPA Campo Limpo entre 2015 e 2016. São Paulo, SP, 2017.

\begin{tabular}{lcc}
\hline & UPA $(\mathbf{n}=\mathbf{4 3 4 . 8 8 3})$ & ICSAP $(\mathbf{n = 7 4 . 2 4 8})$ \\
\hline Sexo & & \\
Feminino & $235017(54,04 \%)$ & $38819(52,28 \%)$ \\
Masculino & $199866(45,96 \%)$ & $35429(47,72 \%)$ \\
& & \\
Faixa etária (anos) & & \\
Até 1 & $21499(4,94 \%)$ & $6764(9,11 \%)$ \\
1 a 4 & $52026(11,96 \%)$ & $17327(23,34 \%)$ \\
5 a 9 & $27609(6,35 \%)$ & $8282(11,15 \%)$ \\
10 a 14 & $21492(4,94 \%)$ & $4316(5,81 \%)$ \\
15 a 19 & $34573(7,95 \%)$ & $4744(6,39 \%)$ \\
20 a 39 & $147649(33,95 \%)$ & $17078(23,00 \%)$ \\
40 a 49 & $47520(10,93 \%)$ & $4725(6,36 \%)$ \\
50 a 59 & $35671(8,20 \%)$ & $4019(5,41 \%)$ \\
$\geq 0$ & $46844(10,77 \%)$ & $6993(9,42 \%)$ \\
\hline
\end{tabular}


Quanto aos dados da classificação de risco de Manchester (tabela 2), observou-se semelhança entre a totalidade dos atendimentos realizados na UPA e os atendimentos classificados como ICSAP, com predominância da classificação de risco verde (UPA 48,3\%; ICSAP 56,3\%).

Tabela 2 - Classificação de risco de Manchester dos atendimentos realizados na UPA Campo Limpo entre 2015 e 2016. São Paulo, SP, 2017.

\begin{tabular}{lcc}
\hline & UPA $(\mathbf{n}=\mathbf{4 3 4 . 8 8 3})$ & ICSAP $(\mathbf{n}=\mathbf{7 4 . 2 4 8})$ \\
\hline Classificação de Risco & & \\
Branco & $23426(5,39 \%)$ & $752(1,01 \%)$ \\
Azul & $14808(3,41 \%)$ & $962(1,30 \%)$ \\
Verde & $210439(48,39 \%)$ & $41838(56,35 \%)$ \\
Amarelo & $93918(21,60 \%)$ & $15801(21,28 \%)$ \\
Laranja & $51880(11,93 \%)$ & $14367(19,35 \%)$ \\
Vermelho & $1018(0,23 \%)$ & $143(0,19 \%)$ \\
Sem Informação & $39394(9,06 \%)$ & $385(0,52 \%)$ \\
\hline
\end{tabular}

Quanto ao tipo de finalização dos atendimentos, os dados estão descritos na tabela 3.

Tabela 3 - Tipo de finalização dos atendimentos realizados na UPA Campo Limpo entre 2015 e 2016. São Paulo, SP, 2017.

\begin{tabular}{lcc}
\hline & UPA $(\mathbf{n}=\mathbf{4 3 4 . 8 8 3})$ & ICSAP $(\mathbf{n}=\mathbf{7 4 . 2 4 8})$ \\
\hline Tipo de Encerramento & & \\
Alta & $160968(37,01 \%)$ & $41816(56,32 \%)$ \\
Evasão* & $93473(21,49 \%)$ & $6618(8,91 \%)$ \\
Liberação** & $70695(16,26 \%)$ & $15748(21,21 \%)$ \\
Óbito & $226(0,05 \%)$ & $27(0,04 \%)$ \\
Transferência hospitalar & $30963(7,12 \%)$ & $3480(4,69 \%)$ \\
Sem Informação & $78558(18,06 \%)$ & $6559(8,83 \%)$ \\
\hline
\end{tabular}

Utilizando o CID-10 do diagnóstico principal, os pacientes atendidos na UPA foram classificados em grupos de causa (Tabela 4), encontrando-se mais atendimentos por causas externas $(15,9 \%)$, sintomas e sinais anormais $(15,1 \%)$ e doenças do aparelho respiratório $(13,3 \%)$.

*Evasão é caracterizada por pacientes que abandonaram a unidade sem terem concluído o atendimento; **Liberação é caracterizada pelos pacientes que tiveram seu atendimento finalizado pelo médico após a primeira consulta, sem necessidade de reavaliação médica após realização de algum procedimento. 
Tabela 4 - Identificação dos grupos de causa nos atendimentos realizados na UPA Campo Limpo entre 2015 e 2016 ( $n=434.883$ ). São Paulo, SP, 2017.

\begin{tabular}{lr}
\hline Grupo de causa & \\
Afecções no período perinatal & $328(0,08 \%)$ \\
Causas Externas & $69062(15,88 \%)$ \\
Contato com serviço de saúde & $4920(1,13 \%)$ \\
Doenças da pele/subcutâneo & $7161(1,65 \%)$ \\
Doenças do aparelho circulatório & $8670(1,99 \%)$ \\
Doenças do aparelho digestivo & $12207(2,81 \%)$ \\
Doenças do aparelho geniturinário & $16540(3,80 \%)$ \\
Doenças do aparelho respiratório & $57876(13,31 \%)$ \\
Doenças do olho & $8075(1,86 \%)$ \\
Doenças do ouvido & $6837(1,57 \%)$ \\
Doenças do sangue & $501(0,12 \%)$ \\
Doenças do sistema nervoso & $4096(0,94 \%)$ \\
Doenças do sistema osteomuscular & $30086(6,92 \%)$ \\
Doenças infecciosas e parasitárias & $21124(4,86 \%)$ \\
Doenças nutricionais e metabólicas & $2040(0,47 \%)$ \\
Gravidez, parto e puerpério & $503(0,12 \%)$ \\
Malformações congênitas/anomalias cromossômicas & $106(0,02 \%)$ \\
Neoplasias & $612(0,14 \%)$ \\
Sintomas e sinais anormais & $65846(15,14 \%)$ \\
Transtornos mentais & $6568(1,51 \%)$ \\
Sem informação & $111725(25,69 \%)$ \\
\hline
\end{tabular}

A tabela 5 descreve a identificação dos tipos de ICSAP em relação ao total de atendimentos na unidade no período estudado, e em relação apenas às condições sensíveis separadamente, com destaque para o grande número de atendimentos por infecções de ouvido, nariz e garganta. 
Tabela 5 - Identificação de ICSAP nos atendimentos realizados na UPA Campo Limpo entre 2015 e 2016. São Paulo, SP, 2017.

\section{UPA $(n=434.883)$}

\section{Tipo de ICSAP}

Anemia

Angina

Asma

Bronquite

Bronquite aguda

Deficiências nutricionais

Diabetes

Doença inflamatória órgãos pélvicos femininos

Doenças cerebrovasculares

Doenças preveníveis por imunização

Doenças relacionadas ao pré-natal e parto

DPOC

Epilepsias

Febre reumática

Gastroenterites infecciosas e complicações

Hipertensão

Infecção da pele e tecido subcutâneo

Infecção no rim e trato urinário

Infecções de ouvido, nariz e garganta

Insuficiência cardíaca

Parasitose

Pneumonias bacterianas

Úlcera gastrointestinal

$$
\begin{gathered}
104(0,02 \%) \\
249(0,06 \%) \\
3817(0,88 \%) \\
121(0,03 \%) \\
8917(2,05 \%) \\
47(0,01 \%) \\
1073(0,25 \%) \\
410(0,09 \%) \\
941(0,22 \%) \\
1648(0,38 \%) \\
21(0,00 \%) \\
1308(0,30 \%) \\
629(0,14 \%) \\
6(0,00 \%) \\
11132(2,56 \%) \\
2905(0,67 \%) \\
3808(0,88 \%) \\
1560(0,36 \%) \\
33743(7,76 \%) \\
1130(0,26 \%) \\
12(0,00 \%) \\
623(0,14 \%) \\
44(0,01 \%)
\end{gathered}
$$

$\operatorname{ICSAP}(n=74.248)$

$$
\begin{gathered}
104(0,14 \%) \\
249(0,34 \%) \\
3817(5,14 \%) \\
121(0,16 \%) \\
8917(12,01 \%) \\
47(0,06 \%) \\
1073(1,45 \%) \\
410(0,55 \%) \\
941(1,27 \%) \\
1648(2,22 \%) \\
21(0,03 \%) \\
1308(1,76 \%) \\
629(0,85 \%) \\
6(0,01 \%) \\
11132(14,99 \%) \\
2905(3,91 \%) \\
3808(5,13 \%) \\
1560(2,10 \%) \\
33743(45,45 \%) \\
1130(1,52 \%) \\
12(0,02 \%) \\
623(0,84 \%) \\
44(0,06 \%)
\end{gathered}
$$

Sem informação ou não era icsap
$0(0,0 \%)$

Na Tabela 6 estão apresentadas as distribuições dos tipos de ICSAP por faixa etária dos pacientes com ICSAP atendidos na UPA Campo Limpo, no período de estudo. Observouse que nos menores de 1 ano houve prevalência de bronquite aguda (41,4\%). Nas demais faixas etárias houve predomínio das infecções de ouvido, nariz e garganta, exceto nos maiores de 60 anos, onde a maioria dos atendimentos se deu por hipertensão arterial sistêmica $(15,6 \%)$. 
Tabela 6 - Número (\%) dos tipos de atendimento por ICSAP por faixa etária dos pacientes (n=74.248). São Paulo, SP, 2017.

(continua)

\begin{tabular}{|c|c|c|c|c|c|c|c|c|c|}
\hline \multirow[b]{2}{*}{ Tipo de ICSAP } & \multicolumn{9}{|c|}{ Faixa etária (anos) } \\
\hline & $<1$ & 1 a 4 & 5 a 9 & 10 a 14 & 15 a 19 & 20 a 39 & 40 a 49 & 50 a 59 & $\geq 60$ \\
\hline Anemia & $2(0,03 \%)$ & $7(0,04 \%)$ & $3(0,04 \%)$ & $2(0,05 \%)$ & $7(0,15 \%)$ & $16(0,09 \%)$ & $24(0,51 \%)$ & $10(0,25 \%)$ & $33(0,47 \%)$ \\
\hline Angina & $0(0,00 \%)$ & $0(0,00 \%)$ & $0(0,00 \%)$ & $0(0,00 \%)$ & $2(0,04 \%)$ & $14(0,08 \%)$ & $43(0,91 \%)$ & $71(1,77 \%)$ & $119(1,70 \%)$ \\
\hline Asma & $123(1,82 \%)$ & $760(4,39 \%)$ & $702(8,48 \%)$ & $381(8,83 \%)$ & $306(6,45 \%)$ & $879(5,15 \%)$ & $226(4,78 \%)$ & $185(4,60 \%)$ & $255(3,65 \%)$ \\
\hline Bronquite & $7(0,10 \%)$ & $33(0,19 \%)$ & $13(0,16 \%)$ & $2(0,05 \%)$ & $5(0,11 \%)$ & $17(0,10 \%)$ & $5(0,11 \%)$ & $12(0,30 \%)$ & $27(0,39 \%)$ \\
\hline Bronquite aguda & $2806(41,48 \%)$ & $3078(17,76 \%)$ & $1386(16,74 \%)$ & $578(13,39 \%)$ & $127(2,68 \%)$ & $462(2,71 \%)$ & $149(3,15 \%)$ & $143(3,56 \%)$ & $188(2,69 \%)$ \\
\hline Deficiências nutricionais & $6(0,09 \%)$ & $3(0,02 \%)$ & $0(0,00 \%)$ & $0(0,00 \%)$ & $2(0,04 \%)$ & $5(0,03 \%)$ & $2(0,04 \%)$ & $6(0,15 \%)$ & $23(0,33 \%)$ \\
\hline Diabetes & $1(0,01 \%)$ & $10(0,06 \%)$ & $16(0,19 \%)$ & $35(0,81 \%)$ & $40(0,84 \%)$ & $153(0,90 \%)$ & $166(3,51 \%)$ & $208(5,18 \%)$ & $444(6,35 \%)$ \\
\hline Doença inflamatória órgãos pélvicos femininos & $0(0,00 \%)$ & $15(0,09 \%)$ & $13(0,16 \%)$ & $8(0,19 \%)$ & $57(1,20 \%)$ & $229(1,34 \%)$ & $52(1,10 \%)$ & $24(0,60 \%)$ & $12(0,17 \%)$ \\
\hline Doenças cerebrovasculares & $3(0,04 \%)$ & $0(0,00 \%)$ & $2(0,02 \%)$ & $0(0,00 \%)$ & $3(0,06 \%)$ & $53(0,31 \%)$ & $97(2,05 \%)$ & $193(4,80 \%)$ & $590(8,44 \%)$ \\
\hline Doenças preveníveis por imunização & $39(0,58 \%)$ & $117(0,68 \%)$ & $106(1,28 \%)$ & $206(4,77 \%)$ & $355(7,48 \%)$ & $657(3,85 \%)$ & $94(1,99 \%)$ & $43(1,07 \%)$ & $31(0,44 \%)$ \\
\hline Doenças relacionadas ao pré-natal e parto & $6(0,09 \%)$ & $0(0,00 \%)$ & $0(0,00 \%)$ & $0(0,00 \%)$ & $1(0,02 \%)$ & $14(0,08 \%)$ & $0(0,00 \%)$ & $0(0,00 \%)$ & $0(0,00 \%)$ \\
\hline DPOC & $4(0,06 \%)$ & $9(0,05 \%)$ & $3(0,04 \%)$ & $3(0,07 \%)$ & $23(0,48 \%)$ & $125(0,73 \%)$ & $104(2,20 \%)$ & $254(6,32 \%)$ & $783(11,20 \%)$ \\
\hline Epilepsias & $14(0,21 \%)$ & $49(0,28 \%)$ & $41(0,50 \%)$ & $37(0,86 \%)$ & $39(0,82 \%)$ & $209(1,22 \%)$ & $104(2,20 \%)$ & $67(1,67 \%)$ & $69(0,99 \%)$ \\
\hline Febre reumática & $0(0,00 \%)$ & $0(0,00 \%)$ & $0(0,00 \%)$ & $0(0,00 \%)$ & $0(0,00 \%)$ & $6(0,04 \%)$ & $0(0,00 \%)$ & $0(0,00 \%)$ & $0(0,00 \%)$ \\
\hline
\end{tabular}


(continuação)

\begin{tabular}{|c|c|c|c|c|c|c|c|c|c|}
\hline \multirow[b]{2}{*}{ Tipo de ICSAP } & \multicolumn{9}{|c|}{ Faixa etária (anos) } \\
\hline & $<1$ & 1 a 4 & 5 a 9 & 10 a 14 & 15 a 19 & 20 a 39 & 40 a 49 & 50 a 59 & $\geq 60$ \\
\hline $\begin{array}{l}\text { Gastroenterites infecciosas e } \\
\text { complicações }\end{array}$ & $802(11,86 \%)$ & $\begin{array}{c}2860 \\
(16,51 \%)\end{array}$ & $\begin{array}{c}1142 \\
(13,79 \%)\end{array}$ & $593(13,74 \%)$ & $735(15,49 \%)$ & $\begin{array}{c}3350 \\
(19,62 \%)\end{array}$ & $602(12,74 \%)$ & $\begin{array}{c}428 \\
(10,65 \%)\end{array}$ & $620(8,87 \%)$ \\
\hline Hipertensão & $2(0,03 \%)$ & $0(0,00 \%)$ & $0(0,00 \%)$ & $3(0,07 \%)$ & $9(0,19 \%)$ & $497(2,91 \%)$ & $620(13,12 \%)$ & $\begin{array}{c}677 \\
(16,84 \%)\end{array}$ & $\begin{array}{c}1097 \\
(15,69 \%)\end{array}$ \\
\hline Infecção da pele e tecido subcutâneo & $118(1,74 \%)$ & $577(3,33 \%)$ & $322(3,89 \%)$ & $241(5,58 \%)$ & $250(5,27 \%)$ & $1108(6,49 \%)$ & $383(8,11 \%)$ & $342(8,51 \%)$ & $467(6,68 \%)$ \\
\hline Infecção no rim e trato urinário & $18(0,27 \%)$ & $67(0,39 \%)$ & $33(0,40 \%)$ & $27(0,63 \%)$ & $200(4,22 \%)$ & $703(4,12 \%)$ & $151(3,20 \%)$ & $122(3,04 \%)$ & $239(3,42 \%)$ \\
\hline Infecções de ouvido, nariz e garganta & $\begin{array}{c}2776 \\
(41,04 \%)\end{array}$ & $\begin{array}{c}9630 \\
(55,58 \%)\end{array}$ & $\begin{array}{c}4469 \\
(53,96 \%)\end{array}$ & $\begin{array}{c}2181 \\
(50,53 \%)\end{array}$ & $\begin{array}{c}2558 \\
(53,92 \%)\end{array}$ & $\begin{array}{c}8429 \\
(49,36 \%)\end{array}$ & $\begin{array}{c}1756 \\
(37,16 \%)\end{array}$ & $\begin{array}{c}960 \\
(23,89 \%)\end{array}$ & $984(14,07 \%)$ \\
\hline Insuficiência cardíaca & $0(0,00 \%)$ & $1(0,01 \%)$ & $0(0,00 \%)$ & $0(0,00 \%)$ & $0(0,00 \%)$ & $37(0,22 \%)$ & $78(1,65 \%)$ & $212(5,27 \%)$ & $802(11,47 \%)$ \\
\hline Parasitose & $0(0,00 \%)$ & $5(0,03 \%)$ & $5(0,06 \%)$ & $1(0,02 \%)$ & $1(0,02 \%)$ & $0(0,00 \%)$ & $0(0,00 \%)$ & $0(0,00 \%)$ & $0(0,00 \%)$ \\
\hline Pneumonias bacterianas & $37(0,55 \%)$ & $106(0,61 \%)$ & $26(0,31 \%)$ & $17(0,39 \%)$ & $20(0,42 \%)$ & $101(0,59 \%)$ & $60(1,27 \%)$ & $56(1,39 \%)$ & $200(2,86 \%)$ \\
\hline Úlcera gastrointestinal & $0(0,00 \%)$ & $0(0,00 \%)$ & $0(0,00 \%)$ & $1(0,02 \%)$ & $4(0,08 \%)$ & $14(0,08 \%)$ & $9(0,19 \%)$ & $6(0,15 \%)$ & $10(0,14 \%)$ \\
\hline Número de atendimentos & 6764 & 17327 & 8282 & 4316 & 4744 & 17078 & 4725 & 4019 & 6993 \\
\hline
\end{tabular}


Para as análises de associação entre os tipos de atendimento (sem e com ICSAP) e as características dos pacientes atendidos na UPA Campo Limpo no período de estudo foram selecionados 323.158 atendimentos. Para essas análises foram excluídos os atendimentos sem informação sobre o atendimento ter sido ou não por ICSAP (Tabela 7).

Observou-se a associação entre o sexo dos pacientes e o atendimento por ICSAP ( $p<0,001$ ), onde mulheres tem chance de atendimento por ICSAP estimada em 1,05 vezes a chance dos homens.

Pacientes com idade entre um e quatro anos tem a chance aumentada de atendimento por ICSAP, quando comparados aos pacientes com idade abaixo de um ano $(p<0,001)$, estimada em 1,13 vezes. Observou-se menores chances de atendimentos por ICSAP nas demais faixas etárias comparados aos pacientes com idade abaixo de um ano.

Há evidências de aumento da chance de atendimento por ICSAP em pacientes crônicos $(\mathrm{p}<0,001)$, onde pacientes crônicos tem chance estimada em torno de quatro vezes a chance dos pacientes não crônicos.

Tabela 7 - Associação entre ICSAP e características dos pacientes (n=323.158). São Paulo, SP, 2017.

\begin{tabular}{|c|c|c|c|c|}
\hline & \multicolumn{4}{|c|}{ ICSAP } \\
\hline & Não & & Sim & \\
\hline & $\mathrm{n}(\%)$ & $\mathrm{n}(\%)$ & $\begin{array}{c}\mathrm{RC} \\
\text { (IC 95\%) }\end{array}$ & valor $\mathrm{p}$ \\
\hline \multicolumn{5}{|l|}{ Sexo } \\
\hline Masculino (n=172068) & $133249(77,4 \%)$ & $38819(22,6 \%)$ & 1 & \\
\hline Feminino $(\mathrm{n}=151090)$ & $115661(76,6 \%)$ & $35429(23,4 \%)$ & $\begin{array}{c}1,051 \\
(1,034 ; 1,069)\end{array}$ & $<0,001$ \\
\hline \multicolumn{5}{|l|}{ Faixa etária (anos) } \\
\hline$<1(\mathrm{n}=17777)$ & $11013(62,0 \%)$ & $6764(38,0 \%)$ & 1 & \\
\hline 1 a $4(n=42337)$ & $25010(59,1 \%)$ & $17327(40,9 \%)$ & $\begin{array}{c}1,128 \\
(1,088 ; 1,169)\end{array}$ & $<0,001$ \\
\hline 5 a $9(n=22791)$ & $14509(63,7 \%)$ & $8282(36,3 \%)$ & $\begin{array}{c}0,929 \\
(0,892 ; 0,968)\end{array}$ & $<0,001$ \\
\hline 10 a $14(n=17776)$ & $13460(75,7 \%)$ & $4316(24,3 \%)$ & $\begin{array}{c}0,522 \\
(0,499 ; 0,547)\end{array}$ & $<0,001$ \\
\hline 15 a $19(n=23673)$ & $18929(80,0 \%)$ & $4744(20,0 \%)$ & $\begin{array}{c}0,408 \\
(0,391 ; 0,426)\end{array}$ & $<0,001$ \\
\hline 20 a $39(n=103255)$ & $86177(83,5 \%)$ & $17078(16,5 \%)$ & $\begin{array}{c}0,323 \\
(0,312 ; 0,334)\end{array}$ & $<0,001$ \\
\hline 40 a $49(n=34246)$ & $29521(86,2 \%)$ & $4725(13,8 \%)$ & $\begin{array}{c}0,261 \\
(0,250 ; 0,272)\end{array}$ & $<0,001$ \\
\hline 50 a $59(n=26007)$ & $21988(84,5 \%)$ & $4019(15,5 \%)$ & $\begin{array}{c}0,298 \\
(0,284 ; 0,311)\end{array}$ & $<0,001$ \\
\hline$\geq 60(\mathrm{n}=35296)$ & $28303(80,2 \%)$ & $6993(19,8 \%)$ & $\begin{array}{c}0,402 \\
(0,387 ; 0,419)\end{array}$ & $<0,001$ \\
\hline \multicolumn{5}{|l|}{ Crônico } \\
\hline Não crônico (n=303259) & $239280(78,9 \%)$ & $63979(21,1 \%)$ & 1 & \\
\hline Crônico (n=19899) & $9630(48,4 \%)$ & $10269(51,6 \%)$ & $\begin{array}{c}3,988 \\
(3,874 ; 4,106)\end{array}$ & $<0,001$ \\
\hline
\end{tabular}


$\mathrm{Na}$ Tabela 8 foram apresentadas as descrições dos possíveis fatores associados aos desfechos de atendimento na amostra de pacientes com ICSAP atendidos na UPA Campo Limpo no período de estudo. Observou-se prevalência do desfecho "alta", com maioria do sexo feminino (51,1\%), faixa etária de 1 a 4 anos (30\%), com classificação de risco de Manchester verde (61\%), não-crônicos $(86,3 \%)$ e com doenças do aparelho respiratório $(66,4 \%)$.

Tabela 8 - Descrição dos possíveis fatores associados aos desfechos de atendimento na amostra de pacientes com ICSAP atendidos na UPA Campo Limpo entre 2015 e 2016 (n=74.248). São Paulo, SP, 2017.

(continua)

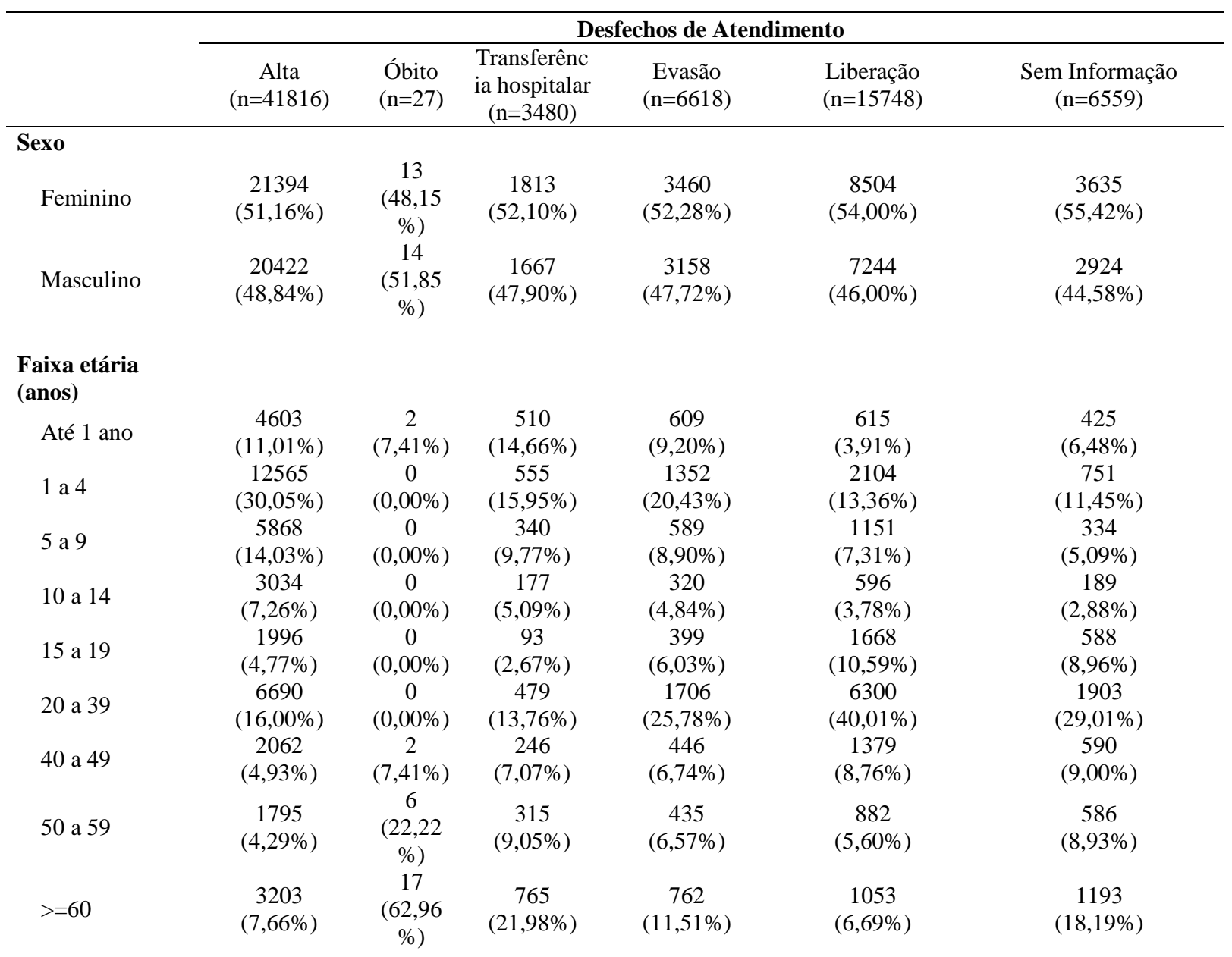


Ana Cláudia Medeiros Galvão de Lima

(continuação)

\begin{tabular}{|c|c|c|c|c|c|c|c|}
\hline \multicolumn{8}{|c|}{$\begin{array}{l}\text { Desfechos de Atendimento } \\
\end{array}$} \\
\hline \multicolumn{2}{|c|}{$\begin{array}{cc}\text { Alta }(\mathrm{n}=41816) & \begin{array}{c}\text { Óbito } \\
(\mathrm{n}=27)\end{array} \\
\text { ăo de Risco de Manchester }\end{array}$} & $\begin{array}{c}\text { Transferência } \\
\text { hospitalar } \\
(\mathrm{n}=3480)\end{array}$ & \multicolumn{2}{|c|}{ Evasão $(n=6618)$} & Liberação (n=15748) & \multicolumn{2}{|c|}{ Sem Informação $(\mathrm{n}=6559)$} \\
\hline Branco & & $\begin{array}{c}434 \\
(1,04 \%)\end{array}$ & $\begin{array}{c}0 \\
(0,00 \%)\end{array}$ & $\begin{array}{c}55 \\
(1,58 \%)\end{array}$ & $\begin{array}{c}77 \\
(1,16 \%)\end{array}$ & $\begin{array}{c}99 \\
(0,63 \%)\end{array}$ & $\begin{array}{c}87 \\
(1,33 \%)\end{array}$ \\
\hline Azul & & $\begin{array}{c}662 \\
(1,58 \%)\end{array}$ & $\begin{array}{c}0 \\
(0,00 \%)\end{array}$ & $\begin{array}{c}29 \\
(0,83 \%)\end{array}$ & $\begin{array}{c}56 \\
(0,85 \%)\end{array}$ & $\begin{array}{c}149 \\
(0,95 \%)\end{array}$ & $\begin{array}{c}66 \\
(1,01 \%)\end{array}$ \\
\hline Verde & & $\begin{array}{c}25513 \\
(61,01 \%)\end{array}$ & $\begin{array}{c}1 \\
(3,70 \%)\end{array}$ & $\begin{array}{c}853 \\
(24,51 \%)\end{array}$ & $\begin{array}{c}3126 \\
(47,23 \%)\end{array}$ & $9541(60,59 \%)$ & $\begin{array}{c}2804 \\
(42,75 \%)\end{array}$ \\
\hline Amarelo & & $\begin{array}{c}7767 \\
(18,57 \%)\end{array}$ & $\begin{array}{c}3 \\
(11,11 \%)\end{array}$ & $\begin{array}{c}1073 \\
(30,83 \%)\end{array}$ & $\begin{array}{c}1606 \\
(24,27 \%)\end{array}$ & $\begin{array}{c}3504 \\
(22,25 \%)\end{array}$ & $\begin{array}{c}1848 \\
(28,18 \%)\end{array}$ \\
\hline Laranja & & $\begin{array}{c}7220 \\
(17,27 \%)\end{array}$ & $\begin{array}{c}17 \\
(62,96 \%)\end{array}$ & $\begin{array}{c}1379 \\
(39,63 \%)\end{array}$ & $\begin{array}{c}1697 \\
(25,64 \%)\end{array}$ & $\begin{array}{c}2423 \\
(15,39 \%)\end{array}$ & $\begin{array}{c}1631 \\
(24,87 \%)\end{array}$ \\
\hline Vermelho & & $\begin{array}{c}42 \\
(0,10 \%)\end{array}$ & $\begin{array}{c}6 \\
(22,22 \%)\end{array}$ & $\begin{array}{c}33 \\
(0,95 \%)\end{array}$ & $\begin{array}{c}23 \\
(0,35 \%)\end{array}$ & $\begin{array}{c}6 \\
(0,04 \%)\end{array}$ & $\begin{array}{c}33 \\
(0,50 \%)\end{array}$ \\
\hline Sem Informação & & $\begin{array}{c}178 \\
(0,43 \%)\end{array}$ & $\begin{array}{c}0 \\
(0,00 \%)\end{array}$ & $\begin{array}{c}58 \\
(1,67 \%)\end{array}$ & $\begin{array}{c}33 \\
(0,50 \%)\end{array}$ & $\begin{array}{c}26 \\
(0,17 \%)\end{array}$ & $\begin{array}{c}90 \\
(1,37 \%)\end{array}$ \\
\hline \multicolumn{8}{|l|}{ Crônico } \\
\hline Não & & $\begin{array}{c}36101 \\
(86,33 \%)\end{array}$ & $\begin{array}{c}23 \\
(85,19 \%)\end{array}$ & $\begin{array}{c}2885 \\
(82,90 \%)\end{array}$ & $\begin{array}{c}5348 \\
(80,81 \%)\end{array}$ & $\begin{array}{c}14350 \\
(91,12 \%)\end{array}$ & $\begin{array}{c}5272 \\
(80,38 \%)\end{array}$ \\
\hline Sim & & $\begin{array}{c}5715 \\
(13,67 \%)\end{array}$ & $\begin{array}{c}4 \\
(14,81 \%)\end{array}$ & $\begin{array}{c}595 \\
(17,10 \%)\end{array}$ & $\begin{array}{c}1270 \\
(19,19 \%)\end{array}$ & $\begin{array}{c}1398 \\
(8,88 \%)\end{array}$ & $\begin{array}{c}1287 \\
(19,62 \%)\end{array}$ \\
\hline \multicolumn{8}{|l|}{ Grupo de causa } \\
\hline $\begin{array}{l}\text { Doenças da } \\
\text { pele/subcutâneo }\end{array}$ & & $\begin{array}{c}1924 \\
(4,60 \%)\end{array}$ & $\begin{array}{c}0 \\
(0,00 \%)\end{array}$ & $\begin{array}{c}396 \\
(11,38 \%)\end{array}$ & $\begin{array}{c}179 \\
(2,70 \%)\end{array}$ & $\begin{array}{c}515 \\
(3,27 \%)\end{array}$ & $\begin{array}{c}244 \\
(3,72 \%)\end{array}$ \\
\hline $\begin{array}{l}\text { Doenças do } \\
\text { aparelho } \\
\text { circulatório }\end{array}$ & & $\begin{array}{c}2261 \\
(5,41 \%)\end{array}$ & $\begin{array}{c}10 \\
(37,04 \%)\end{array}$ & $\begin{array}{c}647 \\
(18,59 \%)\end{array}$ & $\begin{array}{c}608 \\
(9,19 \%)\end{array}$ & $\begin{array}{c}508 \\
(3,23 \%)\end{array}$ & $\begin{array}{c}945 \\
(14,41 \%)\end{array}$ \\
\hline $\begin{array}{l}\text { Doenças do } \\
\text { aparelho } \\
\text { digestivo }\end{array}$ & & $\begin{array}{c}7 \\
(0,02 \%)\end{array}$ & $\begin{array}{c}0 \\
(0,00 \%)\end{array}$ & $\begin{array}{c}16 \\
(0,46 \%)\end{array}$ & $\begin{array}{c}6 \\
(0,09 \%)\end{array}$ & $\begin{array}{c}3 \\
(0,02 \%)\end{array}$ & $\begin{array}{c}12 \\
(0,18 \%)\end{array}$ \\
\hline $\begin{array}{l}\text { Doenças do } \\
\text { aparelho } \\
\text { geniturinário }\end{array}$ & & $\begin{array}{c}857 \\
(2,05 \%)\end{array}$ & $\begin{array}{c}1 \\
(3,70 \%)\end{array}$ & $\begin{array}{c}315 \\
(9,05 \%)\end{array}$ & $\begin{array}{c}239 \\
(3,61 \%)\end{array}$ & $\begin{array}{c}354 \\
(2,25 \%)\end{array}$ & $\begin{array}{c}204 \\
(3,11 \%)\end{array}$ \\
\hline $\begin{array}{l}\text { Doenças do } \\
\text { aparelho } \\
\text { respiratório }\end{array}$ & & $\begin{array}{c}27767 \\
(66,40 \%)\end{array}$ & $\begin{array}{c}12 \\
(44,44 \%)\end{array}$ & $\begin{array}{c}1416 \\
(40,69 \%)\end{array}$ & $\begin{array}{c}3808 \\
(57,54 \%)\end{array}$ & $\begin{array}{c}10717 \\
(68,05 \%)\end{array}$ & $\begin{array}{c}3269 \\
(49,84 \%)\end{array}$ \\
\hline $\begin{array}{l}\text { Doenças do } \\
\text { ouvido }\end{array}$ & & $\begin{array}{c}1048 \\
(2,51 \%)\end{array}$ & $\begin{array}{c}0 \\
(0,00 \%)\end{array}$ & $\begin{array}{c}18 \\
(0,52 \%)\end{array}$ & $\begin{array}{c}100 \\
(1,51 \%)\end{array}$ & $\begin{array}{c}376 \\
(2,39 \%)\end{array}$ & $\begin{array}{c}60 \\
(0,91 \%)\end{array}$ \\
\hline $\begin{array}{l}\text { Doenças do } \\
\text { sangue }\end{array}$ & & $\begin{array}{c}37 \\
(0,09 \%)\end{array}$ & $\begin{array}{c}0 \\
(0,00 \%)\end{array}$ & $\begin{array}{c}35 \\
(1,01 \%)\end{array}$ & $\begin{array}{c}12 \\
(0,18 \%)\end{array}$ & $\begin{array}{c}7 \\
(0,04 \%)\end{array}$ & $\begin{array}{c}13 \\
(0,20 \%)\end{array}$ \\
\hline $\begin{array}{l}\text { Doenças do } \\
\text { sistema nervoso }\end{array}$ & & $\begin{array}{c}271 \\
(0,65 \%)\end{array}$ & $\begin{array}{c}0 \\
(0,00 \%)\end{array}$ & $\begin{array}{c}209 \\
(6,01 \%)\end{array}$ & $\begin{array}{c}97 \\
(1,47 \%)\end{array}$ & $\begin{array}{c}61 \\
(0,39 \%)\end{array}$ & $\begin{array}{c}194 \\
(2,96 \%)\end{array}$ \\
\hline $\begin{array}{l}\text { Doenças } \\
\text { infecciosas e } \\
\text { parasitárias }\end{array}$ & & $\begin{array}{c}7030 \\
(16,81 \%)\end{array}$ & $\begin{array}{c}2 \\
(7,41 \%)\end{array}$ & $\begin{array}{c}271 \\
(7,79 \%)\end{array}$ & $\begin{array}{c}1426 \\
(21,55 \%)\end{array}$ & $\begin{array}{c}3095 \\
(19,65 \%)\end{array}$ & $\begin{array}{c}1420 \\
(21,65 \%)\end{array}$ \\
\hline $\begin{array}{l}\text { Doenças } \\
\text { nutricionais e } \\
\text { metabólicas }\end{array}$ & & $\begin{array}{c}612 \\
(1,46 \%)\end{array}$ & $\begin{array}{c}2 \\
(7,41 \%)\end{array}$ & $\begin{array}{c}149 \\
(4,28 \%)\end{array}$ & $\begin{array}{c}142 \\
(2,15 \%)\end{array}$ & $\begin{array}{c}111 \\
(0,70 \%)\end{array}$ & $\begin{array}{c}195 \\
(2,97 \%)\end{array}$ \\
\hline $\begin{array}{l}\text { Gravidez, parto } \\
\text { e puerpério }\end{array}$ & & $\begin{array}{c}2 \\
(0,00 \%) \\
\end{array}$ & $\begin{array}{c}0 \\
(0,00 \%) \\
\end{array}$ & $\begin{array}{c}8 \\
(0,23 \%) \\
\end{array}$ & $\begin{array}{c}1 \\
(0,02 \%) \\
\end{array}$ & $\begin{array}{c}1 \\
(0,01 \%) \\
\end{array}$ & $\begin{array}{c}3 \\
(0,05 \%) \\
\end{array}$ \\
\hline
\end{tabular}


Para as análises de associação entre os desfechos de atendimento e as características dos pacientes com ICSAP atendidos na UPA Campo Limpo no período de estudo foram selecionados 67.662 atendimentos de 50.030 pacientes. Para essas análises foram mantidos os desfechos: alta ou liberação, transferência hospitalar e evasão e as variáveis explicativas sexo, faixa etária, classificação de risco de Manchester e crônico por meio de modelos logísticos em abordagem simples (Tabela 9).

Em 295 atendimentos a classificação de risco de Manchester não foi avaliada. Destes, 204 atendimentos foram finalizados como "alta", 58 como transferência hospitalar e 33 como evasão. Esses atendimentos foram excluídos da análise de associação com os desfechos de atendimento por falta de informação.

Não se observou evidência de associação do sexo dos pacientes com os desfechos transferência hospitalar ( $\mathrm{p}=0,855)$ e evasão $(\mathrm{p}=0,597)$.

Comparados aos pacientes com idade abaixo de um ano, aqueles com idade mais elevada têm chance aumentada de transferência hospitalar. Pacientes com idades nas faixas entre 50 e 59 anos e 60 anos ou mais tem chances de transferência hospitalar estimadas, respectivamente, em 1,2 vezes $(p=0,014)$ e 1,8 vezes $(p<0,001)$, respectivamente, a chance dos pacientes com idade abaixo de um ano. Observou-se menores chances de transferência nas demais faixas etárias comparadas aos pacientes com idade abaixo de um ano.

Quanto à classificação de risco de Manchester, pacientes com maior classe de risco têm chance aumentada de transferência hospitalar comparados aos pacientes classificados como branco. Pacientes com riscos laranja e vermelho têm chances de transferência hospitalar estimadas em 1,4 vezes $(p=0,024)$ e 6,7 vezes $(p<0,001)$ a chance dos pacientes de risco branco. Observou-se menores chances de transferência nas classes azul e verde comparadas aos pacientes de risco branco.

Há evidências de aumento da chance de transferência hospitalar estimada em 1,5 vezes em pacientes crônicos $(\mathrm{p}<0,001)$, quando comparada aos pacientes não crônicos. 
Tabela 9 - Associação entre desfechos de atendimento e características dos pacientes na amostra de atendimentos com ICSAP na UPA Campo Limpo entre 2015 e 2016 ( $n=67.662)$. São Paulo, SP, 2017.

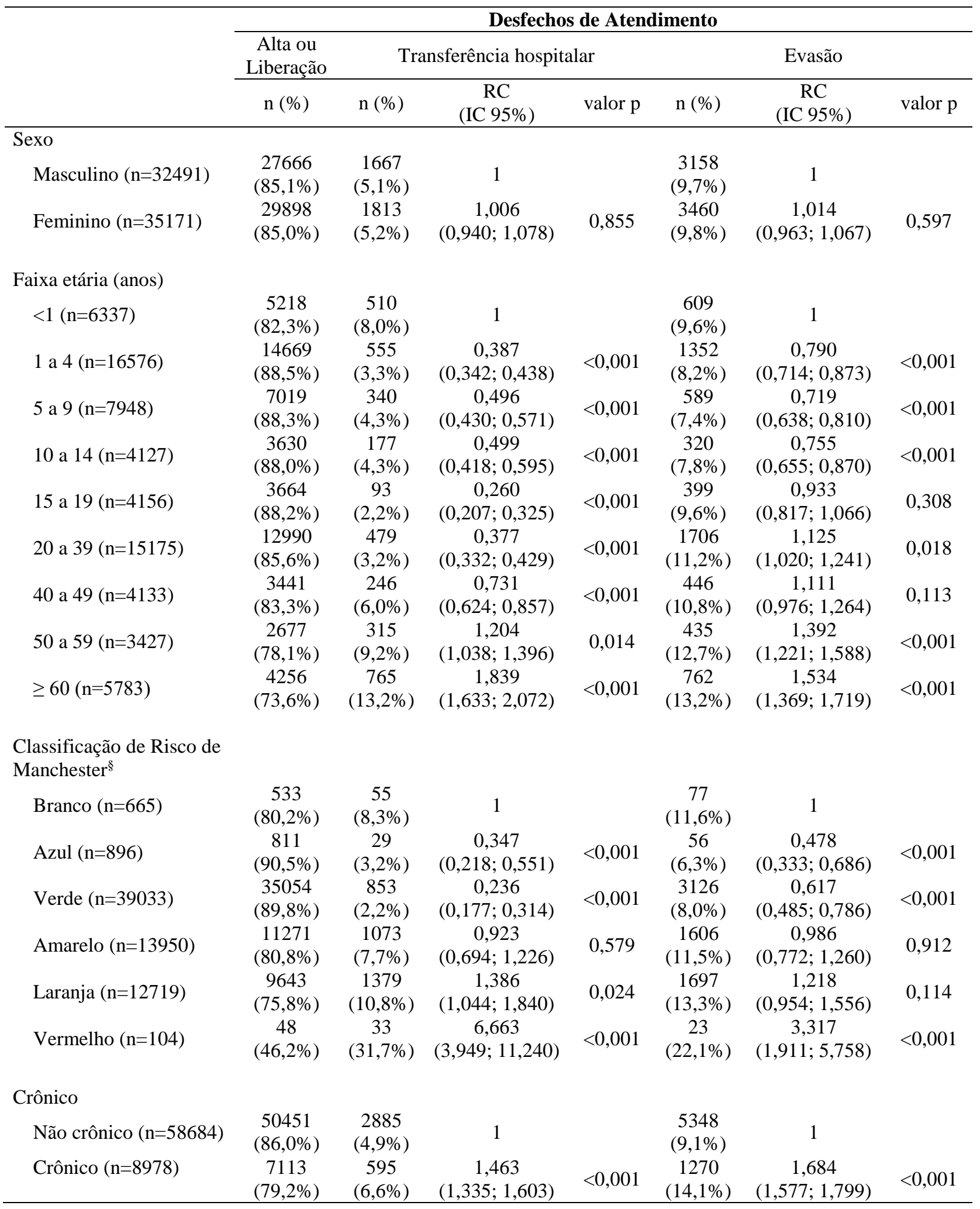


Em relação às condições associadas aos atendimentos realizados na UPA dos pacientes com ICSAP (Tabela 10), é importante destacar que em 13,8\% destes foram encontradas doenças concomitantes crônicas (asma, diabetes, hipertensão arterial ou transtorno mental).

Tabela 10 - Condições associadas nos atendimentos realizados na UPA Campo Limpo com ICSAP entre 2015 e 2016 (n=74.248). São Paulo, SP, 2017.

\begin{tabular}{lc}
\hline Crônico & \\
Não & $63979(86,17 \%)$ \\
Sim & $10269(13,83 \%)$ \\
& \\
Tipo de crônico & \\
Asma & $5805(7,82 \%)$ \\
Asma / Hipertensão & $30(0,04 \%)$ \\
Diabetes & $1140(1,54 \%)$ \\
Hipertensão & $2863(3,86 \%)$ \\
Hipertensão / Diabetes & $56(0,08 \%)$ \\
Transtorno mental & $276(0,37 \%)$ \\
Transtorno mental / Asma & $18(0,02 \%)$ \\
Transtorno mental / Diabetes & $20(0,03 \%)$ \\
Transtorno mental / Hipertensão & $61(0,08 \%)$ \\
Não crônico & $63979(86,17 \%)$ \\
\hline
\end{tabular}

\subsection{PROPOSTA DE FLUXOGRAMA DE COMUNICAÇÃO PARA A COORDENAÇÃO DO CUIDADO}

A partir da vivência profissional na UPA Campo Limpo, pôde-se observar a fragilidade existente na comunicação entre atenção secundária e primária, pois os profissionais da unidade têm pouco contato com a equipe de saúde das UBS. Esse fator repercute na continuidade do cuidado dos pacientes que apresentam necessidade de acompanhamento do seu problema de saúde, pois, na maioria das vezes, a APS desconhece que o paciente realizou atendimento em outros equipamentos de saúde e quais foram os cuidados prestados àquele usuário.

Como proposta do Mestrado Profissional e a partir da análise dos dados obtidos na pesquisa, elaborou-se uma proposta de fluxograma de comunicação (Figura 2) entre a 
Unidade de Pronto-Atendimento (UPA 24h) Campo Limpo e as 13 Unidades Básicas de Saúde que tem cogestão com a SBIBAE (UBS Alto do Umuarama, UBS Arrastão, UBS Campo Limpo, UBS Jardim das Palmas, UBS Jardim Helga, UBS Jardim Mistutani, UBS Jardim Olinda, UBS Paraisópolis 1, UBS Paraisópolis 2, UBS Paraisópolis 3, UBS Parque Arariba, UBS Parque Regina e UBS Vila Prel) com o objetivo de disponibilizar informações a respeito dos atendimentos por ICSAP realizados na UPA e assim fortalecer o trabalho em rede, tomando a comunicação como eixo para coordenação do cuidado na APS.

Atualmente, tal fluxo de comunicação é inexistente, mas esta pesquisa propõe a elaboração de uma comunicação a partir de um programa informatizado existente e já utilizado no processo de trabalho das equipes. Este programa foi desenvolvido pela SBIBAE, atualmente conhecido como NISI-Einstein.

Na UPA, o NISI-Einstein é utilizado para a realização da Sistematização da Assistência de Enfermagem (SAE), a qual foi implantada no formato eletrônico recentemente. Anteriormente, a mesma era realizada de forma manual. Optou-se, inicialmente, pela realização do fluxograma apenas com as UBS que são gerenciadas pela parceria públicoprivada SBIBAE e Secretaria Municipal de Saúde, considerando que o programa informatizado é compartilhado entre as UBS e a UPA.

Considerando o numeroso fluxo de atendimentos por ICSAP na UPA e a dificuldade que as UBS teriam em realizar a coordenação do cuidado de todos esses usuários, optou-se pela formulação de uma proposta de fluxograma de comunicação para a coordenação do cuidado de pacientes com as doenças crônicas mais prevalentes nos atendimentos por ICSAP na UPA e com importância de intervenção junto à APS, sendo eles: hipertensão arterial sistêmica (HAS), diabetes mellitus (DM) e asma/bronquite.

Contudo, apesar dos transtornos mentais não estarem classificados como ICSAP na lista brasileira de acordo com a Portaria $n^{\circ} .221$ de 17 de abril de 2008, elegeu-se a inclusão destes considerando sua importância no contexto atual e manejo clínico junto à APS.

Propõe-se que façam parte do fluxo de comunicação os pacientes que forem classificados com as condições crônicas selecionadas e que forem admitidos na Observação Infantil (OI), Observação Adulto (OA) ou Sala de Choque (SC), pois são os locais de observação clínica onde o enfermeiro do setor realiza a admissão do paciente e a SAE.

A SAE é uma etapa estratégica do cuidado para a identificação destes pacientes e produção de informação relevante para a coordenação do cuidado. A SAE em funcionamento na UPA é acessada pelo sistema informatizado (NISI-Einstein), onde o enfermeiro 
assistencial com o seu login e senha (Figura 3), acessa o sistema e o preenche com as informações básicas do paciente como nome completo, data de nascimento, idade, cadastro nacional de saúde (CNS), gênero, estabelecimento de vínculo (UBS de origem), médico e enfermeiro da UBS responsáveis pelo usuário e informações adicionais, como e-mail da UBS, CPF e RG do usuário, telefone para contato, entre outros (Figura 4).

Após informar os dados iniciais, o enfermeiro preenche o campo "histórico de enfermagem" (Figura 5) onde, atualmente, há espaço para informar os antecedentes pessoais e clínicos do paciente, como queixa principal do atendimento atual, comorbidades, medicações de uso contínuo, dentre outros. No caso do paciente atender aos critérios do fluxograma de comunicação e apresentar as condições crônicas citadas anteriormente, propõe-se que haja a implantação de um campo que o enfermeiro possa inserir o resumo de admissão do paciente, informando a queixa principal, motivo da necessidade de observação clínica na unidade e o CID-10. Após finalizar a realização da SAE, as informações deverão ser enviadas diretamente para a UBS do paciente informada no início.

Atualmente, quando o atendimento do paciente é encerrado na UPA, não há a realização de resumo de alta. Sugere-se que, ao finalizar o atendimento do paciente na unidade no sistema utilizado para a realização da SAE, o enfermeiro possa inserir o resumo de alta do paciente que contenha informações sobre o atendimento e cuidados prestados ao paciente, mudança ou inserção de novos medicamentos, resultado de exames, quantidade de vezes que o paciente já ficou em observação clínica na UPA, além do tipo de finalização do atendimento na UPA (alta hospitalar, liberação, evasão, transferência hospitalar ou óbito). 
Figura 2 - Proposta de fluxograma de comunicação entre UPA e UBS para coordenação do cuidado dos pacientes com ICSAP. Elaboração própria. São Paulo, SP, 2017.

\section{FLUXOGRAMA DE COMUNICAÇÃO ENTRE UPA E UBS PARA COORDENAÇÃO DO CUIDADO DOS PACIENTES} COM ICSAP

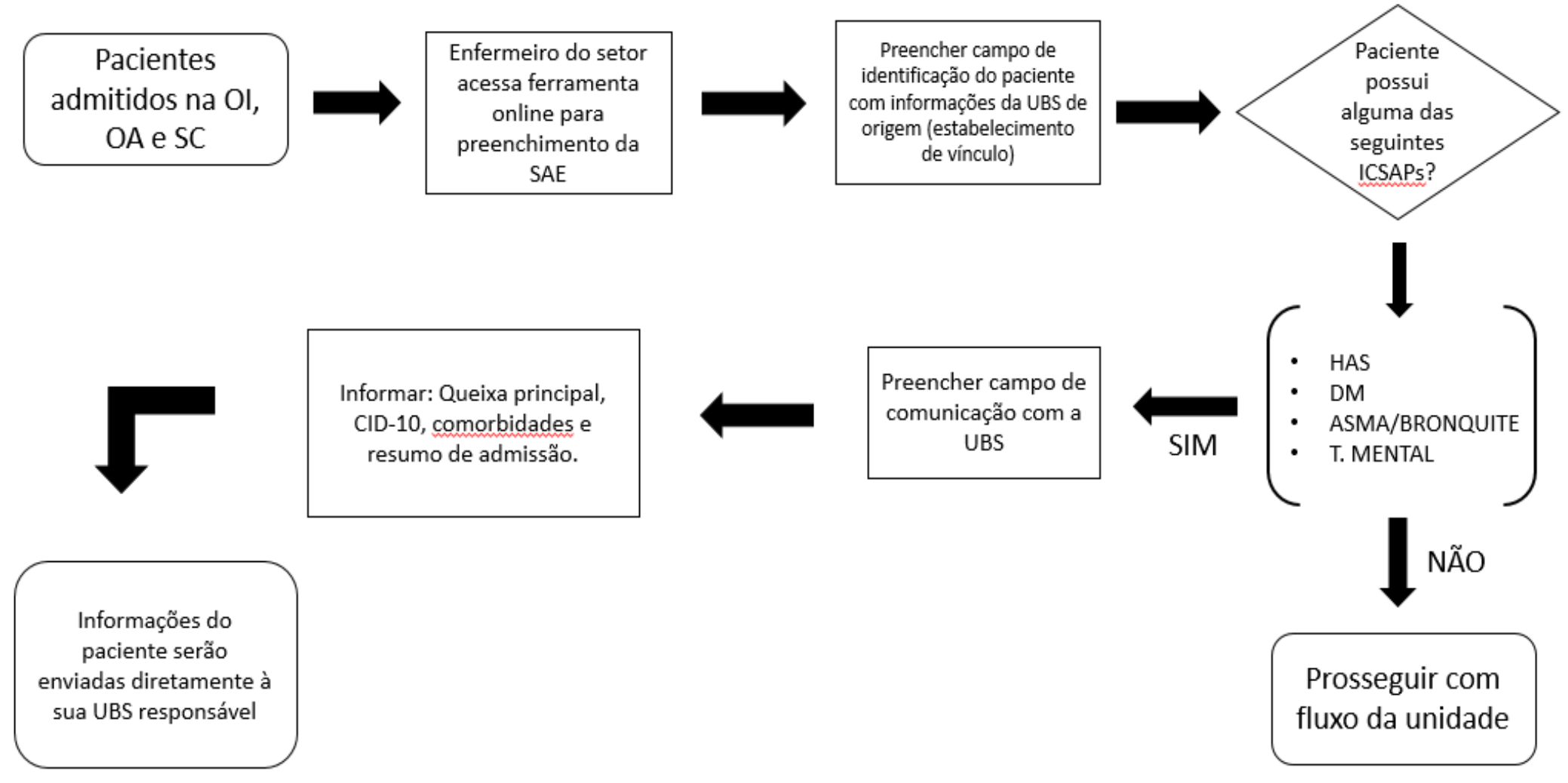


Figura 3 - Tela de entrada do Sistema NISI Einstein utilizado na UPA Campo Limpo. Figura extraída do Sistema Nisi Einstein

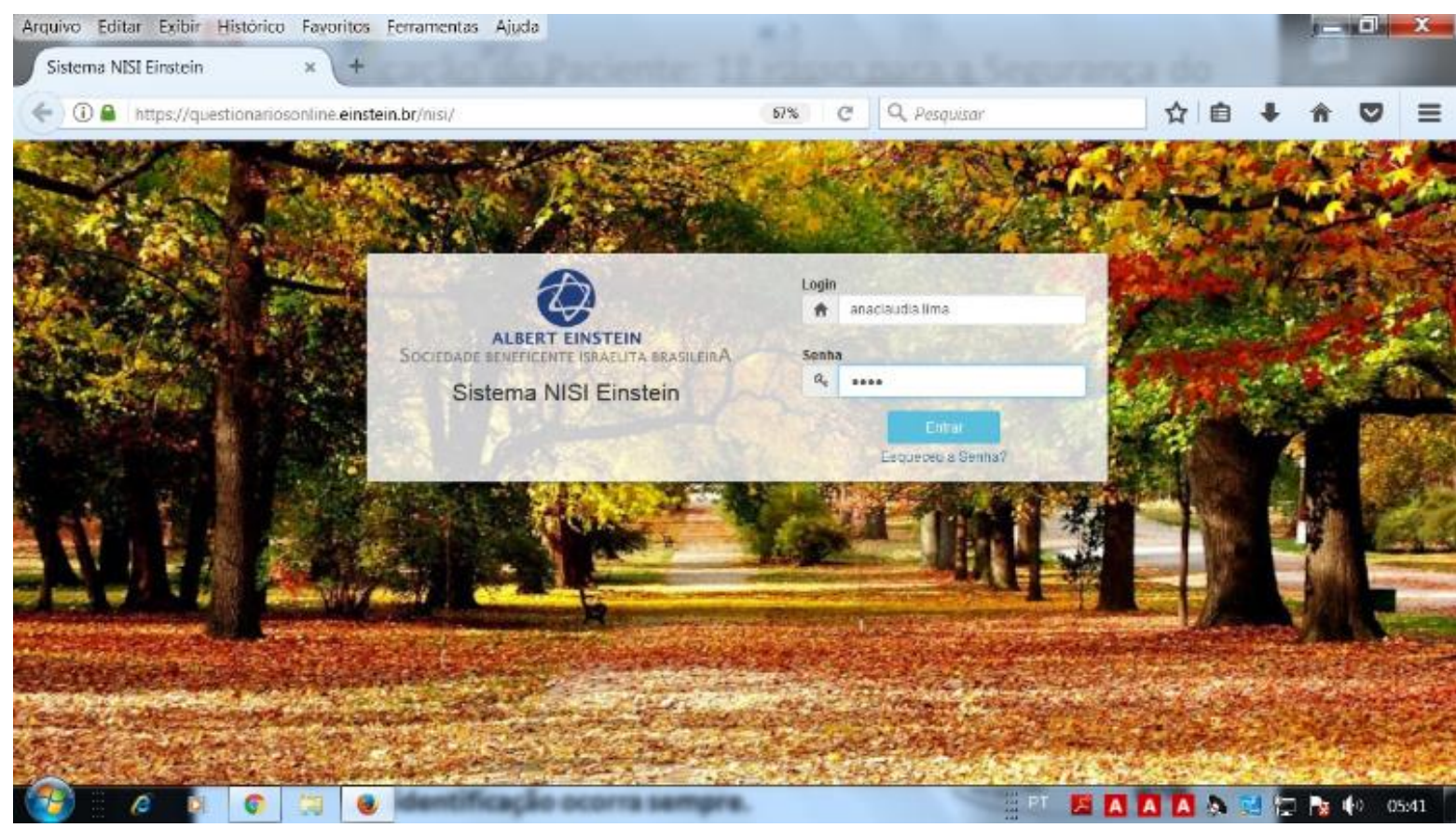

Figura 4 - Tela de cadastro do paciente no Sistema NISI Einstein utilizado na UPA Campo Limpo. Figura extraída do Sistema Nisi Einstein.

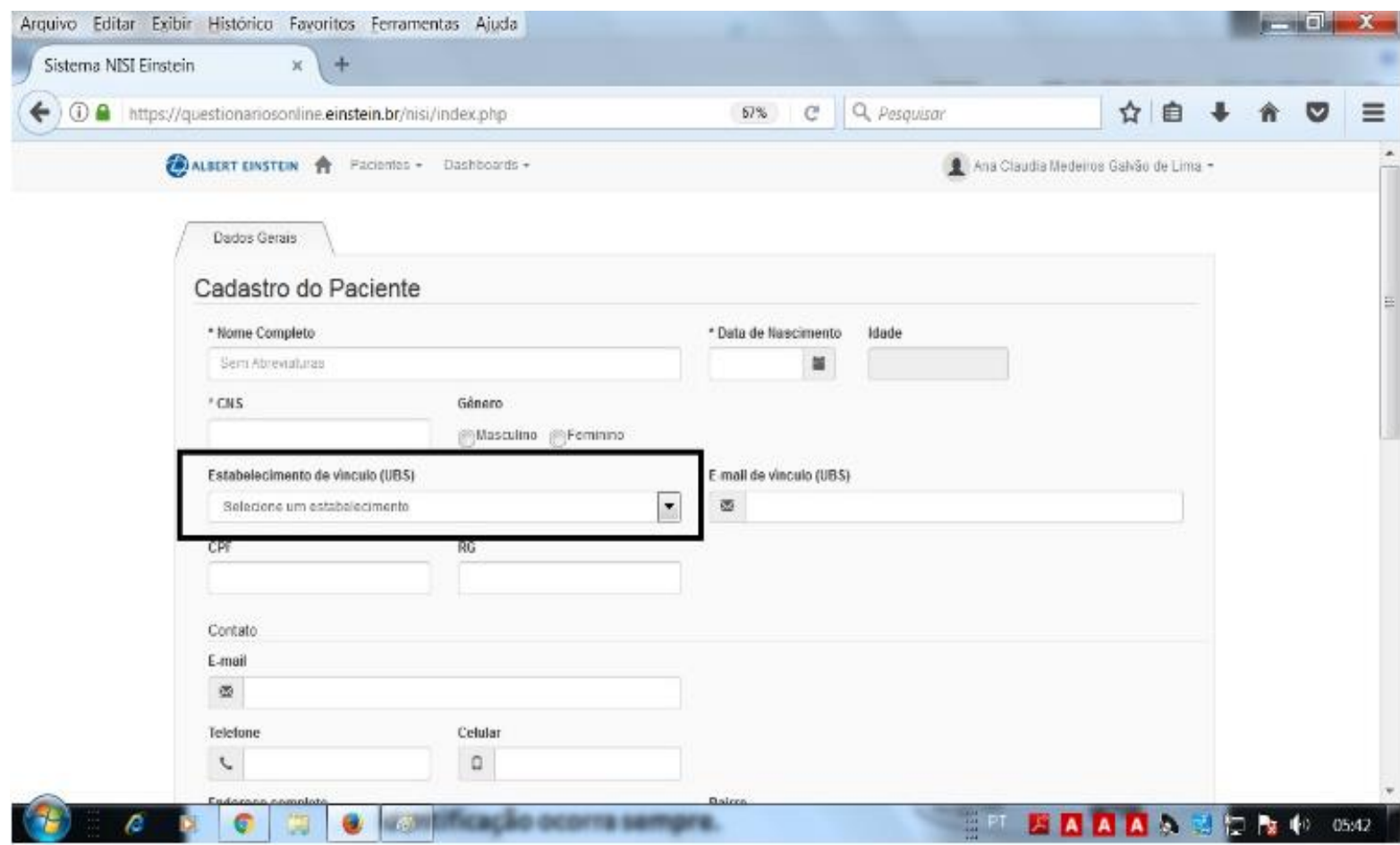


Ana Cláudia Medeiros Galvão de Lima

Figura 5 - Tela do Histórico de enfermagem Sistema NISI Einstein utilizado na UPA Campo Limpo. Figura extraída do Sistema Nisi Einstein.

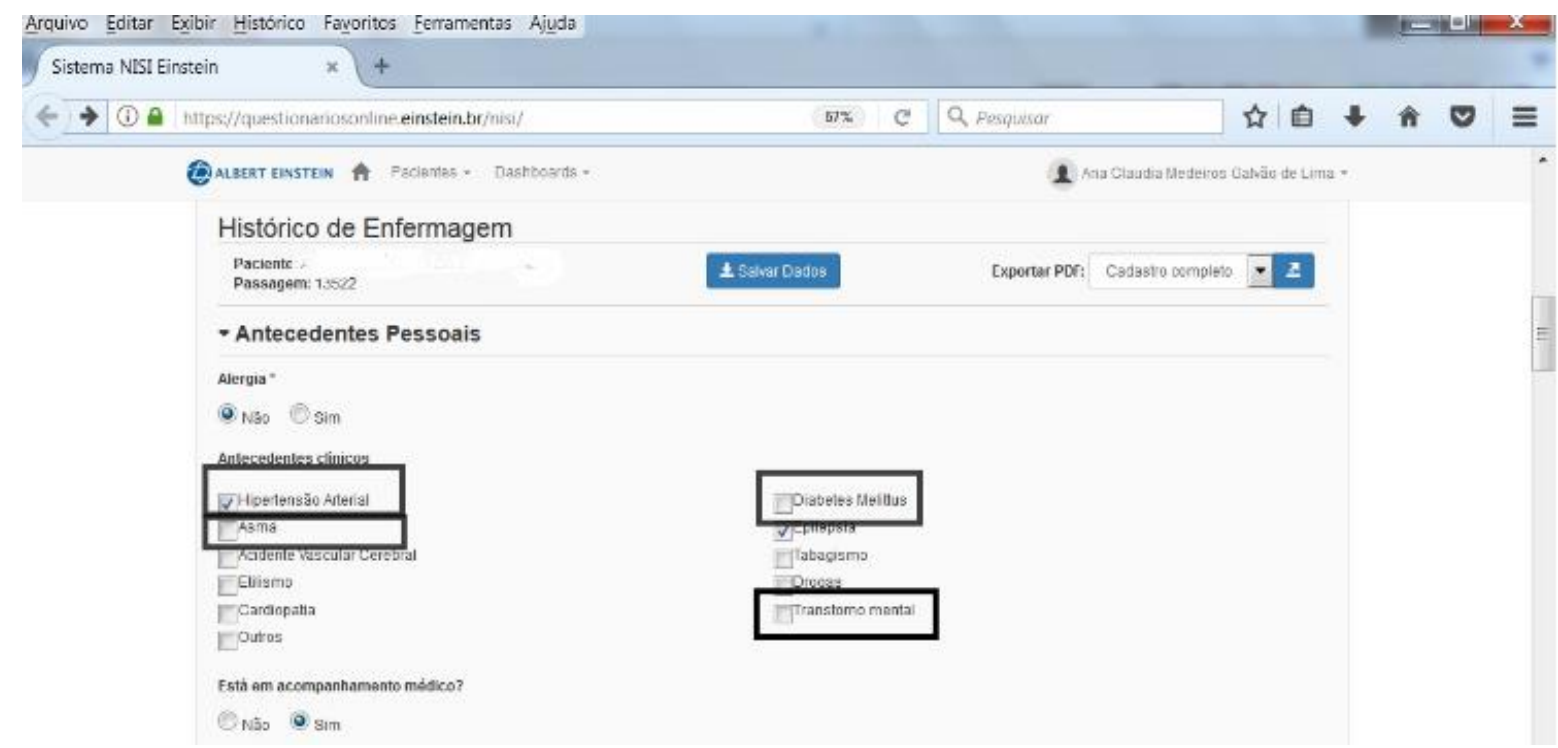




\section{Discussão}




\section{DISCUSSÃO}

Este estudo descreve o desenvolvimento de um fluxo de comunicação entre UPA e UBS a partir da identificação e análise dos atendimentos por condições sensíveis a atenção primária. É uma importante ferramenta para a coordenação do cuidado na APS por meio do ponto da rede altamente acessado pelos pacientes, a urgência e emergência.

A Unidade de Pronto-Atendimento Campo Limpo realizou mais de $400 \mathrm{mil}$ atendimentos entre os meses de janeiro de 2015 e dezembro de 2016. Tais dados demonstram o quanto a população procura o serviço de urgência para a resolução dos mais diversos problemas de saúde. Esse contingente também pode estar ligado à região em que a unidade de saúde se encontra, constituindo-se como a que teve maior taxa de crescimento populacional nos últimos anos (CEINFO, 2010).

Estudo realizado por Gomide, Pinto e Figueiredo (2012), apontou a constante busca pelo serviço de urgência para o atendimento da atenção primária, o que pode demonstrar uma falha no vínculo do sistema de saúde, onde o usuário busca o seu atendimento no local onde satisfaz suas necessidades sem levar em consideração a localização geográfica do serviço. Os autores acrescentam, ainda, como fatores do aumento da demanda nas UPAs, a difícil acessibilidade organizacional nas UBS e a questão sociocultural de como o indivíduo entende seu processo saúde-doença.

Quanto ao meio pelo qual os pacientes chegam até a UPA, os resultados do estudo são semelhantes ao estudo de Garcia (2014), o qual relatou 97,7\% de procura espontânea pela unidade, seguido pelos encaminhamentos por ambulâncias (1,9\%) e UBS $(0,4 \%)$. Essas informações sugerem que os usuários, em sua maioria, optam por procurar o serviço de urgência em detrimento da UBS para resolução do seu problema de saúde, o que leva à sobrecarga do sistema. A preferência da população pelos serviços de pronto-atendimento também foi constatada em estudo que avaliou o perfil dos usuários de urgência de serviço de média complexidade (OLIVEIRA, 2008), bem como de serviço de urgências hospitalares para adultos (FURTADO, 2004) e pediátricos (SIMONS, 2010).

Observou-se neste estudo, a presença de usuários ditos como "hiperutilizadores" dos serviços de saúde, na qual ressalta-se o episódio de um paciente ter realizado até 165 atendimentos na UPA Campo Limpo no período de dois anos. A definição do que seja um 
usuário hiperutilizador não é consensual na literatura e depende do tipo de equipamento de saúde estudado. Em sua maioria, é considerado hiperutilizador no serviço de urgência, o paciente que recorre em quatro ou mais vezes ao serviço no período de um ano (LOCKER et.al., 2007). Apesar de não ter sido foco da presente pesquisa, a presença de hiperutilizadores nas urgências sugere fragilidade e dificuldade de acesso à APS, o que abre espaço para futuras pesquisas.

Foram realizados 74.248 atendimentos classificados como ICSAP no período do estudo, com prevalência de 17,1\%. Reduções significativas nas taxas de ICSAP em diferentes países vem sendo relatadas na literatura. Em Cingapura houve queda de 9,1\% de 1991 a 1998 (NITI, 2003). No Canadá, houve decréscimo de 22\% entre os anos de 2001-2002 e 2006-2007 (SANCHEZ et.al., 2008). As mesmas tendências foram observadas na Itália (PIRANI, 2006) e Estados Unidos (FINEGAN, 2010).

Em 2006, as internações por CSAP no SUS correspondiam a 28,5\% do total de hospitalizações, excluindo os partos (ALFRADIQUE et. al., 2009). Nos últimos anos, observou-se redução substancial nas internações por CSAP no Brasil (BOING et.al., 2012). Pesquisa realizada em São Paulo identificou 10.616 internações por CSAP no período de 1 ano, o que corresponde a 15,9\% do total de atendimentos (REHEM \& EGRY, 2011). Importante destacar que tais estudos se utilizaram de análises das ICSAP por meio do Sistema de Informações Hospitalares (SIH-SUS).

Apesar da escassez de pesquisas na literatura que tomem o estudo de ICSAP em equipamentos de saúde de atenção secundária, estudo comparativo entre um hospital geral e uma unidade de pronto-atendimento foi realizado em Divinópolis (MG), onde cerca de um terço das internações do município ocorreram na UPA, a qual atendeu mais da metade das ICSAP investigadas (CARDOSO et. al., 2013). Nessa realidade, muitas ICSAP têm sido identificadas nos equipamentos de atenção secundária em detrimento do cuidado continuado na atenção primária em saúde, o que configura um evento silencioso, uma vez que não existe emissão de guia de internação que permita o registro dessas ocorrências nas estatísticas oficiais (CARDOSO et. al., 2013).

As diferenças nas informações encontradas na presente pesquisa e na literatura podem ser explicadas pelo fato de que as internações que são realizadas na UPA não exigem uma autorização de internação hospitalar (AIH), e, portanto, não entram nas estatísticas oficiais do Ministério da Saúde (MS), disponibilizadas no banco do DATASUS. 
A tendência de redução das taxas de ICSAP vem sendo relacionada à adoção da Estratégia de Saúde da Família (REHEM \& EGRY, 2011). Segundo dados da Secretaria Municipal de Saúde de São Paulo, no início de 2005, o município contava com 722 equipes de ESF implantadas em 197 unidades, e cobertura de 27\%. Em 2012, já estavam implantadas 1277 equipes de ESF, distribuídas em 270 Unidades Básicas de Saúde (UBS) e cobertura de $45,1 \%$, correspondendo a uma expansão de 76,8\% das equipes. Apesar da expansão da APS no município nos últimos anos, atuais propostas de reformas na Política Nacional de Atenção Básica (PNAB) com redução das verbas destinadas à ESF e ao Programa de Agentes Comunitários de Saúde (PACS) publicada pela Portaria n 2.436, de 21 de setembro de 2017 (BRASIL, 2017), gera preocupação por afetar a organização e o financiamento do atendimento comunitário.

Estudos nacionais e internacionais apontam que menores taxas de internações por CSAP estão associadas à maior disponibilidade de médicos generalistas por habitantes na APS, melhor avaliação do serviço por parte do usuário (RIZZA, 2007), continuidade da assistência com o mesmo médico de família e maior número de consultas preventivas e regiões com centros de saúde (NEDEL, 2010). Independentemente da carga de doenças e da própria oferta de médicos, o melhor acesso à atenção primária está associado a menos internações por CSAP (ANSARI, 2006).

A continuidade da atenção em saúde tem sido associada a menores taxas de internação por CSAP nos Estados Unidos e Canadá (GILL, 1998; MENEC et. al., 2006; GILL, 1997). Em municípios da Catalunha, com apenas uma Área Básica de Salud (ABS), Caminal e colaboradores (2001) encontraram menores taxas em pacientes oriundos de ABS cujo centro de saúde funcionava em horário normal que nas daqueles com funcionamento continuado durante as 24 horas do dia (NEDEL et.al., 2010).

Em tese, as equipes de saúde da família estão aptas para prestar uma atenção mais coordenada e integral aos usuários e comunidade, o que tenderia a reduzir o percentual de internações por condições sensíveis à assistência primária (CALDEIRA et. al., 2011).

Levando em conta o fato de que as internações por condições sensíveis à atenção primária podem refletir uma fragilidade da oferta, resolubilidade e acesso na atenção primária à saúde (FERREIRA et. al., 2014), a investigação e os resultados deste estudo são importantes ferramentas para avaliar este ponto de atenção no território estudado.

Ao se comparar os atendimentos por ICSAP com o total de atendimentos na UPA, observa-se perfil semelhante no que diz respeito à maioria ser do sexo feminino e diferença 
em relação à faixa etária (UPA 33,9\% 20 a 39 anos; ICSAP 23,3\% 1 a 4 anos). Evidências de associação entre o sexo dos pacientes e o atendimento por ICSAP (p<0,001), demonstrou que as mulheres têm chance de atendimento por ICSAP estimada em 1,05 vezes a chance dos homens. Estudo realizado em um equipamento de saúde de atenção secundária (GARCIA, 2014) também constatou predomínio do sexo feminino $(53,7 \%)$ e faixa etária com idades entre 20 a 29 anos $(23,9 \%)$. Além deste, tais características também foram corroboradas por outros estudos realizados em serviços de urgência com complexidades diferentes (OLIVATI, 2010; OLIVEIRA, 2011). Já em relação às ICSAP observou-se na literatura semelhança no que diz respeito a maioria do sexo feminino $(54,1 \%)$ e diferença importante na faixa etária, com predomínio de indivíduos acima de 65 anos (28,3\%) (REHEM \& EGRY, 2011).

No Brasil, estudo transversal identificou maior probabilidade de ICSAP em pessoas do sexo feminino, em menores de cinco anos, com menor escolaridade, história de consulta médica de emergência no mês anterior e de hospitalização no ano anterior (NEDEL, et. al., 2008). Em uma coorte de adultos, foram observadas maiores taxas de ICSAP em pessoas com mais de 60 anos e cor não branca, porém não foram identificadas diferenças entre os sexos (GONÇALVES et. al., 2016).

Pacientes com idade entre um e quatro anos tiveram chance aumentada de atendimento por ICSAP estimada em 1,13 vezes quando comparados aos pacientes com idade abaixo de um ano $(\mathrm{p}<0,001)$. Observou-se menores chances de atendimentos por ICSAP nas demais faixas etárias comparados aos pacientes com idade abaixo de um ano. Tais dados, como já discutido anteriormente, diferem da literatura atual, por haver maior ocorrência de ICSAP em idosos (PERPETUO, 2006). Outra justificativa é a de que a área geográfica em que a UPA se encontra apresentou um dos menores contingentes de idosos do município de São Paulo (CEINFO, 2010).

Estudo realizado por Cardoso e colaboradores (2013) no município de Divinópolis (MG), o qual analisou as ICSAP em um hospital conveniado com o SUS e em uma unidade de pronto-atendimento, constatou maior prevalência de ICSAP na unidade de prontoatendimento, no sexo feminino e nas faixas etárias menores de 13 anos e acima de 40 anos. As internações ocorridas nesta UPA tiveram uma chance 2,64 (IC95\%: 2,36 a 2,95) vezes maior de ser ICSAP. Além disso, mulheres e pacientes menores de 13 anos e acima de 40 anos $(P<$ $0,01)$ tiveram mais chance de ter ICSAP. Tais informações sugerem que as unidades de pronto-atendimento abrangem grande quantitativo de atendimentos por ICSAP, o que 
demonstra, mais uma vez, a preferência da população por este tipo de serviço e a importância de intervenção neste ponto de assistência à saúde.

Quanto à Classificação de Risco de Manchester atribuída aos pacientes, a maioria foi classificada como verde (UPA 48,3\%; ICSAP 56,3\%), seguido pela classificação amarela (UPA 21,6\%; ICSAP 21,2\%) e laranja (UPA 11,9\%; ICSAP 19,3\%) com direcionamento maior para a especialidade de clínica médica $(72,7 \%)$. Esta tendência já foi evidenciada em outros estudos nacionais (OLIVEIRA et. al., 2015; OLIVEIRA et.al., 2016; SOUZA et. al., 2011), o que demonstra maior procura do serviço de urgência para atendimentos de baixa complexidade. Importante destacar que $8,8 \%$ do total de atendimentos tiveram classificação branco e azul, os quais são casos que poderiam ser atendidos pela UBS por se tratar de problemas de saúde não-urgentes e de ordem ambulatorial, como realização de curativos e troca de sondas.

Diante de tais evidências, observa-se que a estrutura organizacional do serviço atende a todos os usuários, sem qualquer restrição de entrada, o que acarreta uma sobrecarga de atendimentos e assistência fragmentada baseada no sistema de queixa-conduta.

Ao utilizar o CID-10 do diagnóstico principal, os usuários da UPA no período estudado foram classificados em grupos de causa, com maioria dos atendimentos por causas externas $(15,9 \%)$, sintomas e sinais anormais $(15,1 \%)$ e doenças do aparelho respiratório $(13,3 \%)$. As causas externas estão entre os principais grupos de causa com maior mortalidade no país, com aproximadamente $13,5 \%$, perdendo apenas para as doenças do aparelho circulatório $(30,8 \%)$ e neoplasias $(16,9 \%)$, segundo Sistema de Informações sobre Mortalidade (SIM) (MINISTÉRIO DA SAÚDE/SVS, 2010).

Ao se analisar o perfil das ICSAP encontradas no estudo, observou-se maioria dos atendimentos por infecções de ouvido, nariz e garganta, seguido pelas gastroenterites infecciosas e complicações. Em um relevante estudo realizado pelo Projeto ICSAP - Brasil (ALFRADIQUE et. al., 2009), as internações por condições sensíveis à atenção primária mais frequentes foram as gastroenterites e suas complicações $(23,2 \%)$. Todavia, em outra pesquisa realizada em São Paulo (REHEM \& EGRY, 2011), observou-se maiores taxas de pneumonias bacterianas $(17,4 \%)$, o que nos leva a crer que não há uma linearidade absoluta na literatura.

$\mathrm{Na}$ análise das taxas de ICSAP por faixa etária, observou-se que nos menores de 1 ano houve prevalência de bronquite aguda $(41,4 \%)$. Contudo, nas demais faixas etárias houve predomínio das infecções de ouvido, nariz e garganta, exceto nos maiores de 60 anos, onde a maioria dos atendimentos se deu por hipertensão arterial sistêmica (15,6\%) e maior 
acometimento das doenças crônicas. Caminal e colaboradores (2002) corroboram nosso estudo ao apontar que na população infantil predominam as condições agudas, como as afecções das vias aéreas.

Estudo realizado no estado de São Paulo mostrou resultados mais heterogêneos. Ressaltou que nos menores de 1 ano houve predomínio de pneumonias bacterianas, asma e doenças pulmonares (bronquite e bronquite aguda), semelhante ao nosso estudo. Já nas faixas etárias de 1 a 14 anos prevaleceram os atendimentos por gastroenterites infecciosas e suas complicações. Para os adolescentes (15 a 19 anos) e adultos (20 a 39 anos), a causa mais comum da ICSAP foi infecção do aparelho urinário. Ao considerar os pacientes com idade superior a 39 anos, percebeu-se que os grupos das ICSAP mais frequentes foram insuficiência cardíaca, angina, doenças cerebrovasculares e por último, hipertensão arterial (FERREIRA et. al., 2014).

Moura e colaboradores (2010), ao analisarem as principais causas de ICSAP no Brasil, destacaram que nas cinco regiões brasileiras as gastroenterites infecciosas e complicações, asma e pneumonias bacterianas mantiveram-se como as três principais causas de internação por CSAP, em menores de 20 anos.

Os dados encontrados apontam para a importância da oferta de serviços de saúde que mais acometem a população, constituídas principalmente de afecções agudas, além de atividades de promoção e prevenção de saúde. Tais informações também parecem estar interligadas às características populacionais da região geográfica em que a UPA está inserida, que conta com a maior proporção de pessoas vivendo em aglomerados subanormais $(23,5 \%)$, problemas urgentes de saneamento básico (coleta de esgoto), maiores proporções de baixa escolaridade e pior distribuição de renda da população (CeInfo, 2010).

Quanto ao tipo de finalização e desfecho dos atendimentos realizados, "alta" foi o mais frequente. Este desfecho pode estar relacionado à baixa complexidade do quadro clínico que esses pacientes apresentavam, o que nos permite suspeitar que esta demanda poderia ter sido absorvida na UBS, além de evidenciar a preferência da população em procurar os serviços de emergência, por se tratar de locais que funcionam $24 \mathrm{~h}$ e por sua localização geográfica.

Foram analisadas as principais associações (alta ou liberação, transferência hospitalar e evasão) entre os desfechos de atendimento e características dos pacientes na amostra de atendimentos com ICSAP na UPA Campo Limpo. Comparados aos pacientes com idade abaixo de um ano, aqueles com idade mais elevada têm chance aumentada de transferência 
hospitalar. Pacientes com idades nas faixas entre 50 e 59 anos e 60 anos ou mais tem chances de transferência hospitalar estimadas, respectivamente, em 1,2 vezes $(p=0,014)$ e 1,8 vezes $(\mathrm{p}<0,001)$ a chance dos pacientes com idade abaixo de um ano. Esses dados podem estar relacionados às patologias mais graves que esses pacientes tendem a apresentar e maior associação com doenças crônicas. Tais dados sugerem ainda, a importância da continuidade do cuidado desse perfil de paciente pela APS.

Quanto à classificação de risco de Manchester, observou-se menores chances de transferência nas classes azul e verde comparados aos pacientes de risco branco. Esses dados devem-se a relação que as classificações do protocolo de Manchester têm com a condição clínica do paciente, onde pacientes com maior classe de risco tendem a apresentar maior gravidade clínica e, por isso, maior necessidade de internação.

Diante do panorama das doenças crônicas no Brasil e no mundo, e com o objetivo de fornecer dados à APS para uma melhor coordenação do cuidado de seus pacientes adscritos, realizou-se análise do perfil das condições crônicas da UPA Campo Limpo, onde 5,4\% do total de atendimentos tinham alguma condição crônica associada. Em relação às condições associadas nos atendimentos realizados apenas dos pacientes com ICSAP este número aumenta para $13,8 \%$.

As condições crônicas merecem destaque por se constituírem como importantes causas para aumento da morbimortalidade, levando em consideração que as doenças do aparelho circulatório lideram as principais causas de mortalidade no país (MINISTÉRIO DA SAÚDE/SVS, 2010). Além disso, constatou-se no presente estudo evidências de aumento da chance de transferência hospitalar em pacientes crônicos $(\mathrm{p}<0,001)$, onde os mesmos têm chance estimada em 1,5 vezes a chance dos pacientes não crônicos. Tais problemas de saúde sugerem importância de intervenção junto à APS.

Estudo que analisou as reduções das ICSAPs no Brasil (BOING et. al., 2012), identificou que a insuficiência cardíaca e a asma constituíram-se como $2^{\mathrm{a}}$ e $3^{\mathrm{a}}$ principais causas de ICSAP no período estudado. Em outro estudo, realizado por Ferreira e seus colaboradores (2014), os diagnósticos mais frequentes encontrados em adultos dizem respeito às doenças do aparelho circulatório, onde o manejo dessas doenças está intimamente ligado ao desempenho dos serviços de atenção primária. Há, portanto, a necessidade de um olhar crítico não só para a ocorrência das afecções agudas, mas também para os problemas de saúde crônicos, proporcionando uma melhor gestão e adequação da rede de atenção primária frente aos problemas de saúde de sua população. 
Em se tratando de doenças crônicas, como a hipertensão arterial, diabetes e doenças cardiovasculares a APS tem apresentado amplo potencial para atuação (MACINKO, 2010). Em relação à hipertensão arterial, têm-se registrado resultados positivos, em função da capacidade dos profissionais de atuar no monitoramento da pressão arterial, da disponibilidade de medicamentos gratuitos de baixo custo para os pacientes, além de amplo incentivo monetário para os municípios desenvolverem programas de controle de hipertensão nas ESF. A longo prazo, a implantação dessas medidas na atenção primária por meio da ESF tem grande impacto nas ICSAP, principalmente aquelas que sofrem influência da hipertensão arterial (CARDOSO et. al., 2013).

Ao analisar a associação entre as ICSAP e as características dos pacientes, houve evidências de aumento da chance de atendimento por ICSAP em pacientes crônicos $(p<0,001)$, com chance estimada em torno de quatro vezes a chance dos pacientes não crônicos. Atendimentos recorrentes nesta população sugerem piora clínica dos mesmos e maior chance de observação clínica na UPA ou transferência hospitalar para hospital terciário. A coordenação do cuidado nestes pacientes tem como objetivo prover a continuidade da atenção dos problemas de saúde que requerem maior vigilância pela APS evitando, assim, múltiplos atendimentos pela atenção secundária.

Estudos referem que as condições crônicas exigem um sistema de atenção que responda de forma proativa, contínua e integrada, por meio do compromisso político com a APS, à implementação de um acolhimento qualificado e das práticas inovadoras no âmbito da política e da atenção. Porém, a APS como coordenadora do cuidado ainda encontra vários desafios, sobretudo pela fragilidade de se implantar uma rede que permita a integração entre os diferentes níveis de atenção, bem como sistemas de apoio e logística para sustentar os fluxos de comunicação e os processos para a produção social em saúde (MENDES, 2012).

Ao considerar que as ICSAP são utilizadas para avaliar qualidade e acesso na APS e diante da realidade observada no local de estudo e da necessidade de aprimorar a comunicação entre a atenção primária e secundária, o fluxograma proposto sugere uma comunicação entre UPA e UBS, que forneça informações sobre os pacientes admitidos na UPA com condições crônicas (Asma/Bronquite, HAS, DM e Transtorno Mental), que necessitem de observação clínica, direcionando assim, perfis específicos com importância e necessidade de intervenção junto à APS.

Abordar especificamente alguns problemas de saúde que configuram importância de continuidade do cuidado junto à APS permite avaliar os efeitos da mesma frente a 
determinadas situações de saúde permitindo, assim, um melhor direcionamento das intervenções para qualificar este nível de atenção, além de fortalecer a rede de atenção à saúde.

A proposta de implantação de um fluxo de comunicação surgiu da necessidade de melhorar a continuidade do cuidado prestado ao paciente e facilitar a comunicação entre os diferentes pontos da rede. A relevância desta proposta pode ser corroborada por Shimazaki (2009), a qual refere que a coordenação tem como essência a disponibilidade das informações sobre os cuidados em saúde prestados ao usuário, onde os sistemas informatizados podem contribuir para tal, quando possibilitam o compartilhamento de informações referentes ao atendimento do indivíduo, fortalecendo a rede de atenção à saúde.

A coordenação do cuidado constitui-se como um desafio para os profissionais e serviços de saúde pois, na maioria das vezes, a equipes de saúde não tem informações sobre os atendimentos prestados ao paciente nos demais pontos da rede, o que dificulta a continuidade do cuidado (SHIMAZAKI, 2009). O fluxograma de comunicação para coordenação do cuidado proposto neste estudo caracteriza-se pela sua inovação no serviço, a fim de integrar atenção primária e secundária para alcançar melhores resultados no cuidado em saúde dos usuários. Além disso, há o fortalecimento da rede de atenção à saúde a partir da integração dos serviços e aproximação dos gestores e profissionais de saúde. O fluxograma tem como limitação para sua realização a necessidade de funcionamento do sistema online.

Estudos evidenciam que a APS eleva sua capacidade de resolver os problemas de saúde por meio da coordenação das RAS, tornando os sistemas mais custo-efetivos, em termos de organização interna, alocação de seus recursos e gestão clínica (BRASIL, 2010). No campo das políticas públicas, a organização do sistema em redes possibilita a construção de vínculos de solidariedade e cooperação entre trabalhadores, serviços e comunidade (NNAJI, 2011).

Revisão integrativa que avaliou 18 artigos sobre APS como coordenadora das redes de atenção à saúde destacou que a dificuldade de coordenação entre os níveis de atenção, o precário funcionamento dos serviços de referência e contrarreferência, o desconhecimento dos vários pontos de atenção pelos profissionais da APS e a dificuldade de cooperação entre profissionais da atenção primária e secundária configuram algumas das principais fragilidades encontradas no sistema de saúde. (RODRIGUES et. al., 2014). O mesmo estudo trouxe como potencialidade para melhora da coordenação do cuidado o investimento em tecnologia de 
informação e comunicação, com implantação de sistemas informatizados e prontuários eletrônicos.

Apesar da atual Lista Brasileira de ICSAP não incluir os transtornos mentais, devido à complexidade do processo da reforma psiquiátrica no Brasil e da implantação heterogênea dos serviços de atenção psiquiátrica em diferentes regiões do país (Alfradique et.al., 2009), optouse pela abrangência dessas afecções no estudo pela importância da continuidade do cuidado e direcionamento pela APS. Estudo de Alfradique e colaboradores (2009) sugere que listas futuras devem considerar a inclusão de algumas condições que passaram a ser objeto da ESF ao longo do desenvolvimento desta política.

O estudo teve como limitações o fato de estar baseado em dados secundários referentes ao registro no banco de dados, o qual depende das informações registradas pelos profissionais da unidade. Alguns dados foram excluídos da amostra pela falta de disponibilidade das informações.

A opção pela pesquisa quantitativa também não é suficiente para a análise de todos os elementos que influenciam no bom funcionamento da rede, requerendo outras abordagens metodológicas que agreguem conhecimento. $\mathrm{O}$ estudo tem como sugestão a realização de outras abordagens de pesquisa que se complementem como, por exemplo, a realização de um grupo focal com os gestores da APS e atenção secundária, a fim de promover a troca de conhecimentos e aproximar os profissionais.

Importante destacar o papel fundamental do enfermeiro na realização da sistematização de sua assistência e na disponibilização dos dados do atendimento realizado pela equipe multiprofissional por meio do fluxograma. O conjunto desses profissionais e de suas ações integradas à APS pode desempenhar papel importante na redução das ICSAP e na melhor coordenação do cuidado pela APS. 


\section{Conclusão}




\section{CONCLUSÃO}

O banco de dados foi composto por 434.883 atendimentos, no período de 2 anos, com prevalência de ICSAP de 17,1\%. O sexo feminino foi o mais acometido pelas internações sensíveis e crianças de 1 a 4 anos apresentaram chance aumentada de atendimento por ICSAP.

A maioria das ICSAP foi composta por infecções de ouvido, nariz e garganta $(45,4 \%)$. Houve evidência de aumento da chance de atendimento por ICSAP em pacientes crônicos, com possibilidade estimada em torno de quatro vezes a dos pacientes não crônicos.

A proposta de fluxograma de comunicação entre UPA e APS se deu a partir de pacientes com doenças crônicas (asma/bronquite, hipertensão arterial sistêmica, diabetes mellitus e transtorno mental) com importância de intervenção junto à APS.

Diante da presença de hiperutilizadores no local do estudo, com elevadas taxas de atendimentos na unidade, sugere-se estudos futuros com esse perfil de usuário.

Reitera-se a importância da construção e implementação de um fluxograma que visa aproximar os diferentes pontos de assistência à saúde e prover uma melhor coordenação do cuidado pautado nas redes de atenção.

Sugere-se a realização de outros tipos metodologias de estudo, como a realização de grupo focal entre os gestores e profissionais da atenção secundária para a efetiva implantação do fluxo de comunicação.

Espera-se que esta pesquisa estimule o uso e o aperfeiçoamento da análise das internações por condições sensíveis à atenção primária nos equipamentos de saúde de atenção secundária, diante da escassez observada na literatura. 


\section{Referências}




\section{REFERÊNCIAS}

ALFRADIQUE, M. E. et al. Internações por condições sensíveis à atenção primária: a construção da lista brasileira como ferramenta para medir o desempenho do sistema de saúde (Projeto ICSAP — Brasil). Cad. Saúde Pública, v. 25, n. 6, p. 1337-49, 2009.

ALTMAN, D. G. Practical statistics for medical research, London: CRC press, 1991.

ANDERSON, M. I. P.; DEMARZO, M.; RODRIGUES, R. D. A medicina de família e comunidade, a atenção primária à saúde e o ensino de graduação: recomendações e potencialidades. Rio de Janeiro: Sociedade Brasileira de Medicina de Família e Comunidade; 2007. Disponível em: <www.rbmfc.org.br/rbmfc/article/view/334/221>. Acesso em 04 jun. 2016.

ANDER-EGG, A. S. In: OMISTE et al. Formação de grupos populares: uma proposta educativa. Rio de Janeiro: DP\&A; 2000.

ANSARI, Z. et al. The Victorian ambulatory care sensitive conditions study: rural and urban perspectives. Soz Praventivmed, v. 48, p. 33-43, 2003.

ANSARI, Z.; LADITKA, J. N.; LADITKA, S. B. Access to health care and hospitalization for Ambulatory Care Sensitive Conditions. Med. Care Res. Rev., v. 63, n. 6, p. 719-41, 2006.

ANTONELLI, R. C.; MCALLISTER, J. W.; POPP, J. Making care coordination a critical component of the pediatric healthcare system: a multidisciplinary framework. New York: The Commonwealth Fund; 2009.

ARRUDA, J. R. Lançamento das UPASs. Correio Braziliense, 20 de dezembro de 2008.

BARDSLEY, M. et al. Is secondary preventive care improving? Observational study 10-year trends in emergency admissions for conditions amenable to ambulatory care. BMJ Open, v. 3, p. 2-7, 2013. Disponível em: < http://bmjopen.bmj.com/content/3/1/e002007>. DOI:10.1136/bmjopen-2012-002007. Acesso em 27 set. 2017.

BERMÚDEZ-TAMAYO, C. et al. Características organizativas de la atención primaria y hospitalización por los principales ambulatory care sensitive conditions. Atención Primária, v. 33, n. 6, p. 305-11, 2004.

BILLINGS, J. et al. Impact of socioeconomic status on hospital use in New York City. Health Affairs, v. 12, p. 162-73, 1993. 
BOING, A. F. et al. Redução das Internações por Condições Sensíveis à Atenção Primária no Brasil entre 1998-2009. Rev. Saúde Pública, v. 46, n. 2, p. 359-66, 2012. Disponível em: <http://www.scielo.br/pdf/rsp/v46n2/3709.pdf>.

BRASIL. Conselho Nacional de Secretários de Saúde. A Atenção Primária e as Redes de Atenção à Saúde. Brasília: CONASS, 2015. 127 p.

Decreto $\mathrm{n}^{\mathrm{o}} 7.508$ de 28 de julho de 2011. Regulamenta a Lei no 8.080, de 19 de setembro de 1990, para dispor sobre a organização do Sistema Único de Saúde - SUS, o planejamento da saúde, a assistência à saúde e a articulação interfederativa, e dá outras providências. In: Diário Oficial da União, Brasília, 29 jun. 2011.

Instituto Brasileiro de Geografia e Estatística. Rio de Janeiro: IBGE, 2011. Disponível em: <http://www.censo2010.ibge.gov.br/sinopse/index.php?uf=35\&dados $=0$ >

Ministério da Saúde. Conselho Nacional de Saúde. Resolução no 510 de 07 de abril de 2016. In: Diário Oficial da União, Brasília, 24 mai. 2016. N. 98, seção 1, p. 44-45,56. Disponível em: <http://conselho.saude.gov.br/resolucoes/2016/Reso510.pdf>.

Ministério da Saúde. Indicadores de Mortalidade. Disponível em: <http://tabnet.datasus.gov.br/cgi/tabcgi.exe?idb2011/c04.def>. Acesso em: 10 set. 2017.

Ministério da Saúde. Portaria $n^{\circ}$ 221/SAS de 17 de abril de 2008, que define a Lista Brasileira de Internações por Condições Sensíveis à Atenção Primária. In: Diário Oficial da União, Brasília, 18 abr. 2008. Disponível em: < http://www.brasilsus.com.br/index.php/legislacoes/gabinete-do-ministro/16247-portaria-n-2436-de-21-de-setembro-de-2017>.

Ministério da Saúde. Portaria $\mathrm{n}^{\circ}$ 2.436, de 21 de setembro de 2017. Aprova a Política Nacional de Atenção Básica, estabelecendo a revisão de diretrizes para a organização da Atenção Básica, no âmbito do Sistema Único de Saúde (SUS). In: Diário Oficial da União, Brasília, 22 set. 2017.

Ministério da Saúde. Portaria GM n ${ }^{\circ}$ 2.922, de 2 de dezembro de 2008. Estabelece diretrizes para organização das redes loco-regionais de atenção integral às urgências. In: Diário Oficial da União, Brasília, 03 dez. 2008. Seção 1, p. 66. Disponível em: < adcon.rn.gov.br/ACERVO/Suvisa/doc/DOC000000000024988.PDF>.

Ministério da Saúde. Saúde da Família nos Territórios da Cidadania. Entrevista sobre internações por condições sensíveis à atenção primária. Hospitalizações entre crianças e adolescentes no território de abrangência de um serviço de atenção primária. Revista Brasileira Saúde Família, v. 9, n. 18, p. 4-6,2008. Disponível em: <http://189.28.128.100/dab/docs/publicacoes/revistas/revista_saude_familia18.pdf>. 
. Ministério da Saúde. Secretaria de Assistência à Saúde. Coordenação de Saúde da Comunidade. Saúde da Família: uma estratégia para a reorientação do modelo assistencial. Brasília: Ministério da Saúde; 1997.

Ministério da Saúde. Secretaria de Atenção à Saúde. Portaria $N^{\circ}$ 221/2008. In: Diário Oficial da União, Brasília, p. 70, 18 abr. 2008 Disponível em: $<$ http://www.saude.pr.gov.br/arquivos/File/CIB/Portaria_SAS_N_221_08_Lista_Internacoes_ Condicoes_Sensiveis_Atencao_Basica.pdf $>$.

Portal Brasil. Primeira UPA 24 horas da capital paulista é inaugurada. 2014. Disponível em: <http://www.brasil.gov.br/saude/2014/04/primeira-upa-24-horas-da-capitalpaulista-e-inaugurada>. Acesso em 14 set. 2017.

CAMINAL, H. J. et al. La Atencion primaria de salud y las hospitalizaciones por ambulatory care sensitive conditions en Cataluna. Revista Clinica Española, v. 201, n. 9, p. 501-07, 2001 .

CAMINAL-HOMAR, J.; CASANOVA-MATUTANO, C. La evaluación de la atención primaria y las hospitalizaciones por ambulatory care sensitive conditions. Marco conceptual. Atención Primaria, v. 31, p. 61-5, 2003.

CAMPOS, A. Z.; THEME-FILHA, M. M. Internações por condições sensíveis à atenção primária em Campo Grande, Mato Grosso do Sul, Brasil, 2000 a 2009. Cad. Saúde Pública, v. 28, n. 5, p. 845-55, 2012. Disponível em: <http://www.scielo.br/scielo.php?pid=S0102311X2012000500004\&script=sci_arttext $\geq$.

CAMPOS, C. E. A. O desafio da integralidade segundo as perspectivas da vigilância da saúde e da saúde da família. Ciência \& Saúde Coletiva, v. 8, n. 2, p. 569-84, 2003.

CANDAU,V. M.; ZENAIDE, M. N. T. Oficinas Aprendendo e Ensinando Direitos Humanos, João Pessoa: Programa Nacional de Direitos Humanos; Secretaria da Segurança Pública do Estado da Paraíba; Conselho Estadual da Defesa dos Direitos do Homem e do Cidadão, 1999.

CARDOSO, C. S. et al. Contribuição das internações por condições sensíveis à atenção primária no perfil das admissões pelo sistema público de saúde. Rev. Panam. Salud Publica, v. 34, n. 4, p. 227-34, 2013. Disponível em: $<$ http://www.scielosp.org/scielo.php?script=sci_arttext\&pid=S1020-49892013001000003 .

CASANOVA, C.; STARFIEL, B. Hospitalizations of children and access to primary care: a cross-national comparison. Int. J. Health Services, v. 25, p. 283-94, 1995.

CASTRO, M. S. M. A utilização das internações hospitalares no Brasil: Fatores associados, grandes usuários, reinternação e efeito da oferta de serviços sobre o uso. 
2004. Tese (Doutorado em Saúde Pública) - Escola Nacional de Saúde Pública da Fundação Oswaldo Cruz, Rio de Janeiro.

CECILIO, L. C. O. Apontamentos teórico-conceituais sobre processos avaliativos considerando as múltiplas dimensões da gestão do cuidado em saúde. COMUNICAÇÃO SAÚDE EDUCAÇÃ̃, v. 15, n. 37, p. 589-99, 2011.

COCHRAN, W. G. (1977) Sampling Techniques. 3rd Edition, John Wiley and Sons, New York.

CUMMINS, R. O.; SMITH, R. W.; INUI, T. S. Communication failure in primary care. Failure of consultants to provide follow-up information. JAMA, v. 243, p. 1650-52, 1980.

DELIA, D. Distributional issues in the analysis of preventable hospitalizations. Health Serv. Res., v. 38, n. 6 pt. 2, p. 1761-79, 2003.

ELIAS, E.; MAGAJEWSKI, F. A Atenção Primária à Saúde no sul de Santa Catarina: uma análise das internações por condições sensíveis à atenção ambulatorial, no período de 1999 a 2004. Rev. Bras. Epidemiol., v. 11, n. 4, p. 633-47, 2008.

FACCHINI, L. A. et al. Desempenho do PSF no Sul e no Nordeste do Brasil: avaliação institucional e epidemiológica da Atenção Básica à Saúde. Cienc. Saúde Coletiva, v. 11, n. 3, p. 669-81, 2006.

FERNANDES, V. B. L. et al. Internações sensíveis na atenção primária como indicador de avaliação da Estratégia Saúde da Família. Rev. Saúde Pública, v. 43, n. 6, p. 928-36, 2009.

FERREIRA, J. B. B. et al. Internações por condições sensíveis à atenção primária à saúde em uma região de saúde paulista, 2008 a 2010. Epidemiol. Serv. Saúde, v. 23, n. 1, p. 45-56, 2014.

FINEGAN, M. S. et al. Trends and geographic variation of potentially avoidable hospitalizations in the veterans health-care system. Health Serv. Manage Res., v. 23, n. 2, p. 66-75, 2010. Disponível em: http://journals.sagepub.com/doi/abs/10.1258/hsmr.2009.009023?url_ver=Z39.882003\&rfr_id=ori:rid:crossref.org\&rfr_dat=cr_pub\%3dpubmed $>$. DOI:10.1258/hsmr.2009.009023. Acesso em: 07 jun 2016.

FLEISS, J. L., Levin, B., Paik, M.C. 2003. Statistical Methods for Rates and Proportions. Third Edition. John Wiley \& Sons. New York.

FURTADO, B. M. A. S. M.; ARAÚJO JÚNIOR, J. C. L.; CAVALCANTI, P. O perfil da emergência do Hospital da restauração: uma análise dos possíveis impactos após a municipalização dos serviços de saúde. Rev Bras. Epidemiol., v. 7, n. 3, p. 279-89, 2004. 
GANDHI, T. K. et al. Communication breakdown in the outpatient referral process. J. Gen. Intern. Med., v. 15, p. 626-31, 2000.

GARCIA, V. M.; REIS, R. K. Perfil de usuários atendidos em uma unidade não hospitalar de urgência. Rev. Bras. Enferm., v. 67, n. 2, p. 261-67, 2014.

GARIGLIO, M.T. O cuidado em Saúde. In: MINAS GERAIS, Escola de Saúde Pública do Estado de Minas Gerais. Oficinas de qualificação da atenção primária à Saúde em Belo Horizonte: Oficina 2 - Atenção centrada na pessoa. Belo Horizonte: ESPMG, 2012.

GÉRVAS, J.; HOMAR, J. C. Hospitalizations by ambulatory care sensitive conditions (ACSC) from the general practioner/family physician's point of view. Rev. Esp. Salud Publica, v. 81, n. 1, p. 7-13, 2007.

GIBSON, O. R.; SEGAL, L. L.; MCDERMOTT, R. A. A systematic review of evidence on the association between hospitalization for chronic disease related ambulatory care sensitive conditions and primary heath care resourcing. BMC Health Serv. Res., v. 13, p. 336, 2013. Disponível em: <http://bmchealthservres.biomedcentral.com/articles/10.1186/1472-6963-13336>. Acesso em: 07 jun. 2016.

GILL, J. M. Can hospitalizations be avoided by having a regular source of care? Archives of Family Medicine, v. 29, n. 3, p. 166-71, 1997.

GILL, J. M.; MAINOUS, A. G. The role of provider continuity in preventing hospitalizations. $3^{\text {rd }}$. Archives of Family Medicine, v. 7, n. 4, p. 352-57, 1998.

GIOVANELLA, L. et al. Sistemas municipais de saúde e a diretriz da integralidade da atenção: critérios para a avaliação. Saúde em Debate, v. 26, n. 60, p. 37-61, 2002.

GOMIDE, M. F. S.; PINTO, I. C.; FIGUEIREDO, L. A. Acessibilidade e demanda em uma Unidade de Pronto Atendimento: perspectiva do usuário. Acta Paul. Enferm., v. 25, n. spe. 2, p. 19-25, 2012.

GONÇALVES, M. R. et al. Primary health care quality and hospitalizations for ambulatory care sensitive conditions in the public health system in Porto Alegre, Brazil. Fam. Pract., v. 33, n. 3, p. 238-42, 2016. Disponível em: < https://academic.oup.com/fampra/articlelookup/doi/10.1093/fampra/cmv051>. Acesso em: 20 fev. 2017.

GRUPO BRASILEIRO DE CLASSIFICAÇÃO DE RISCO. Diretrizes para implementação do Sistema Manchester de Classificação de Risco nos pontos de atenção às urgências e emergências. 2 ed. Belo Horizonte, 2015. Disponível em: < http://gbcr.org.br/public/uploads/filemanager/source/54c127352e3b2.pdf >. Acesso em: 21 mar. 2017.

GUIMARÃES, H. P., AVEZUN, Álvaro; PIEGAS, L. S. Epidemiologia do infarto agudo do miocárdio. Rev. Soc. Cardiol. Estado de São Paulo, v. 16, n. 1, p. 1-7, 2006. 
HARTZ, Z. M. A.; CONTANDRIOPOULOS, A. P. Integralidade da Atenção e Integração de Serviços de Saúde. Cad. Saúde Pública, v. 2, p. 331-S336, 2004.

IBAÑEZ, N. Os hospitais e a Rede de Atenção às Urgências e Emergências: desafios. Rev Conselho Nacional Secretários Saúde, v. 3, n. 7, p. 39-43, 2013.

IBM CORP, IBM SPSS Statistics for Windows, Version 24.0, Armonk, NY: IBM Corp, 2016.

LADITKA, J. N.; LADITKA, S. B.; PROBST, J. C. More may be better: evidence of a negative relationship between physician supply and hospitalization for ambulatory care sensitive conditions. Health Serv. Res., v. 40, n. 4, p. 1148-66, 2005.

LEATT, P.; PINK, G.; GUERRIERE, M. Towards a Canadian model of integrated healthcare. Healthc. Pap., v. 1, p. 13-55, 2000.

LEONE, C.; DUSSAULT, G.; LAPÃO, L. V. Reforma na atenção primária à saúde e implicações na cultura organizacional dos Agrupamentos dos Centros de Saúde em Portugal. Cad. Saúde Pública, v. 30, n. 1, p. 149-60, 2014. Disponível em: $<$ http://www.scielo.br/pdf/csp/v30n1/0102-311X-csp-30-01-00149.pdf>. Acesso em_ 21 jun. $\underline{2017 .}$

MACINKO, J. Estados Unidos: Estudo da lista de internações por condições sensíveis à atenção básica. In: SEMINÁRIO INTERNACIONAL DE ATENÇÃO PRIMÁRIA EM SAÚDE DA FAMÍLIA, 3., 2007, Recife. Relatório de Atividades. Brasília: Ministério da Saúde; $2008 . \quad$ P. 186-92. Disponível em: <http://bvsms.saude.gov.br/bvs/publicacoes/III_seminario_atencao_primaria_familia_recife.p df $>$.

MACINKO, J. et al. Major expansion of primary care in Brazil linked to decline in unnecessary hospitalization. Health Affairs, v. 12, p. 2149-60, 2010.

MAGAN, P. et al. Geographic variations in avoidable hospitalizations in the elderly, in a health system with universal coverage. BMC Health Serv. Res., v. 8, p. 42, 2008.

MATTOS, R. A.; PINHEIRO, R. Os sentidos da integralidade na atenção e no cuidado à

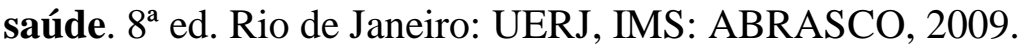

MCDONALD, K. M. et al. Care Coordination Atlas Version 3. Rockville: Agency for Healthcare Research and Quality; 2010.

MELLO JORGE, M.H. P., YUNES, J. Violência e saúde no Brasil. Revista da USP, v. 51, p. 114-27, 2001.

MENDES, E. V. A atenção primária à saúde no SUS. Fortaleza: Escola de Saúde Pública do Ceará, 2002. 
Saúde; 2011.

As redes de atenção à saúde. Brasília: Organização Pan-Americana da

O cuidado das condições crônicas na atenção primária à saúde: o imperativo da consolidação da estratégia da saúde da família. Brasília: Organização PanAmericana da Saúde, 2012. 512 p.: il.

MENEC, V. H. et al. Does continuity of care with a family physician reduce hospitalizations among older adults? J Health Serv. Res. Policy 2006; 11:196-201.

MINICH-POURSHADI, K. Process improvements cur fat, beef up quality. Health Leaders Media. Disponível em: <http://www.healthleadersmedia.com>. Acesso em 15 jan. 2017.

MOORE, G. T. Primary care in crisis. In: SHOWSTACK, J.; ROTHMAN, A. A.; HASSMILLER, S. B. (Editors). The future of primary care. San Francisco: CA JosseyBass; 2004.

MOURA, B. L. A. et al. Principais causas de ICSAP por idade, Brasil e região. Rev. Bras. Saúde Matern. Infant., v. 10, n. 1, p. 83-91, 2010.

NASCIMENTO, M. S. et al. Oficinas pedagógicas: construindo estratégias para a ação docente. Rev. Saúde.com, v. 3, n. 1, p. 85-9, 2007.

NCQA Patient-Centered Medical Home. National Committee for Quality Assurance (NCQA). Care coordination standards. 2011. Disponível em: 〈http://www.ncqa.org〉. Acesso em 02 jan. 2012.

NEDEL, F. B. et al. Aspectos conceituais e metodológicos no estudo das hospitalizações por condições sensíveis à atenção primária. Ciênc. Saúde Coletiva, vol. 16, n. 1, p. 1145-54, 2011.

NEDEL, F. B. et al. Características da atenção básica associadas ao risco de internar por condições sensíveis à atenção primária: revisão sistemática da literatura. Rev. Epidemiol. Serv. Saúde, v. 19, n. 1, p. 61-75, 2010.

NEDEL, F. B. et al. Programa Saúde da Família e condições sensíveis à atenção primária, Bagé (RS). Rev. Saúde Pública, v. 42, n. 6, p. 1041-52, 2008. Disponível em: <http://www.scielo.br/scielo.php?pid=S0034-

89102008000600010\&script=sci_abstract\&tlng=pt $>$ DOI: $\quad$ 10.1590/S003489102008000600010 .

NEWCOMBE, R. G. 1998. 'Two-Sided Confidence Intervals for the Single Proportion: Comparison of Seven Methods.' Statistics in Medicine, 17, pp. 857-872.

NITI, M.; NG, T. P. Avoidable hospitalization rates in Singapore, 1991-1998: assessing trends and inequities of quality in primary care. J. Epidemiol. Community Health, v. 57, n. 
1, p. 17-22, 2003. Disponível em: < http://jech.bmj.com/content/57/1/17.long>. DOI: 10.1136/jech.57.1.17

NNAJI GA. Shifting Focus of Primary Health Care in the Context of Health Systems Reform in Resource Poor Settings. Primary Health Care: Open Access 2011; 1(1):1-5.

OLIVATI, F. N. et al. Perfil da demanda de um pronto-socorro em um município do interior do estado de São Paulo. RFO UPH, v. 15, n. 3, p. 245-50, 2010.

OLIVEIRA, G. N. et al. Correlation between classification in risk categories and clinical aspects and outcomes. Rev. Latino-Am. Enfermagem, v. 24, p. 2842, 2016.

OLIVEIRA, G. N. et al. Perfil da população atendida em uma unidade de emergência referenciada. Rev. Latinoam. Enferm., v. 19, n. 3, p. 548-56, 2011.

OLIVEIRA, N. A. A. Análise das características das internações por condições sensíveis à Atenção Primária. 2011. Monografia de Conclusão de Curso (Graduação em Medicina) Faculdade de Medicina, Universidade de São Paulo, Ribeirão Preto (SP).

OLIVEIRA, R. Adequação da demanda atendida em serviço de urgência de média complexidade em Londrina, Paraná, Brasil. 2008. Dissertação (Mestrado em Enfermagem) - Centro de Ciências da Saúde, Universidade Estadual de Londrina, Paraná.

ORGANIZAÇÃO MUNDIAL DA SAÚDE. Cuidados inovadores para condições crônicas: componentes estruturais de ação. Brasília: Organização Mundial da Saúde; 2003.

ORGANIZAÇÃO MUNDIAL DA SAÚDE/UNICEF. Cuidados primários de saúde. Relatório da Conferência Internacional sobre Cuidados Primários de Saúde, Alma-Ata, Rússia. Brasília: Unicef, 1979.

ORGANIZAÇÃO PAN-AMERICANA DA SAÚDE - OPAS. A atenção à saúde coordenada pela APS: construindo as redes de atenção no SUS - Contribuições para o debate. Brasília: OPAS, 2011.

ORGANIZACIÓN PANAMERICANA DE LA SALUD. Redes integradas de servicios de salud: conceptos, opciones de políticas y hoja de ruta para su implementación en las Américas. Serie Renovación de la Atención Primaria de Salud en las Americas $n^{\circ} 4$. Washington: HSS, 2010.

PAYMENT, P. Waste in US healthcare spending: potentially avoidable complications, chronic condition care. Princeton: Robert Wood Johnson Foundation; 2009.

PAZÓ, R. G. et al. Internações por condições sensíveis à atenção primária no Espírito Santo: estudo ecológico descritivo no período 2005-2009. Epidemiol. Serv. Saúde, v. 21, n. 2, p. 275-282, 2012. 
PENN, D. et al. Interim report on the future provision of medical and allied services. London: Ministry of Health/Consultative Council on Medicine and Allied Services,1920. Disponível em: <http://www.sochealth.co.uk/history/Dawson.html>. Acesso em 28 nov. 2008.

PEREIRA, A. B. C. N. da G. et al. Prevalência de acidente vascular cerebral em idosos no município de Vassouras, Rio de Janeiro, Brasil, através do rastreamento de dados do Programa Saúde da Família. Cadernos de Saúde Pública, v. 25, n. 9, p. 1929-36, 2009.

PERPETUO, I. H. O.; WONG, L. R. Atenção hospitalar por Condições Sensíveis à Atenção Ambulatorial (CSAA) e as mudanças de seu padrão etário: uma análise exploratória dos dados de Minas Gerais. In: SEMINÁRIO DE ECONOMIA MINEIRA. 62., 2006, Diamantina. Anais. Diamantina: Universidade Federal de Minas Gerais, 2006. Disponível em:

<http://www.cedeplar.ufmg.br/seminarios/seminario_diamantina/2006/D06A043.pdf>.

PESTANA, M. Devagar com a UPA. O Globo, 11 de novembro de 2008.

PETER, P. et al. A Simulation Study of the Number of Events per Variable in Logistic Regression Analysis. Journal of Clinical Epidemiololy Vol. 49, No. 12, pp. 1373-1379, 1996.

PHAM, H. H. et al. Primary care physicians links to other physicians through Medicare patients: the scope of care coordination. Ann. Intern. Med., v. 150, p. 236-42, 2009.

PIRANI, M. et al. Ospedalizzazione potenzialmente evitabile nella città di Bologna, 19972000: andamento temporale e differenze per livello di reddito. Epidemiol. Prev., v. 30, n. 3, p. 169-77, 2006.

REHEM, T. C. M. S. B.; EGRY, E. Y.; CIOSAK, S. I. Internações Sensíveis à Atenção Primária: uso de ferramenta decodificadora para estudo das percepções dos profissionais de saúde, São Paulo, Brasil. Indagatio Didactica, v. 5, n. 2, 2013.

RIZZA, P. et al. Preventable hospitalization and access to primary health care in an area of Southern Italy. BMC Health Serv. Res., v. 7, p. 134, 2007. Disponível em: < https://bmchealthservres.biomedcentral.com/articles/10.1186/1472-6963-7-134>.

DOI:10.1186/1472-6963-7-134

RODRIGUES-BASTOS, R. M. et al. Internações Sensíveis à Atenção Primária em município do sudeste do Brasil. Rev. Assoc. Med. Bras., v. 59, n. 2, p. 120-27, 2013.

RODRIGUES LBB et al. A atenção primária à saúde na coordenação das redes de atenção: uma revisão integrativa. Ciência \& Saúde Coletiva, 19(2):343-352, 2014

ROSANO, A. et al. Hospitalization for ambulatory care sensitive conditions and the role of primary care in Italian. Ital J Public Health, v. 8, n. 1, p. 77-88, 2011. Disponível em: <http://ijphjournal.it/article/view/5648>. Acesso em: 30 dez. 2016. 
RUBINSTEIN, A. et al. Avoidable hospitalizations for ambulatory care sensitive conditions as an indicator of primary health care effectiviness in Argentina. J Ambul Care Manage, v. 37, n. 1, p. 69-81, 2014.

RYCHETNIK, L. et al. A glossary for evidence based public health. J Epidemiol Community Health, London v. 5, n. 7, p. 538-45, 2004.

SALA, A. Atenção Básica: organização do trabalho na perspectiva da longitudinalidade e da coordenação do cuidado. In: CONGRESSO DE SECRETÁRIOS MUNICIPAIS DE SAÚDE DO ESTADO DE SÃO PAULO, 30, 2016, São Paulo. Disponível em: < http://www.cosemssp.org.br/downloads/Arnaldo-Sala.pdf>. Acesso em: 17 set. 2017.

SALTMAN, R. B. Drawing the strands together: primary care in perspectives. In: SALTMAN, R. S.; RICO, A.; BOERMA, W. (Editors). Primary care in the driver's seat? Organizational reform in European primary care. European Observatory on Health Systems and Policies/Nuffield Trust. Maidenhead: Open University Press/McGraw Hill; 2006.

SALTMAN R. S.; RICO, A.; BOERMA, W. (Editors). Primary care in the driver's seat? Organizational reform in European primary care. European Observatory on Health Systems and Policies/Nuffield Trust. Maidenhead: Open University Press/McGraw Hill; 2006.

SANCHEZ, M. et al. Variations in Canadian rates of hospitalization for ambulatory care sensitive conditions. Healthc. Q., v. 11, n. 4, p. 20-22, 2008.

SÃO PAULO (Município). Coordenação de Epidemiologia e Informação. Resultados parciais do Censo Demográfico 2010 para o Município de São Paulo. São Paulo, 2012. Disponível em: <http://www.prefeitura.sp.gov.br/cidade/secretarias/upload/saude/arquivos/publicacoes/Boleti m_CEInfo_Censo_02.pdf $>$.

Disponível

Coordenadorias Regionais de Saúde do Município de São Paulo. São Paulo, 2015. <http://www.prefeitura.sp.gov.br/cidade/secretarias/upload/saude/coordenadorias2015.pdf >.

Disponível

Diretrizes Operacionais para o fortalecimento da atenção básica. 2016. $<$ http://www.prefeitura.sp.gov.br/cidade/secretarias/upload/diretrizesoperacionaisatencaobasic a.pdf $>$.

ESTRATÉGIA SAÚDE DA FAMÍLIA - ESF. Disponível em: <http://www.capital.sp.gov.br/cidadao/saude-e-bem-estar/melhorias-na-saudemunicipal/estrategia-saude-da-familia-esf>. Acesso em 14 set. 2017.

Lei n. 13.399 de $1^{\circ}$ de agosto de 2002. Dispõe sobre a criação, estrutura e atribuições das Subprefeituras no Município de São Paulo, estabelece procedimentos para sua 
implantação e prevê a transferência gradual de órgãos e funções da administração direta municipal. Diário Oficial do Município de São Paulo, São Paulo, 2 ago. 2002. Seção 1:47.

Secretaria Municipal de Saúde. Coordenação de Atenção Básica e PSF. Perfil das categorias profissionais do Programa de Saúde da Família na cidade de São Paulo: geral, por região, por parceria, por profissão. 2005. Disponível em: < http://www.cealag.com.br/Trabalhos/ATEN\%C3\%87\%C3\%83O\%20B\%C3\%81SICA\%20\% E2\%80\%93\%20ESTRAT\%C3\%89GIA\%20SA\%C3\%9ADE\%20DA\%20FAM\%C3\%8DLIA \%20PROJETO\%20914\%20BRA1079\%20-\%20UNESCO/SegundoDocumentoTecnico.pdf>. <http://www.prefeitura.sp.gov.br/cidade/secretarias/regionais/campo_limpo/historico/index.p hp?p=131>. Acesso em 10 set. 2017.

Secretaria Municipal de Saúde. UPA Campo Limpo ajuda a elevar em $35 \%$ capacidade de internação no Pronto Socorro do Complexo Hospitalar. 2015. Disponível em: <http://www.prefeitura.sp.gov.br/cidade/secretarias/saude/noticias/?p=198292>. Acesso em 14 set. 2017.

SCHELLER-KREINSEN, D.; BLÜMEL, M.; BUSSE, R. Chronic disease management in Europe. Eurohealth, v. 15, n. 1, p. 1-5, 2009.

SHI, L. The impact of primary care: a focused review. Scientifica, p. 1-22, 2012. Disponível em: $\quad<$ http://www.hindawi.com/journals/scientifica/2012/432892>.

DOI: $10.6064 / 2012 / 432892$

SHIMAZAKI, M.E. (Org.). A Atenção Primária à Saúde. In: MINAS GERAIS. Escola de Saúde Pública do Estado de Minas Gerais. Implantação do Plano Diretor da Atenção Primária à Saúde. Oficina 2 e 3. Análise da Atenção Primária à Saúde e diagnóstico local. Guia do tutor/facilitador. Belo Horizonte: Oficina 1 - Análise da Atenção Primária à Saúde. Guia do participante. Belo Horizonte: ESPMG, 2009. P. 10-16.

SILVA, G. S. et al. Redes de atenção às urgências e emergências: pré-avaliação das Unidades de Pronto Atendimento (UPAs) em uma região metropolitana do Brasil. Rev. Bras. Saúde Mater. Infant., Recife, v. 12, n. 4, p. 445-458, 2012.

SIMONS, D. A. et al. Adequação da demanda de crianças e adolescentes atendidos na Unidade de Emergência em Maceió-AL. Rev Bras Saúde Mater Infant., v. 10, n. 1, p. 5967, 2010.

SOCIEDADE BENEFICENTE ISRAELITA BRASILEIRA ALBERT EINSTEIN (SBIBAE). Estratégia Saúde da Família. São Paulo, 2016. Disponível em: $<$ https://www.einstein.br/responsabilidade-social/parcerias-publicas/estrategia-saudefamilia>. Acesso em: 03 jul. 2017. 
SOUZA, C. C. et al. Risk classification in an emergency room: agreement level between a Brazilian institutional and the Manchester Protocol. Rev. Latino-Am. Enfermagem, vol. 19, n. 1, p. 26-33, 2011. Disponível em: <http://www.scielo.br/scielo.php?pid=S0104$11692011000100005 \&$ script $=$ sci_abstract\&tlng=pt $>$ DOI: $\quad$ 10.1590/S010411692011000100005 .

STARFIELD, B. Atenção Primária: equilíbrio entre necessidades de saúde, serviços e tecnologia. Brasília: UNESCO, Ministério da Saúde, 2002. 726 p. Disponível em: <http://www.dominiopublico.gov.br/pesquisa/DetalheObraForm.do?select _action=\&co_obra=14609>. Acesso em: 20 mar. 2017.

THE COMMONWEALTH FUND. Reducing care fragmentation. s/data [acesso em 12 de outubro de 2011]. Disponível em: <http://improvingchroniccare.org>.

TORRES, R. L. et al. O panorama das internações por condições sensíveis à Atenção Primária em um distrito de São Paulo. Rev. Esc. Enferm. USP, v. 45, n. 2, p. 1661-6, 2011. (Especial).

TRIVIÑOS, A. N. S. Introdução à pesquisa em ciências sociais: a pesquisa qualitativa em educação. São Paulo: Atlas, 1987.

TURA, L. M. T.; SOARES, K.; CASARTELlI, C. H. Atenção Primária em Saúde. In: SOUZA, M. M.; FRANCO, M. S.; MENDONÇA, A. V. M. Saúde da Família nos municípios brasileiros: Os reflexos dos 20 anos no espelho do futuro. Campinas: Saberes Editora; 2014. p. 178-205.

VALENZUELA-LOPEZ, M. I. et al. Intervenciones sanitárias en atención primaria que disminuyen la hospitalización por Ambulatory Care Sensitive Conditions en mayores de 65 anos. Atención Primaria, v. 39, n. 10, p. 525-32, 2007.

VUORI, H. Primary care in Europe: problems and solutions. Community Medicine, v. 6, p. 221-31, 1984.

WONG, L. et al. Atenção hospitalar por condições sensíveis à atenção ambulatorial (CSAA) no contexto de mudanças no padrão etário da população brasileira. Caxambu: XV Encontro Nacional de Estudos Populacionais, ABEP; 2006.

WORLD HEALTH ORGANIZATION. Preventing chronic diseases: a vital investment. Geneva: WHO/ Public Health Agency of Canada; 2005. 
Ana Cláudia Medeiros Galvão de Lima 


\section{ANEXO}

\section{ANEXO A}

\begin{tabular}{|c|c|c|}
\hline \multicolumn{3}{|c|}{ LISTA DE CONDIÇÕES SENSÍVEIS À ATENÇÃO PRIMÁRIA } \\
\hline Grupo & Diagnósticos & CID 10 \\
\hline $\mathbf{1}$ & \multirow{2}{*}{$\begin{array}{l}\text { DOENÇAS PREVENÍVEIS } \\
\text { Coqueluche }\end{array}$} & POR IMUNIZAÇÃO E CONDIÇÕES SENSÍVEIS \\
\hline & & A37 \\
\hline & Difteria & A36 \\
\hline & Tétano & A33 a A35 \\
\hline & Parotidite & B26 \\
\hline & Rubéola & B06 \\
\hline & Sarampo & B05 \\
\hline & Febre Amarela & A95 \\
\hline & Hepatite B & B16 \\
\hline & $\begin{array}{|ll|}\begin{array}{l}\text { Meningite } \\
\text { Haemophilus }\end{array} & \text { por } \\
\end{array}$ & G00.0 \\
\hline & Meningite Tuberculosa & A17.0 \\
\hline & Tuberculose miliar & A19 \\
\hline & Tuberculose Pulmonar & $\begin{array}{l}\text { A15.0 a A15.3, A16.0 a A16.2, A15.4 a A15.9, } \\
\text { A16.3 a A16.9, A17.1 a A17.9 }\end{array}$ \\
\hline & Outras Tuberculoses & A18 \\
\hline & Febre reumática & I00 a I02 \\
\hline & Sífilis & A51 a A53 \\
\hline & Malária & B50 a B54 \\
\hline & Ascaridiase & B77 \\
\hline \multirow[t]{3}{*}{2} & GASTROENTERITES INFE & CCIOSAS E COMPLICAÇÕES \\
\hline & Desidratação & E86 \\
\hline & Gastroenterites & A00 a A09 \\
\hline \multirow[t]{2}{*}{3} & ANEMIA & \\
\hline & $\begin{array}{l}\text { Anemia por deficiência de } \\
\text { ferro }\end{array}$ & D50 \\
\hline \multirow[t]{3}{*}{4} & \multicolumn{2}{|c|}{ DEFICIÊNCIAS NUTRICIONAIS } \\
\hline & \begin{tabular}{|l|l} 
Kwashiokor e outras \\
formas de desnutrição \\
protéico calórica \\
\end{tabular} & E40 a E46 \\
\hline & $\begin{array}{ll}\text { Outras } & \text { deficiências } \\
\text { nutricionais } & \end{array}$ & E50 a E64 \\
\hline \multirow[t]{7}{*}{5} & \multicolumn{2}{|c|}{ INFECÇÕES DE OUVIDO, NARIZ E GARGANTA } \\
\hline & Otite média supurativa & H66 \\
\hline & $\begin{array}{ll}\text { Nasofaringite } & \text { aguda } \\
\text { [resfriado comum] } & \\
\end{array}$ & 300 \\
\hline & Sinusite aguda & J01 \\
\hline & Faringite aguda & $\mathrm{J02}$ \\
\hline & Amigdalite aguda & J03 \\
\hline & Infecção Aguda VAS & J06 \\
\hline
\end{tabular}




\begin{tabular}{|c|c|c|}
\hline & \begin{tabular}{ll|l} 
Rinite, nasofaringite e & $\mathrm{J}$ \\
faringite crônicas & & \\
\end{tabular} & J31 \\
\hline 6 & \multicolumn{2}{|l|}{ PNEUMONIAS BACTERIANAS } \\
\hline & \begin{tabular}{|l|l} 
Pneumonia Pneumocócica & J
\end{tabular} & $\mathrm{J13}$ \\
\hline & \begin{tabular}{l|l|l} 
Pneumonia por & $\mathrm{J}$ \\
Haemophilus infuenzae & \\
\end{tabular} & $\mathrm{J} 14$ \\
\hline & \begin{tabular}{ll|l} 
Pneumonia & por & $\mathrm{J}$ \\
Streptococus & & \\
\end{tabular} & $\mathrm{J} 15.3, \mathrm{~J} 15.4$ \\
\hline & \begin{tabular}{|l|l} 
Pneumonia bacteriana NE & J \\
\end{tabular} & $\mathrm{J} 15.8, \mathrm{~J} 15.9$ \\
\hline & Pneumonia lobar NE & $\mathrm{J} 18.1$ \\
\hline 7 & \multicolumn{2}{|l|}{ ASMA } \\
\hline & Asma & $\mathrm{J45}, \mathrm{J46}$ \\
\hline 8 & \multicolumn{2}{|l|}{ DOENÇAS PULMONARES } \\
\hline & Bronquite aguda & $\mathrm{J} 20, \mathrm{~J} 21$ \\
\hline & \begin{tabular}{l|l} 
Bronquite não especificada & J \\
como aguda ou crônica &
\end{tabular} & $\mathrm{J} 40$ \\
\hline & \begin{tabular}{l|l} 
Bronquite crônica simples & J \\
e a mucopurulenta & \\
\end{tabular} & $\mathrm{J41}$ \\
\hline & \begin{tabular}{lll|l}
$\begin{array}{l}\text { Bronquite crônica não } \\
\text { especificada }\end{array}$ & J \\
\end{tabular} & $\mathrm{J} 42$ \\
\hline & \begin{tabular}{l|l} 
Enfisema & $\mathrm{J}$
\end{tabular} & $\mathrm{J43}$ \\
\hline & Bronquectasia & $\mathrm{J47}$ \\
\hline & \begin{tabular}{lr|l} 
Outras & doenças & J \\
pulmonares & obstrutivas \\
crônicas & & \\
\end{tabular} & $\mathrm{J44}$ \\
\hline 9 & \multicolumn{2}{|l|}{ HIPERTENSÃO } \\
\hline & Hipertensão essencial & $\mathrm{I} 10$ \\
\hline & $\begin{array}{ll}\text { Doença } & \text { cardíaca } \\
\text { hipertensiva } & \\
\end{array}$ & I11 \\
\hline 10 & \multicolumn{2}{|l|}{ ANGINA } \\
\hline & Angina pectoris & I20 \\
\hline 11 & \multicolumn{2}{|l|}{ INSUFICIÊNCIA CARDÍACA } \\
\hline & Insuficiência Cardíaca & I50 \\
\hline & Edema agudo de pulmão & $\mathrm{J81}$ \\
\hline 12 & \multicolumn{2}{|c|}{ DOENÇAS CEREBROVASCULARES } \\
\hline & Doenças Cerebrovasculares & I63 a I67; I69, G45 a G46 \\
\hline 13 & \multicolumn{2}{|l|}{ DIABETES MELLITUS } \\
\hline & Com coma ou cetoacidose & $\begin{array}{l}\text { E10.0, E10.1, E11.0, E11.1, E12.0, E12.1;E13.0, } \\
\text { E13.1; E14.0, E14.1 }\end{array}$ \\
\hline & $\begin{array}{l}\text { Com complicações (renais, } \\
\text { oftalmicas, neurol., circulat., } \\
\text { periféricas, múltiplas, outras } \\
\text { e NE) }\end{array}$ & $\begin{array}{lllll}\text { E10.2 a E10.8, E11.2 a E11.8; } & \text { E12.2 a } \\
\text { E12.8;E13.2 a E13.8; E14.2 a E14.8 } & & & \\
& & & & \end{array}$ \\
\hline & $\begin{array}{ll}\text { Sem } & \text { complicações } \\
\text { específicas } & \end{array}$ & E10.9, E11.9; E12.9, E13.9; E14.9 \\
\hline 14 & \multicolumn{2}{|l|}{ EPILEPSIAS } \\
\hline & Eplepsias & G40, G41 \\
\hline 15 & \multicolumn{2}{|c|}{ INFECÇÃO DO RIM E TRATO URINÁRIO } \\
\hline
\end{tabular}




\begin{tabular}{|c|c|c|}
\hline & $\begin{array}{ll}\text { Nefrite } & \text { túbulo-intersticial } \\
\text { aguda } & \\
\end{array}$ & N10 \\
\hline & $\begin{array}{l}\text { Nefrite túbulo-intersticial } \\
\text { crônica }\end{array}$ & N11 \\
\hline & $\begin{array}{l}\text { Nefrite túbulo-intersticial NE } \\
\text { aguda crônica }\end{array}$ & N12 \\
\hline & Cistite & N30 \\
\hline & Uretrite & N34 \\
\hline & $\begin{array}{l}\text { Infecção do trato urinário de } \\
\text { localização NE }\end{array}$ & N39.0 \\
\hline 16 & \multicolumn{2}{|c|}{ INFECÇÃO DA PELE E TECIDO SUBCUTÂNEO } \\
\hline & Erisipela & A46 \\
\hline & Impetigo & L01 \\
\hline & $\begin{array}{l}\text { Abscesso cutâneo furúnculo } \\
\text { e carbúnculo }\end{array}$ & L02 \\
\hline & Celulite & L03 \\
\hline & Linfadenite aguda & L04 \\
\hline & $\begin{array}{l}\text { Outras infecções localizadas } \\
\text { na pele e tecido subcutâneo }\end{array}$ & L08 \\
\hline 17 & \multicolumn{2}{|c|}{ DOENÇA INFLAMATÓRIA DE ÓRGÃOS PÉLVICOS FEMININO } \\
\hline & Salpingite e ooforite & N70 \\
\hline & $\begin{array}{l}\text { Doença inflamatória do } \\
\text { útero exceto o colo }\end{array}$ & N71 \\
\hline & $\begin{array}{l}\text { Doença inflamatória do colo } \\
\text { do útero }\end{array}$ & N72 \\
\hline & $\begin{array}{ll}\text { Outras } & \text { doenças } \\
\text { inflamatórias } & \text { pélvicas } \\
\text { femininas } & \\
\end{array}$ & N73 \\
\hline & $\begin{array}{l}\text { Doenças da glândula de } \\
\text { Bartholin }\end{array}$ & N75 \\
\hline & $\begin{array}{ll}\text { Outras } & \text { afecções } \\
\text { inflamatórias da vagina. e } \\
\text { da vulva }\end{array}$ & N76 \\
\hline 18 & \multicolumn{2}{|c|}{ ÚLCERA GASTROINTESTINAL } \\
\hline & Úlcera gastrointestinal & K25 а K28, K92.0, K92.1, K92.2 \\
\hline 19 & \multicolumn{2}{|c|}{ DOENÇAS RELACIONADAS AO PRÉ-NATAL E PARTO } \\
\hline & $\begin{array}{l}\text { Infecção no Trato Urinário } \\
\text { na gravidez }\end{array}$ & $\mathrm{O} 23$ \\
\hline & Sífilis congênita & A50 \\
\hline & $\begin{array}{lll}\text { Síndrome da } & \text { Rubéola } \\
\text { Congênita } & & \\
\end{array}$ & P35.0 \\
\hline
\end{tabular}

